UNIVERSIDADE DE SÃO PAULO

FACULDADE DE ECONOMIA, ADMINISTRAÇÃO E CONTABILIDADE DEPARTAMENTO DE ADMINISTRAÇÃO PROGRAMA DE PÓS-GRADUAÇÃO EM ADMINISTRAÇÃO

DESENVOLVIMENTO E IMPLEMENTAÇÃO DE PADRÕES DE INTEROPERABILIDADE EM GOVERNO ELETRÔNICO NO BRASIL

Ernani Marques dos Santos

Orientador: Prof. Dr. Nicolau Reinhard

SÃO PAULO 
Prof. Dra. Suely Vilela

Reitora da Universidade de São Paulo

Prof. Dr. Carlos Roberto Azzoni

Diretor da Faculdade de Economia, Administração e Contabilidade

Prof. Dr. Isak Kruglianskas

Chefe do Departamento de Administração

Prof. Dr. Lindolfo Galvão de Albuquerque

Coordenador do Programa de Pós-Graduação em Administração 


\section{DESENVOLVIMENTO E IMPLEMENTAÇÃO DE PADRÕES DE INTEROPERABILIDADE EM GOVERNO ELETRÔNICO NO BRASIL}

Tese apresentada ao Departamento de Administração da Faculdade de Economia, Administração e Contabilidade da Universidade de São Paulo como requisito para a obtenção do título de Doutor em Administração.

Orientador: Prof. Dr. Nicolau Reinhard 
Tese defendida e aprovada no Departamento de Administração da Faculdade de Economia, Administração e Contabilidade da Universidade de São Paulo - Programa de Pós-Graduação em Administração, pela seguinte banca examinadora:

\section{FICHA CATALOGRÁFICA}

Elaborada pela Seção de Processamento Técnico do SBD/FEA/USP

Santos, Ernani Marques dos

Desenvolvimento e implementação de padrões de interoperabilidade em governo eletrônico no Brasil / Ernani Marques dos Santos. -- São Paulo, 2008.

$184 \mathrm{p}$.

Tese (Doutorado) - Universidade de São Paulo, 2008

Bibliografia.

1. Tecnologia da informação - Padrões 2. Tecnologia da comunicação Padrões I. Universidade de São Paulo. Faculdade de Economia, Administração e Contabilidade II. Título. 
A Marina Marques, minha mãe

A Melissa Bahia

A Virgínia Gomes

A Prof ${ }^{a}$. Teresinha Fróes 

Agradeço a todos que contribuíram de forma direta e indiretamente para esse projeto.

Ao professor Nicolau Reinhard, por sua orientação e pelas oportunidades de crescimento proporcionadas.

À professora Chrisanthi Avgerou pelas orientações recebidas durante o "doutorado sanduíche" na London School of Economics and Political Science (LSE).

Ao CNPq pelo apoio recebido para a realização do doutorado, inclusive no período do "doutorado sanduíche" na LSE.

Aos funcionários da Secretaria de Logística e Tecnologia da Informação do Ministério do Planejamento, Orçamento e Gestão (SLTI/MP), especialmente ao Leandro Corte (Ex Coordenador Geral do projeto e-PING) e Leonardo Boselli (Assessor Técnico) pela atenção, receptividade e pronto atendimento às minhas solicitações, bem como a disponibilidade para as entrevistas para a pesquisa. Também a Patrícia Pessi (Diretora do Departamento de Governo Eletrônico) e Nazaré Bretas (Ex Coordenadora do Grupo de Trabalho Áreas de Integração para Governo Eletrônico e atual Coordenador Geral do projeto e-PING) pelas informações complementares prestadas para a pesquisa.

Aos membros da banca, pelos questionamentos e sugestões sobre a pesquisa.

A Lícia Abe, pelo apoio incondicional e presença constante, em todos os momentos cruciais desse projeto.

A Amarolinda Zaccol e Leila Humes, pelas valiosas ajudas no processo para realização do "doutorado sanduíche" na LSE.

Ao Departamento de Administração da FEA/USP e a Fundação de Informática Aplicada FIA, pelos apoios para apresentações de trabalhos em congressos.

A Associação Nacional de Pós-Graduação e Pesquisa em Administração -ANPAD, pelo apoio para participação no Consórcio Doutoral do XXXI Encontro da ANPAD - EnANPAD 2007.

Aos professores, funcionários e colegas da FEA/USP e da LSE pela ajuda, ensinamentos e pela enriquecedora troca de experiências.

A todos os meus amigos e colegas de trabalho pelo apoio, incentivo, confiança e carinho que me deram durante a realização deste projeto. 



\section{RESUMO}

Os padrões de interoperabilidade desempenham um papel importante na integração de sistemas e compartilhamento de informações no ambiente de governo eletrônico. Mas o desenvolvimento e estabelecimento destes padrões não dependem somente de aspectos tecnológicos. A integração de sistemas e compartilhamento de informações não significam apenas troca de dados mas, principalmente, integração de processos e transações. Neste cenário, surgem outras variáveis dos contextos institucional (organizacional e político), econômico e social. Além disso, no ambiente de governo eletrônico as transações envolvem geralmente múltiplos agentes e são condicionadas fortemente por aspectos culturais, o que torna esses processos ainda mais complexos e inter-relacionados. E mais: o estabelecimento de padrões implica reestruturação de processos de negócios e/ou mudanças na forma de interação desses agentes com as várias agências governamentais. A partir desse cenário, a presente pesquisa objetiva compreender os processos de desenvolvimento e implementação de uma arquitetura de interoperabilidade para governo eletrônico e identificar prováveis implicações da condução desses processos na posterior adoção dos padrões especificados. O objeto de estudo do é a arquitetura e-PING, um conjunto de padrões de interoperabilidade definido pelo Governo Federal brasileiro, que abrange cinco principais áreas: interconectividade, segurança, meios de acesso, organização e intercâmbio de informações. A metodologia adotada foi a do estudo de caso único longitudinal, com abordagem qualitativa, tendo como base de análise a Teoria Institucional. Foram utilizados análise documental, entrevistas semi-estruturadas para a coleta de dados. Os resultados apontam que, embora a adoção de mecanismos de isomorfismo e estratégias de legitimação possa influenciar positivamente os processos de institucionalização da arquitetura, essas ações apresentam efetividade limitada em decorrência principalmente do ambiente e do contexto onde os referidos processos ocorrem.

Palavras chaves: Interoperabilidade; padrão; padronização; governo eletrônico; institucionalismo. 



\begin{abstract}
SANTOS, E. Development and Implementation of Interoperability Standards for Electronic Government in Brazil. 2008. Thesis (Doctoral). Universidade de São Paulo, Brazil, 2008.

Interoperability standards play an important role in the integration and sharing of information in electronic government environments. The development and implementation of these standards, however, does not depend solely on technological issues. Systems integration and information sharing is not only about data exchange, but, mainly, about integration of processes and transactions. With this view, other variables from the institutional (organizational and political), economic and social context become relevant. Furthermore, in electronic government environments, transactions usually involve multiple agents and are strongly conditioned by cultural aspects, contributing to the increase of processes complexity and connectivity. The establishment of standards does also require the restructuration of business processes and changes in the way the agents interact with the various government agencies. Based on this scenario, this research aims at understanding the processes of development and implementation of architecture for electronic government interoperability and at identifying possible implications of the way in which these processes have been managed on the ensuing adoption of the specified standards. The research object is the ePING architecture, a set of interoperability standards defined by the Brazilian Federal Government, comprising five main areas: interconnectivity, security, means for access, organization and interchange of information. Single case longitudinal study was the adopted research methodology, with a qualitative approach, using Institutional Theory as the basis for analysis. Data collection was based on document analysis, structured and semi-structured interviews. The results indicate that, although the adoption of isomorphism mechanism and legitimating strategies could contribute to the architecture's institutionalization, these actions have their effectiveness limited by conditions of the environment in which these processes occur.
\end{abstract}

Keywords: Interoperability; framework; standards; standardization; electronic government; institutionalism 



\section{SUMÁRIO}

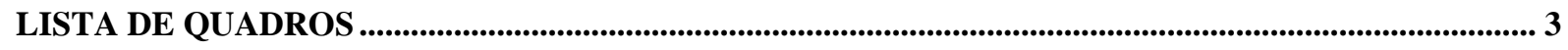

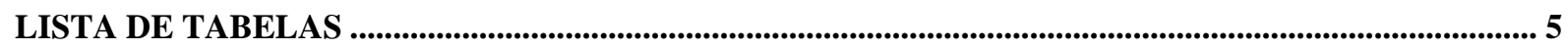

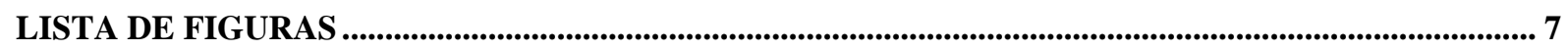

CAPÍTULO 1 - INTRODUÇÃO E PROBLEMA DE PESQUISA............................................................ 9

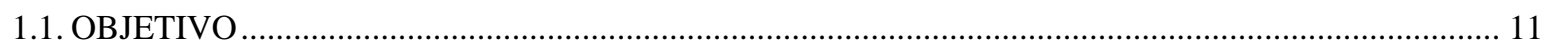

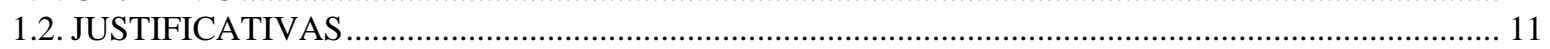

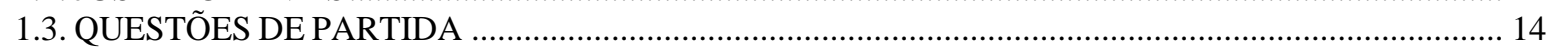

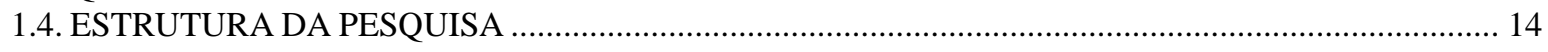

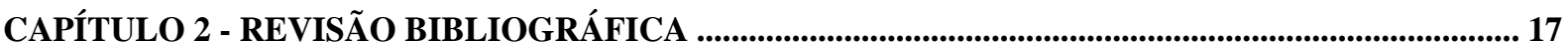

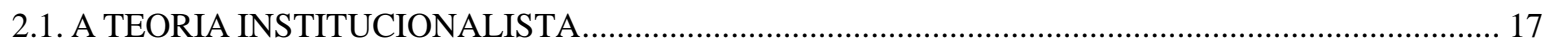

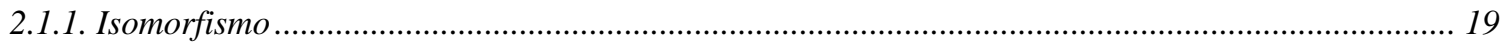

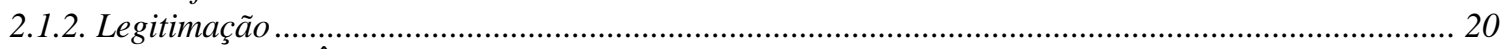

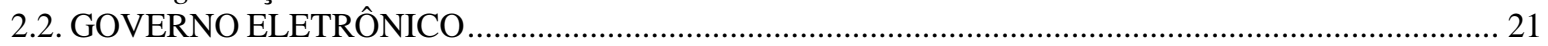

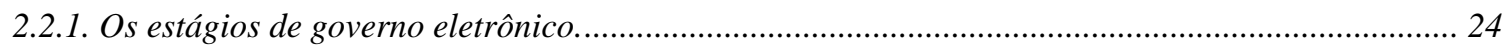

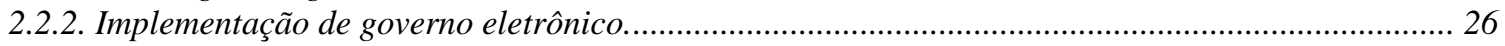

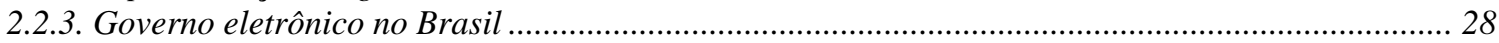

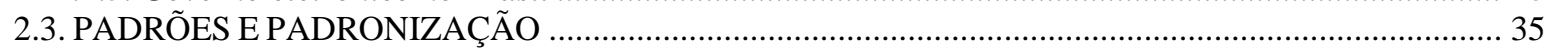

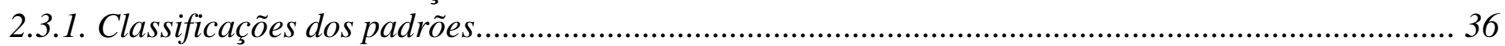

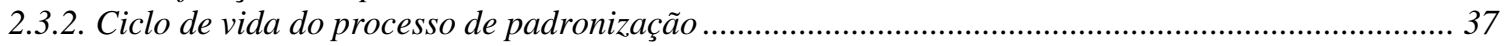

2.3.3. Os estágios de desenvolvimento e implementação de padrões...................................................... 38

2.3.4. As abordagens do desenvolvimento e implementação de padrões. ................................................ 38

2.3.5. Mecanismos de governança na padronização............................................................................ 39

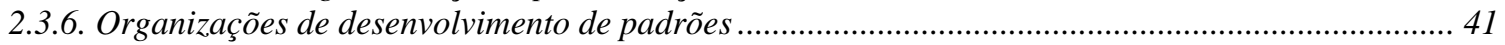

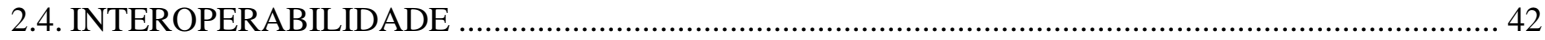

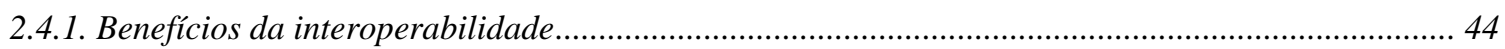

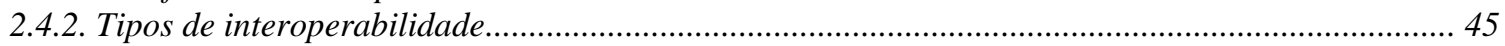

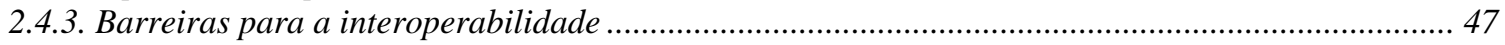

2.4.4. Benefícios e barreiras do compartilhamento de informações para governo eletrônico.................... 47

2.4.5. Fatores condicionantes de sucesso do compartilhamento de informações em governo eletrônico... 48

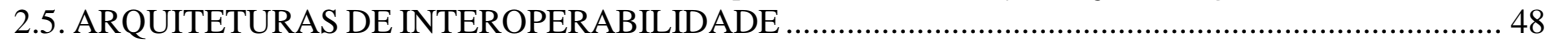

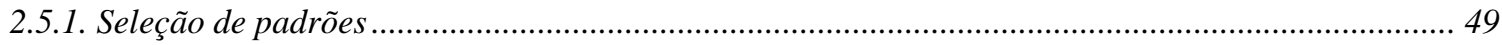

2.5.2. Premissas para o desenvolvimento e implementação................................................................... 51

2.5.3. Atores envolvidos no desenvolvimento e implementação ................................................................. 53

2.5.4. Exemplos de arquiteturas de interoperabilidade em implementação.............................................. 56

CAPÍTULO 3 - METODOLOGIA DE PESQUISA ..................................................................................59

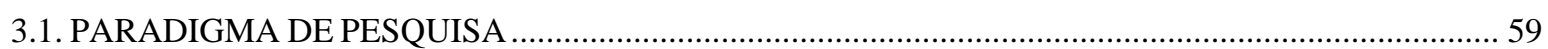

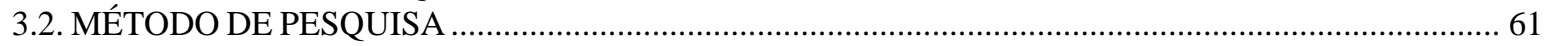

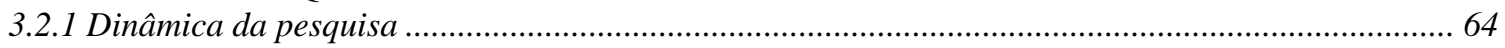

CAPÍTULO 4 - APRESENTAÇÃO DOS DADOS: A ARQUITETURA E-PING....................................... 69

4.1. CONCEPÇÃ

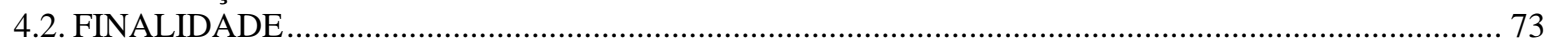

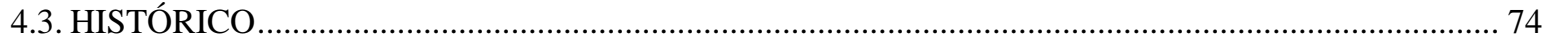

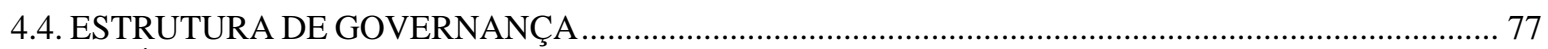

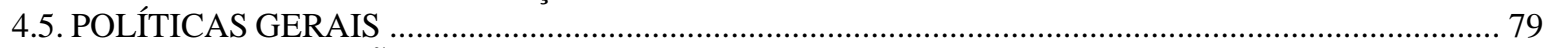

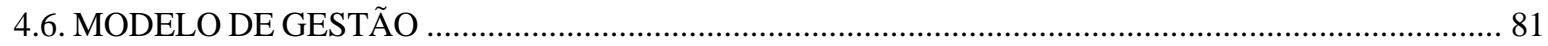

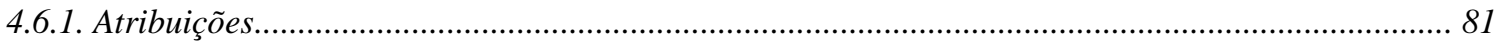

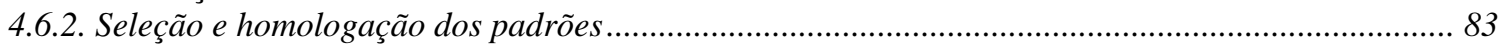

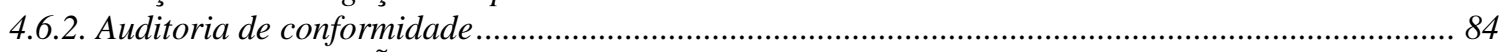

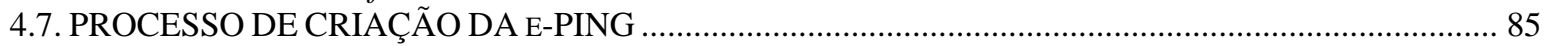

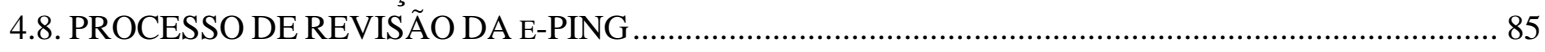

CAPÍTULO 5 - ANÁLISE E DISCUSSÃO DOS DADOS .......................................................................8 89 


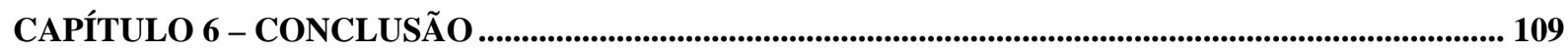

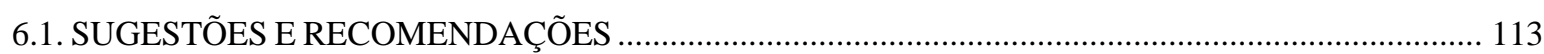

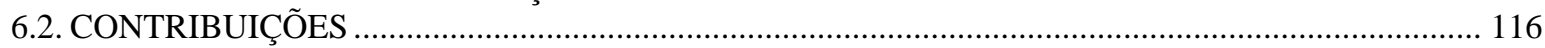

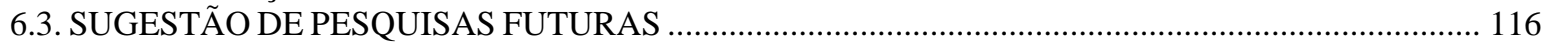

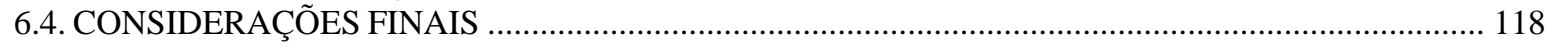

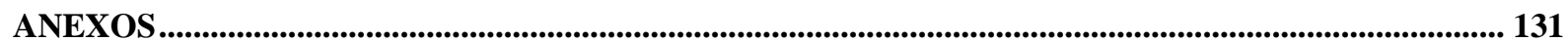




\section{LISTA DE QUADROS}

Quadro 1 - Estágios de governo eletrônico 24

Quadro 2 - Modelo de estágios de governo eletrônico - UN/ASPA ....................................... 25

Quadro 3 - Governo eletrônico no Brasil - principais organizações envolvidas...................... 32

Quadro 4 - Ambiente institucional do governo eletrônico no Brasil ........................................ 33

Quadro 5 - Grupos de Trabalho do Comitê Executivo do Governo Eletrônico - 2000 a 200234

Quadro 6 - Comitês Técnicos do Comitê Executivo do Governo Eletrônico - 2003 em diante

Quadro 7 - Dimensões adotas em algumas arquiteturas de interoperabilidade........................ 46

Quadro 8 - Benefício e barreiras do compartilhamento de informações para governo eletrônico 48

Quadro 9 - Projetos de padrões de interoperabilidade para governo eletrônico em andamento

Quadro 10 - Definição dos segmentos da e-PING

Quadro 11 - Especificações contempladas nos segmentos da e-PING ................................... 70

Quadro 12 - Atividades e seus executantes para a elaboração da e-PING ............................... 86 


\section{LISTA DE TABELAS}

Tabela 1 - Classificação dos padrões da e-PING versão 3.0 .............................................. 71 


\section{LISTA DE FIGURAS}

Figura 1 - Estrutura Organizacional do Programa Governo Eletrônico................................... 31

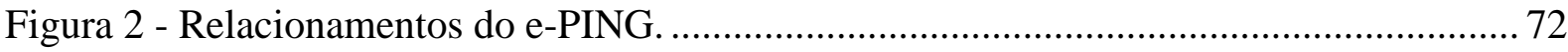

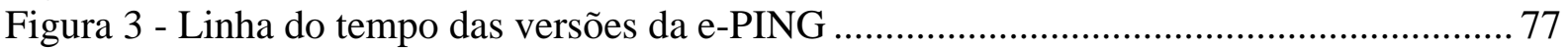

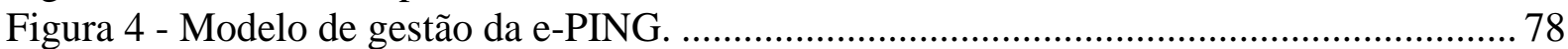

Figura 5 - Estágios do processo simplificado de construção da e-PING ................................ 89 


\section{CAPÍTULO 1 - INTRODUÇÃO E PROBLEMA DE PESQUISA}

Os padrões de interoperabilidade desempenham um papel importante na integração de sistemas e compartilhamento de informações no ambiente de governo eletrônico. Esse ambiente, tendo em vista ser considerado como rico em termos de inovações, pode ser bastante influenciado pelos processos de padronização. Isso porque a taxa de adoção de uma inovação depende das características percebidas pelos potenciais adotantes e a compatibilidade é uma das características observadas (ROGERS, 1995).

Mas o desenvolvimento e estabelecimento destes padrões não dependem somente de aspectos tecnológicos. A integração de sistemas e o compartilhamento de informações não significam apenas troca de dados mas, principalmente, integração de processos e transações. Neste cenário, surgem outras variáveis dos contextos institucional (organizacional e político), econômico e social. Além disso, no ambiente de governo eletrônico as transações envolvem geralmente múltiplos agentes e são condicionadas fortemente por aspectos culturais, o que torna esses processos ainda mais complexos e inter-relacionados. E mais: o estabelecimento de padrões implica reestruturação de processos de negócios e/ou mudanças na forma de interação desses agentes com as várias agências governamentais.

A padronização pode trazer inúmeros benefícios. No caso específico de governo eletrônico, a ONU especifica que o ambiente ideal apresenta-se para seus usuários como uma única porta de acesso às informações e serviços. A partir desse contexto, torna-se fácil identificar a necessidade da adoção de padrões, tendo em vista a necessidade de integração dos sistemas e do compartilhamento das informações. Vários autores, como por exemplo, Akbulut (2003), Dawes (1996), Landsbergen Jr. e Wolken Jr, (2001), já investigaram os processos de integração de sistemas e compartilhamento de informações entre agências governamentais e identificaram a padronização como fator condicionante.

A padronização é necessária para facilitar a troca de dados, sua reutilização ao longo do tempo, e também para prevenir o aprisionamento à ferramentas e formatos proprietários (EPAN, 2004). Mas para um padrão ser considerado bem sucedido é necessário que ele seja usado e aceito por todos os agentes envolvidos. Para a EPAN (2004), a co-operação entre 
todos os agentes envolvidos é necessária, isto é, todos devem ter algum nível de participação na definição dos padrões.

A interoperabilidade é um ponto que está se tornando crítico nas questões de governo eletrônico, principalmente para os países em desenvolvimento que se comprometeram em atingir as Metas de Desenvolvimento do Milênio (Millennium Development Goals - MDGs) em 2015. A ampliação da eficiência e da efetividade do governo juntamente com a prestação dos serviços públicos básicos para todos os cidadãos são componentes essenciais para atingir tais metas. A maioria desses países já finalizou o projeto de suas estratégias de governo eletrônico e está trabalhando nas suas implementações.

Entretanto, esses investimentos em tecnologias não levam automaticamente a serviços eletrônicos mais efetivos. Ao contrário, em muitos casos, terminam reforçando antigas barreiras que tem obstruído o acesso aos serviços públicos ao longo do tempo.

A promessa do governo eletrônico com instituições governamentais mais eficientes e mais efetivas não tem sido cumprida devido, em grande parte, ao processo de desenvolvimento de sistemas de TICs na base ad hoc. Em curto prazo, esse tipo de ações resolve as necessidades específicas dos órgãos, mas não dá a devida importância à necessidade de interação entre os diversos sistemas ou seus componentes para o compartilhamento e/ou troca de informações. Essa colaboração pode ser considerada ponto chave para o estabelecimento de um acesso único aos serviços de governos (one stop shop e-governemnt).

Disponibilizar um único ponto de acesso de serviços para cidadãos e empresários requer interoperabilidade uma vez que os serviços de governo são diversos e prestados por diferentes órgãos. Além disso, aumentar a facilidade com que as informações são compartilhadas entre órgãos individuais (até o ponto permitido por lei) resulta em melhores e/ou novos serviços. Por exemplo, os serviços de saúde podem ser prestados mais rapidamente e ficar mais conveniente para os cidadãos se os hospitais públicos estiverem interconectados com os órgãos de previdência e de saúde. A administração judiciária poderia ser mais rápida e mais efetiva se os sistemas de informação dos vários órgãos componentes do sistema de justiça criminal (polícias, promotorias públicas, procuradorias públicas, cortes, prisões) pudessem compartilhar dados. 
A definição e adoção de padrões de interoperabilidade para governo eletrônico têm se estabelecido como instrumentos estratégicos para suportar e impulsionar a integração envolvendo estruturas e processos dentro da administração pública (KNIGHT e FERNANDES, 2006).

Para Santos, Corte e Motta (2007), "... a interoperabilidade de tecnologia, processos, informação e dados é condição vital para o provimento de serviços de qualidade, tornando-se premissa para governos em todo o mundo, como fundamento para os conceitos de governo eletrônico, o e-gov". Os autores ainda argumentam que a interoperabilidade possibilita a racionalização de investimentos em TICs, visto que esta funciona como elemento facilitador do compartilhamento, reuso e intercâmbio de recursos tecnológicos.

A partir dessas considerações entende-se que os processos de desenvolvimento e estabelecimento de padrões apresentam um alto grau de complexidade, tendo em vista o número de agentes que participam desse processo, o ambiente onde ele ocorre, o nível de inter-relação entre os agentes e o ambiente, além dos possíveis conflitos de interesses decorrentes dessa inter-relação. Por outro lado, o estabelecimento dos padrões de interoperabilidade apresenta-se como um requisito indispensável para a efetiva integração dos sistemas de governo eletrônico. Deste modo, coloca-se como problema de pesquisa a análise e compreensão desse processo, visto que o seu conhecimento mais aprofundado permite, através do direcionamento de ações futuras, a criação de uma melhor condição de disseminação e evolução dos referidos padrões.

\subsection{OBJETIVO}

A presente pesquisa propõe-se a compreender os processos de desenvolvimento e implementação de uma arquitetura de interoperabilidade para governo eletrônico e identificar prováveis implicações da condução desses processos na posterior adoção dos padrões especificados.

\subsection{JUSTIFICATIVAS}

Padrões são difíceis de serem desenvolvidos e implementados. Alguns deles não passam da fase de desenvolvimento, em decorrência de problemas no processo de articulação das discussões e definições. Outros embora especificados, não são adotados, alguns por conta do processo de construção ou institucionalização. Também inovações tecnológicas surgidas ou 
mudanças no mercado podem tornar um padrão irrelevante ou exigir adaptações significativas nas suas especificações e, como conseqüência, torná-lo não adotado. Depois de especificado, um padrão é adotado mais ou menos amplamente, mas pode tornar-se obsoleto, criando uma necessidade de sua substituição ou até mesmo não ser mais aplicável devido as mudanças no contexto tecnológico em que foi criado.

Esse caráter dinâmico da padronização, caracterizado como um processo contínuo de evolução e adaptação, também apresenta uma constante tensão entre suas definições e a flexibilidade e generalização necessárias para que o padrão possa se tornar robusto.

No caso específico de padrões de interoperabilidade em ambiente de governo eletrônico no Brasil, uma outra iniciativa anterior já foi delineada, mas que não logrou êxito. O POSIG (Perfil OSI do Governo Brasileiro), foi instituído através do decreto $n^{\circ}$. 518, em 05 de maio de 1992, e estabelecia a conformidade com as especificações do modelo OSI (Open Systems Interconnection), da "International Organization for Standardization - ISO" no tocante à comunicação e interoperação dos sistemas de informação no âmbito da Administração Pública Federal direta e indireta (BRASIL, 1992). Essas especificações, no entanto, terminaram não sendo adotadas.

A combinação do uso de TICs avançadas, especialmente a internet, no suporte de novas formas de trabalho na administração pública, junto com a disponibilização mais abrangente de informações e serviços interativos acessíveis através de diferentes canais, é a base do governo eletrônico. O desafio existente é o de "reescrever as regras" de como a administração pública trabalha internamente, interage com seus usuários, e usa TICs não somente para aumentar a sua produtividade ao tornar as transações mais fáceis de serem executadas, mas também lidar com questões como inclusão social e exclusão digital.

Para que isso aconteça, não só as tecnologias usadas devem assegurar a comunicação e compartilhamento de informações, mas também os processos administrativos devem ser reorganizados e estarem aptos a co-operar.

Contudo, a realidade que se tem é a emergência de ilhas de governo eletrônico que frequentemente são incapazes de interoperar devido a fragmentação resultante de esforços 
descoordenados no desenvolvimento dos serviços, em todos os níveis da administração pública.

Ao agregar processos administrativos, todos, tanto do setor público como privado, poderiam alcançar um significativo aumento de eficiência e reduzir os custos de operação. A interoperabilidade é essencial para esse agrupamento da administração pública, para compartilhar e reusar informações administrativas e disponibilizar serviços e informações através de múltiplos canais. Na essência, a interoperabilidade é um requisito fundamental tanto na perspectiva técnica como econômica para o desenvolvimento de serviços de governo eletrônico eficientes e efetivos.

A partir desse contexto, podemos enumerar os seguintes pontos principais como base para a justificativa da pesquisa realizada:

- O processo de desenvolvimento e implementação de padrões, devido ao número de agentes envolvidos e eventuais conflitos de interesses, evidencia-se como complexo e dependente de variáveis nem sempre controladas;

- As transações de governo eletrônico envolvem atores de diversos segmentos da sociedade;

- O estabelecimento de padrões implica em redesenho de processos de negócios e/ou mudanças na forma de interação desses atores envolvidos com os diversos níveis de governo;

- As ações/reações/inter-relações desses atores são fatores condicionantes de sucesso do estabelecimento em um primeiro momento e também da posterior adoção e disseminação do padrão;

- O estabelecimento de um padrão precisa ser baseado num processo flexível e aberto suficiente para incorporar as adaptações e mudanças tecnológicas que ocorrerem durante sua definição, implementação e até mesmo após sua implementação.

Portanto, a análise desses processos é importante, pois permite a criação de uma melhor condição de disseminação e evolução dos referidos padrões. Além disso, a perspectiva sociotécnica de análise adotada para a pesquisa pode revelar aspectos significantes da condução dos processos, que poderiam passar despercebidos sob a ótica das abordagens apenas tecnológicas e deterministas. 


\subsection{QUESTÕES DE PARTIDA}

O desenvolvimento e implementação de padrões, ao ser considerado como processos de inovação, pressupõe geração de mudanças nos procedimentos e nas estruturas no contexto onde está ocorrendo. Os agentes envolvidos nos processos desempenham diversos papéis ao longo do tempo, podendo agir como facilitadores ou não. Além disso, acredita-se que existe uma correlação direta entre o nível de percepção por esses agentes da relevância dos padrões especificados e sua intenção em adotá-los.

A partir dessas premissas, foram definidas as seguintes questões como ponto de partida da pesquisa:

(1) como ocorrem os processos de desenvolvimento e implementação de um padrão de interoperabilidade em um ambiente de governo eletrônico, visto que estes se caracterizam por constituírem-se de agentes múltiplos e de ações inter-relacionadas?

(2) que mecanismos e estratégias podem ser adotados para a condução desses processos?

(3) de que forma esses mecanismos e estratégias podem influenciar na percepção pelos agentes implicados pela padronização da relevância dos padrões definidos e na conseqüente propensão a adoção?

(4) de que forma os mecanismos e estratégias adotadas podem influenciar na efetividade desses processos?

\subsection{ESTRUTURA DA PESQUISA}

A pesquisa está estruturada da seguinte forma: o capítulo 1 (Introdução) apresenta a sua contextualização, sua questão central, seu objetivo, justificativas e questões de partida. $\mathrm{Na}$ seqüência, o capítulo 2 é composto de duas partes: a primeira discorre sobre a Teoria Institucionalista, adotada como teoria de base e suporte da análise da pesquisa, com ênfase especificadamente sobre os conceitos de legitimação, seus mecanismos e estratégias; a segunda apresenta o referencial sobre Governo Eletrônico, definindo-o, apresentando as suas principais características e tipologias, assim como discutindo os conceitos de estágios de sua implementação, apontadas pela literatura atual. Trata também dos conceitos de padrões e de 
processos de padronização em geral e em específico das tecnologias da informação e comunicação, e discute os conceitos de interoperabilidade, seus fatores condicionantes e sua importância para a integração de sistemas e compartilhamento de informações no ambiente de governo eletrônico. Por fim, apresenta uma seção sobre arquiteturas de interoperabilidade, que inclui os tópicos sobre seleção de padrões, premissas a atores envolvidos no desenvolvimento e implementação de arquiteturas, além de dar alguns exemplos de outros padrões de interoperabilidade já em implantação. O capítulo 3 apresenta a metodologia de investigação utilizada e a dinâmica de pesquisa operacionalizada. O capítulo 4 apresenta os dados do objeto do estudo de caso da pesquisa - a arquitetura e-PING, enquanto que o capítulo 5 traz a análise e discussão dos dados coletados. Por fim, no capítulo 6 são apresentadas as conclusões do trabalho, incluindo-se as suas contribuições e sugestões para pesquisas futuras. 


\section{CAPÍTULO 2 - REVISÃO BIBLIOGRÁFICA}

Nesse capítulo serão apresentados os referenciais usados para o desenvolvimento da tese. Ele compõe-se de duas partes: a primeira (seções 2.1) apresenta a Teoria Institucionalista, adotada como base para o entendimento das análises da pesquisa e a segunda parte (seções 2.2 a 2.5) trata dos referenciais de contexto do tema da pesquisa, com uma abordagem mais específica para a problematização descrita.

\subsection{A TEORIA INSTITUCIONALISTA}

A teoria institucional emergiu como reação às abordagens econômicas e da dependência de recursos, que conceitualizam as organizações ou como funções de produção ou como sistemas de troca, moldadas ou pelas suas tecnologias e transações ou pela interdependência resultante das trocas com o sistema. Nessa abordagem, os ambientes são concebidos como um estoque de recursos e parceiros de trocas (SCOTT, 1987). Em contraste, a teoria institucional foca nas premissas no centro da ação social (ZUCKER, 1987). As organizações são vistas como cativos do ambiente institucional no qual elas existem. A fim de sobreviverem elas agem de acordo com o que é definido como apropriado e eficiente nesse ambiente social, desconsiderando o real impacto no desempenho organizacional (MEYER e ROWAN, 1977). Uma ênfase particular é dada aos processos de legitimação, e a tendência dos procedimentos e estruturas organizacionais institucionalizadas serem dados como certo ou vistos como legítimas pelas organizações que as adotam e as perpetuam (MEYER e ROWAN, 1977; ZUCKER, 1987; DiMAGGIO e POWELL, 1983; TOLBERT e ZUCKER, 1983).

O processo de legitimação é visto como uma fonte de estrutura formal. Ao ganhar legitimidade, os elementos da estrutura formal tais como as políticas, posições e estruturas de governança tornam-se manifestações de regras institucionais em seus respectivos domínios (MEYER e ROWAN, 1977).

Em contraste com a visão econômica, dentro da teoria institucional o sucesso organizacional é visto como dependente da habilidade da organização em acomodar expectativas institucionais em vez de coordenação de eficiência e controle das atividades produtivas (MEYER e ROWAN, 1977; GREENWOOD e HININGS, 1996). 
A Teoria Institucional, especialmente o Novo Institucionalismo (POWELL e DiMAGGIO, 1991), apresenta um ponto de vista sobre o processo de adoção de tecnologias, que questiona o modelo do ator racional, guiado por cálculos utilitários em suas decisões. Segundo essa abordagem, as organizações sofrem demandas e pressões de seu ambiente externo não só em relação a elementos técnicos e econômicos (produção e intercâmbio de bens e serviços), mas também sofrem demandas de natureza cultural, que exige que elas desempenhem determinados papéis e mantenham certas aparências frente ao ambiente (SCOTT, 2001).

A ação organizacional deixa ser vista como uma escolha entre diversas possibilidades determinadas por arranjos internos, mas ao invés disso, ela enfrenta um conjunto limitado de opções legitimadas, determinadas pelo grupo de atores que compõem o chamado campo organizacional (organizational field). A forma como esse campo organizacional exerce sua influência se dá pelas instituições: o conjunto de normas, regras, valores que demonstram para a organização o que pode ou não ser feito (HOFFMAN, 1999; SCOTT, 2001). Desta forma, as ações organizacionais podem ser guiadas por objetivos individuais ou sociais, independentemente de critérios objetivos, racionais ou de eficiência.

Scott (1995) define instituição como uma estrutura ou atividade cognitiva, normativa ou regulatória que provê estabilidade e significado para o comportamento social. As instituições são suportadas por diversos meios tais como culturas, estruturas e rotinas, que operam em múltiplos níveis de ação. Segundo Jepperson (1991), uma instituição é um processo organizado e estabelecido na forma de um sistema normativo de rotinas auto-reproduzidas e socialmente construídas.

Outro importante conceito estabelecido na teoria neo-institucionalista é o de institucionalização. Para Zucker (1991), refere-se ao processo pelo qual atores individuais transmitem o que é socialmente definido como real e, ao mesmo tempo, como uma variável de quanto uma ação pode ser considerada correta em uma determinada realidade social. Para esse autor esse processo geralmente ocorre como um subproduto da criação de outras estruturas. Já para Powell (1991) a institucionalização é um processo compulsório que força unidades de uma população a agirem da mesma forma que outras unidades que estão enfrentando as mesmas situações, uma idéia que ele denominou de isomorfismo. 


\subsubsection{Isomorfismo}

Um dos principais argumentos da Teoria Institucional é o de que as organizações tendem à imitação, ou isomorfismo, que pode ser definido como a busca pela homogeneidade de estruturas, processos e ações nas organizações. DiMaggio e Powell (1991) afirmam que, em geral, os processos de difusão de inovações se dão pela imitação - inovações bem sucedidas são raras e largamente imitadas.

DiMaggio e Powell (1991) e Powell e DiMaggio (1991), apontam três principais mecanismos pelos quais ocorre o isomorfismo organizacional: pressões coercitivas, processo mimético ou adaptativo, e influências normativas.

O isomorfismo coercitivo provém de pressões formais e informais sobre a organização (DIMAGGIO e POWELL, 1991). Essa pressão pode ser exercida por força, persuasão, ou mesmo por ordem. Algumas mudanças organizacionais podem ocorrer por pressões governamentais e força de lei que impõem procedimentos e padrões de operação sobre determinado setor.

O segundo mecanismo de isomorfismo é o processo mimético, justificado pelo fato de que a incerteza encoraja a imitação. Quando as tecnologias organizacionais são pouco compreendidas, quando as metas são ambíguas ou quando o meio ambiente cria incertezas simbólicas, as organizações podem modelar a si mesmas com base em outras organizações (DIMAGGIO e POWELL, 1991).

Conforme certas organizações adotam práticas que são socialmente reconhecidas como geradoras de eficiência, há pressões por parte de funcionários, acionistas, consumidores e até mesmo da sociedade em geral, para que as demais também adotem. Isto é, a solução mais disponível e reconhecida como adequada em geral é a primeira a ser adotada: existe uma variedade de práticas que as organizações precisam adotar com a finalidade de serem vistas como modernas tanto por seus empregados quanto por seus clientes (ou usuários) (DIMAGGIO e POWELL, 1991). Logo, processos, regras, procedimentos e formatos estruturais podem ser copiados e amplamente difundidos, ainda que não existam evidências concretas de que tais modelos contribuam para a efetividade organizacional. 
O terceiro mecanismo pelo qual ocorre o isomorfismo é por pressões normativas. Essas pressões decorrem da profissionalização das organizações, via educação formal e legitimação de uma base de conhecimentos produzida por especialistas acadêmicos. Da mesma forma, ela provém da rede de contatos profissionais que se estendem entre as organizações e os grupos de profissionais, assim como em instituições de treinamento ou associações comerciais.

DiMaggio e Powell (1991) relacionam essas pressões normativas à chamada cultura do

profissionalismo, que visa estabelecer bases de conhecimento sobre métodos de trabalho como fonte de legitimação para profissionais. Assim como as organizações, os profissionais também sofrem pressões coercitivas e miméticas, seja via educação formal ou via redes de contato informais. A socialização é uma das forças que levam ao isomorfismo dos profissionais, e por conseqüência das práticas que estes aplicam nas organizações.

\subsubsection{Legitimação}

Um outro conceito relacionado à institucionalização é o da legitimação, “uma percepção ou premissa generalizada de que as ações de uma entidade são desejadas, próprias, ou apropriadas dentro de um sistema socialmente construído de normas, valores, crenças e definições” (SUCHMAN, 1995, p. 4). Para esse autor, existem três tipos de legitimação: pragmática, moral e cognitiva:

- pragmática: baseada nos interesses dos atores que possuem uma ligação mais próxima com a organização;

- moral: reflete uma avaliação positiva da organização e suas atividades, baseada em valores socialmente construídos;

- cognitiva: consiste na aceitação da organização como necessária ou inevitável do ponto de vista de uma determinada referência cultural.

Esses três tipos de legitimação co-existem na maioria das situações e são inter-relacionadas. Sob pressões institucionais, as organizações implementam estratégias a fim de obter, manter ou reparar sua legitimação (SUCHMAN, 1995).

Oliver (1991) define cinco tipos de estratégias de legitimação: aceitação passiva, acordo, prevenção, desafio e manipulação. Essas estratégias ajudam a entender como as organizações, 
sob pressões institucionais, gerenciam sua legitimidade e, consequentemente, a aceitação das suas ações pelos atores que interagem com elas.

\subsection{GOVERNO ELETRÔNICO}

O surgimento da Internet e de outras inovações nas Tecnologias de Informação e Comunicações (TICs) proporcionaram às organizações a possibilidade de migrar seus sistemas existentes em plataformas convencionais para sistemas com interface web. $\mathrm{O}$ esgotamento das sobrevidas dos sistemas legados ${ }^{1}$ também pode ser considerado um outro fator que motivou a construção de novos sistemas baseados na Internet - os quais conformam, na prática, o governo eletrônico. No caso específico de organizações governamentais, outros aspectos que incentivaram o surgimento dessa inovação foram a necessidade das administrações aumentarem suas arrecadações e melhorar seus processos internos (KAKABADSE; KAKABADSE; KOUZMIN, 2003), e as pressões da sociedade para que o governo otimizasse seus gastos e atuasse, cada vez mais, com transparência, qualidade e de modo universal na oferta de serviços e provimento de informações aos cidadãos e organizações em geral. Todos esses fatores encontraram na intensificação do uso das TIC o suporte necessário para implementação de projetos que pudessem responder a essas demandas.

As possibilidades de otimização ou mesmo a criação de novos processos no ambiente de governo, baseados em soluções de TICs, se baseiam em princípios definidos pelos conceitos de governo eletrônico. No entanto, por ser um "fenômeno relativamente recente que ainda não foi claramente definido” (GRANDE; ARAUJO; SERNA, 2002, p. 5), várias definições podem ser encontradas na literatura.

Para o World Bank (2003),

governo eletrônico refere-se ao uso, por agências governamentais, de tecnologias de informação (como redes de longa distância, internet e computação móvel) capazes de transformar as relações com cidadãos, empresas e outras unidades do governo. Essas tecnologias podem servir a diferentes fins, como: melhor prestação de serviços aos cidadãos, interações mais eficazes com empresas e a indústria, empoderamento do cidadão por meio do acesso a informações ou mais eficiência na administração governamental.

\footnotetext{
${ }^{1}$ Sistemas aplicativos providos pelos “centros de processamento de dados” governamentais ou demais sistemas passados de uma gestão à outra. Os sistemas legados de governo tratam, em sua maioria, de processos operacionais transacionais.
} 
Segundo o National Audit Office (2002), "governo eletrônico ou e-governo significa prover acesso público via internet a informações sobre os serviços oferecidos pelos departamentos centrais do governo e suas agências, habilitando o público à condução e conclusão de transações para tais serviços".

De acordo com a OCDE (2001), o termo "governo eletrônico aborda o uso de novas tecnologias de informação e comunicação pelos governos, aplicadas a todas as suas funções". Ou ainda (OECD, 2003; p.23), "o uso das tecnologias de informação e comunicação, e principalmente a internet, como ferramentas para conseguir melhor governo" ${ }^{2}$.

A United Nations (2002) define governo eletrônico "como a utilização da Internet e da web para ofertar informações e serviços governamentais aos cidadãos”.

Para a União Européia (2004), governo eletrônico "é o uso de TICs na administração pública combinadas com mudanças organizacionais e novas habilidades a fim de melhorar a prestação dos serviços públicos e os processos democráticos”.

O termo governo eletrônico ainda é definido como "a oferta e troca de informações e serviços governamentais on-line para cidadãos, empresas e outras agências governamentais (INTOSAI, 2003)”.

Para Okot-Uma (2001), governo eletrônico "refere-se a processos e estruturas relativos ao fornecimento eletrônico de serviços governamentais ao público”.

Uma definição mais ampla de governo eletrônico se refere à adoção das TICs pela Administração Pública, como diferentes vias através das quais se conectam e interagem com outras organizações e pessoas, especialmente mediante suas páginas web, mas também através de correio eletrônico e outras ferramentas como o telefone móvel, os PDAs, a vídeo conferência, intranets privadas, extranets, TV a cabo, ondas de radio, o satélite (CRIADO e RAMILO, 2001). Dentro dessa perspectiva conceitual, a utilização de uma definição mais ampla se fundamenta na previsão de um uso cada vez mais integrado das tecnologias.

\footnotetext{
2 "The use of Information and Communication Technologies, and particularly the Internet, as a tool to achieve better government" (OECD, 2003; p. 23).
} 
Finalmente, Baum e Di Maio (Gartner Group - 2000) definem governo eletrônico "como a contínua otimização da prestação de serviços governamentais, participação dos cidadãos e governança pela transformação das relações internas e externas através das tecnologias, internet e novas mídias".

Diferentemente de algumas definições anteriores que se concentram unicamente na dimensão de melhoria da prestação de serviços, a definição do Gartner Group considera a importância da mudança e a transformação institucional e a articulação de consensos entre aqueles agentes e interesses que são fundamentais para lograr o êxito do projeto (PRATCHETT, 1999; FERGUSON, 2000).

Em linhas gerais, as funções características do governo eletrônico são:

- prestação eletrônica de informações e serviços;

- regulamentação das redes de informação, envolvendo principalmente governança, certificação e tributação;

- prestação de contas públicas, transparência e monitoramento da execução orçamentária;

- ensino à distância, alfabetização digital e manutenção de bibliotecas virtuais;

- difusão cultural com ênfase nas identidades locais, fomento e preservação das culturas locais;

- e-procurement, isto é, aquisição de bens e serviços por meio da Internet, como licitações públicas eletrônicas, pregões eletrônicos, cartões de compras governamentais, bolsas de compras públicas virtuais e outros tipos de mercados digitais para bens adquiridos pelo governo;

- estímulo aos negócios eletrônicos, através da criação de ambientes de transações seguras, especialmente para pequenas e médias empresas.

Para realizar essas funções, o governo eletrônico envolve basicamente quatro tipos de transações: G2G, quando se trata de uma relação intra ou inter-governos; G2B, caracterizado por transações entre governos e pessoas jurídicas em seus vários papéis desempenhados; e G2C, envolvendo relações entre governos e cidadãos; e G2E, relacionadas às transações entre governos e seus próprios servidores. 


\subsubsection{Os estágios de governo eletrônico.}

Os processos de implementação de governo eletrônico têm sido analisados sob a perspectiva de algo que apresenta estágios de evolução ao longo do tempo, tendo em vista os níveis de informações e serviços prestados.

Vários modelos são encontrados na literatura para a classificação desses estágios, como pode ser visto no quadro 1.

Quadro 1 - Estágios de governo eletrônico

\begin{tabular}{|c|c|c|}
\hline Proponente & $\mathbf{N}^{\circ}$. de estágios & Estágios \\
\hline $\begin{array}{l}\text { Gartner Group (Baum e } \\
\text { Maio, 2000) }\end{array}$ & 04 & \begin{tabular}{|l} 
Presença \\
Interação \\
Transação \\
Transformação \\
\end{tabular} \\
\hline $\begin{array}{l}\text { Hiller (2001) e UN/ASPA } \\
\text { (2001) }\end{array}$ & 05 & $\begin{array}{l}\text { Presença emergente } \\
\text { Presença aprimorada } \\
\text { Presença interativa } \\
\text { Presença transacional } \\
\text { Presença em rede } \\
\end{array}$ \\
\hline Deloitte and Touche (2001) & 06 & $\begin{array}{l}\text { Publicação / disseminação de informações } \\
\text { Transação bidirecional } \\
\text { Portais multi-propósitos } \\
\text { Portais personalizados } \\
\text { Agrupamento de serviços comuns } \\
\text { Integração total }\end{array}$ \\
\hline Layne e Lee (2001) & 04 & \begin{tabular}{|l} 
Catalogação \\
Transação \\
Integração vertical \\
Integração horizontal \\
\end{tabular} \\
\hline Moon (2002) & 05 & $\begin{array}{l}\text { Comunicação unidirecional } \\
\text { Comunicação bidirecional } \\
\text { Transações de serviços e financeiras } \\
\text { Integração horizontal e vertical } \\
\text { Participação política }\end{array}$ \\
\hline Siau e Long (2004) & 05 & $\begin{array}{l}\text { Presença na web } \\
\text { Interação } \\
\text { Transação } \\
\text { Transformação } \\
\text { Democracia eletrônica } \\
\end{array}$ \\
\hline
\end{tabular}

O modelo da UN/ASPA (2001) é detalhado no quadro 2. 
Quadro 2 - Modelo de estágios de governo eletrônico - UN/ASPA

Fonte: UN/ASPA (2001).

\begin{tabular}{|c|c|}
\hline Estágio & Características \\
\hline I - Presença Emergente & $\begin{array}{l}\text { Presença na web por meio de um website oficial, um portal nacional ou } \\
\text { uma home page oficial; links para os ministérios do governo, governos } \\
\text { estaduais e locais, administração indireta; informação é limitada, básica } \\
\text { e estática. }\end{array}$ \\
\hline II - Presença Aprimorada & $\begin{array}{l}\text { Serviços on line são aprimorados para incluir bases de dados e fontes } \\
\text { de informações atuais e arquivadas, como políticas, leis e regulação, } \\
\text { relatórios, informativos e bases de dados para serem baixadas pela } \\
\text { Internet. O usuário pode procurar por um documento e há função de } \\
\text { ajuda e um mapa do sítio é disponibilizado. }\end{array}$ \\
\hline III - Presença Interativa & $\begin{array}{l}\text { Provisão de serviços on line do governo entra no modo interativo; } \\
\text { facilidades para download on line; link seguro; facilidade de assinatura } \\
\text { eletrônica; capacidade de áudio e vídeo para informação pública } \\
\text { relevante. Os servidores públicos podem ser contactados via e-mail, } \\
\text { fax, telefone e correio. O sítio é atualizado com grande regularidade. }\end{array}$ \\
\hline IV - Presença Transacional & $\begin{array}{l}\text { Usuários têm condições de conduzir transações on line, como pagar } \\
\text { multas por transgressões no trânsito, impostos e taxas por serviços } \\
\text { postais por meio de cartão de crédito, bancário ou de débito. Há } \\
\text { algumas facilidades para licitar on line em contratações públicas via } \\
\text { links seguros. }\end{array}$ \\
\hline V - Presença em Rede & $\begin{array}{l}\text { Uma estrutura G2C (governo para cidadão) baseada em uma rede } \\
\text { integrada de agências públicas para a provisão de informação, } \\
\text { conhecimento e serviços. A ênfase está no feedback para o governo. } \\
\text { Um formulário de comentário na web é disponibilizado. Um calendário } \\
\text { de eventos governamentais futuros existe com um convite do governo à } \\
\text { participação. Governo solicita feedback por meio de mecanismos de } \\
\text { pesquisa de opinião on line; fóruns de discussão; e facilidades de } \\
\text { consulta on line. }\end{array}$ \\
\hline
\end{tabular}

Os estágios apresentados nesse modelo são ascendentes por natureza e construídos de acordo com o nível de maturidade ou sofisticação da presença on line das administrações públicas dos Estados-Membros (UNITED NATIONS, 2001). Os países são classificados considerando se eles provêem produtos específicos e serviços sociais identificados como característicos de um determinado estágio. 


\subsubsection{Implementação de governo eletrônico.}

Para Medeiros (2004), o conceito de governo eletrônico encontra-se na intersecção de três áreas do conhecimento: políticas públicas, gestão e comportamento organizacional, e tecnologia da informação. Ainda deve ser observado que, ao longo da história, desenvolvimentos nas tecnologias têm surgido muito mais rapidamente do que a evolução em formas organizacionais e da gestão das políticas públicas. Independente dessas diferenças nas suas evoluções, esses três domínios interagem constantemente entre si, gerando muitas questões e conflitos sobre o que é tecnicamente possível, organizacionalmente adequado e socialmente desejável (CENTER FOR TECHNOLOGY IN GOVERNMENT, 1999).

Outro ponto a ser considerado é que, na implementação de projetos de governo eletrônico, que são intensivos no uso de TICs, podem existir algumas barreiras ao seu desenvolvimento, impostas pelas culturas e valores existentes nas unidades governamentais, pois novas tecnologias desafiam a maneira usual como os processos internos e externos dessas organizações vinham sendo usualmente conduzidos (NATIONAL AUDIT OFFICE, 2002).

Segundo Avgerou e outros (2005), a implementação de governo eletrônico normalmente têm sido associada à geração de benefícios em vários aspectos, dentre eles:

- na condução da administração pública, proporcionando maior eficiência e melhor prestação de contas;

- nos serviços que os governos disponibilizam aos cidadãos, tais como mais informação sobre serviços, e maior efetividade nas implementações das políticas fiscais e sociais;

- na capacidade do Estado para promover o desenvolvimento, na consolidação da sua defesa, fortalecimento da democracia, na criação de programas para diminuição da pobreza, e distribuição de renda.

No entanto, para Ciborra e Navarra (2003, citados por Avgerou e outros, 2005), boa parte da literatura sobre governo eletrônico é especulativa, fazendo predições de benefícios em longo prazo baseadas na capacidade física das tecnologias, sem levar em consideração os esforços necessários e obstáculos para sua implementação. Ainda segundo esses autores, há uma tendência em extrapolar efeitos de larga escala, como aumento da cidadania e diminuição da pobreza, a partir de evidências de, muitas vezes, esporádicos projetos pilotos. Madon (1992, citada por Avgerou e outros, 2005), ainda acrescenta que o uso de TICs em países emergentes enfrenta problemas de escalabilidade e sustentabilidade. 
Ainda de acordo com Avgerou e outros (2005), o desenvolvimento de sistemas para suporte aos serviços de governo requer a transformação de sistemas legados implantados nas administrações públicas burocráticas em sistemas de informações modernos, o que se constitui numa tarefa bastante difícil, tanto no aspecto tecnológico como organizacional.

Tecnologicamente, o desafio imposto pela implementação de governo eletrônico contempla a modernização e integração de sistemas fragmentados para formar uma infra-estrutura tecnológica capaz de suportar melhorias na prestação de serviços que sejam notadas pelos cidadãos, tais como a redução ou eliminação da necessidade de acessar múltiplos órgãos do governo a fim de obter um serviço (CIBORRA e NAVARRA, 2003). Mas para Avgerou e outros (2005), não existe um método instantâneo ou confiável para se conseguir as mudanças organizacionais necessárias para criar a capacidade da administração em melhorar a disponibilização de serviços públicos em longo prazo.

Segundo Oliveira (2003), no último estágio de implantação do governo eletrônico, as aplicações tornam-se mais avançadas, e um portal de governo eletrônico deixa de ser apenas um simples índice de páginas do governo na internet, e passa a ser um ponto de convergência de todos os serviços digitais prestados por esse governo. Os serviços são disponibilizados por funções ou temas, a despeito da divisão real do governo em seus diversos órgão e níveis. Ao efetuar uma transação com o governo, o usuário não precisa saber quais são os órgãos ou departamentos, de quais níveis de governo e em que sequência são mobilizados, para obtenção de determinado serviço ou informação. As aplicações e o ambiente disponibilizados são responsáveis pelo processamento total da transação, provendo ao usuário a informação ou serviço solicitado através de um único ponto de acesso.

Esse estágio tem sido denominado como "governo de parada única" ou "de janela única" (dos termos em inglês on-stop government e single-window service, respectivamente) (HAGEN E KUBICEK, 2000; BENT, KERNAGHAN E MARSON, 1999).

A essência do conceito de "janela única" é de colocar juntos os serviços de governo, ou informação sobre eles, de modo a reduzir a quantidade de tempo e o esforço que os cidadãos têm de dispender para encontrar e obter os serviços que necessitam (BENT, KERNAGHAN E MARSON, 1999). 
Como já visto, de uma forma simplificada, podemos afirmar que a implementação de governo eletrônico geralmente envolve uma evolução em três etapas: presença na Internet através de informações básicas, capacidades de transação para indivíduos e empresas e informações e transações integradas, com a colaboração entre diversas agências (janela única / governo de parada única). Mas a transição para o último estágio envolve desafios políticos, estratégicos e procedimentais inerentes, quando cooperação interagências é fundamental, além dos aspectos tecnológicos.

Para que essa evolução seja possível, segundo Fernandes (2002), é necessária uma mudança radical na gestão da administração pública, pois muitos dos serviços a serem prestados exigirão uma intensa colaboração, integração e interoperatividade entre os diversos órgãos e níveis de governo. Para a autora, no estágio avançado de governo eletrônico, a automação das atividades e a racionalização dos procedimentos implicam em transformações significativas dos processos de trabalho do governo, e não apenas na agilização desses processos.

\subsubsection{Governo eletrônico no Brasil}

Por intermédio do Decreto Presidencial de 3 de abril de 2000, foi criado um Grupo de Trabalho Interministerial, com a finalidade de examinar e propor políticas, diretrizes e normas relacionadas com as novas formas eletrônicas de interação. Informalmente, esse núcleo de pessoas ficou conhecido como Grupo de Trabalho em Tecnologia da Informação - GTTI. A criação do GTTI foi inserida dentro da política do Governo, para lançar as bases da criação de uma sociedade digital no Brasil. Suas ações alinharam-se com as metas do Programa Sociedade da Informação, coordenado pelo Ministério da Ciência e Tecnologia - MCT. Nesse contexto, o GTTI assumiu o papel de facilitador na busca dos objetivos daquele Programa.

O trabalho do GTTI, inicialmente, concentrou esforços em três das sete linhas de ação do Programa Sociedade da Informação do MCT: universalização de serviços, governo ao alcance de todos e infra-estrutura avançada. Para levar a efeito tais medidas, discutidas no âmbito do GTTI, o governo brasileiro lançou, em setembro de 2000, o documento intitulado "Proposta de Política de Governo Eletrônico para o Poder Executivo Federal” (BRASIL, 2000a), no qual há um detalhamento de macro objetivos prioritários e metas para o período 2000-2003. Os principais objetivos referem-se ao estabelecimento de um novo paradigma cultural de inclusão digital, focado no cidadão/cliente, com a redução de custos unitários, a melhoria na gestão e qualidade dos serviços públicos, a transparência e a simplificação de processos. Esse 
documento ressalta como fundamentais as ações de cooperação, convergência e integração das redes e dos sistemas de informações do governo, o uso do "peso institucional do governo" no mercado, integrando ações de compra e contratação de tecnologias da informação que possam reduzir custos unitários, e a inclusão social e a ampliação do uso da tecnologia da informação pelo cidadão brasileiro.

O GTTI teve atuação decisiva no diagnóstico e formulação da política de Governo Eletrônico, e por esta razão foi mantido para prestar assessoramento a todos os projetos, com a denominação de Grupo de Apoio Técnico - GAT (REF 2 anos de gov eletrônico).

Com a criação do Comitê Executivo do Governo Eletrônico (CEGE), em outubro de 2000 (BRASIL, 2000b), foram definidos papéis a serem cumpridos por diversos órgãos e implementadas ações e normas que conformaram o ambiente institucional no qual o governo eletrônico se estabeleceu no país. Esse comitê foi criado tendo como meta disponibilizar todas as informações e os serviços governamentais na Internet, e também garantir acesso à Internet a toda a população brasileira. Procura contribuir para que os serviços disponibilizados sejam de fato utilizados por todos, ampliando a inclusão digital (BRASIL, 2003a).

Segundo Fernandes e Afonso (2001), para o governo brasileiro, os objetivos do governo eletrônico seriam os seguintes:

- universalização e democratização do acesso aos serviços;

- melhoria da gestão e qualidade dos serviços públicos;

- transparência;

- redução dos custos unitários;

- $\quad$ simplificação de processos;

- informação como fator estratégico;

- convergência e integração das redes e sistemas de informação.

O Programa Governo Eletrônico foi implementado inicialmente com base na atuação coordenadora e mobilizadora, empreendida a partir da Presidência da República (por meio da Casa Civil), com apoio técnico e gerencial da Secretaria de Logística e Tecnologia da Informação - SLTI, do Ministério do Planejamento, Orçamento e Gestão - MPOG. A SLTI foi definida como o órgão responsável pelo planejamento estratégico, coordenação interministerial e emissão de normas relacionadas com a área de informática. O arranjo 
institucional adotado combinava a capacidade técnica e experiência da SLTI em TI com a capacidade de coordenação política da Presidência da República (BRASIL, 2002a).

Esta atuação era sustentada em um comitê interministerial, integrado pelos SecretáriosExecutivos (e cargos equivalentes) dos Ministérios e da Presidência da República, denominado Comitê Executivo de Governo Eletrônico (criado por Decreto de 18 de outubro de 2000) ${ }^{3}$, que possui as seguintes atribuições:

- definir estratégias e coordenar projetos de TI no âmbito do Governo Eletrônico;

- definir diretrizes e metas para a oferta de serviços e de informações por meio eletrônico;

- definir padrões para prestação de serviços e gestão da infra-estrutura de Tecnologia da Informação - TI;

- definir diretrizes e parâmetros para o planejamento de TI pelos ministérios, inclusive para a elaboração do orçamento; e

- coordenar medidas de racionalização de gastos e de controle de recursos em TI.

O patrocínio por dirigentes públicos em posições de liderança estratégica tem sido de grande importância na implementação do programa de governo eletrônico brasileiro. O Chefe da Casa Civil é o Presidente do Comitê de Governo Eletrônico e o Secretário de Logística e Tecnologia da Informação exerce as funções de secretaria-executiva. Em cada Ministério, existe a prerrogativa de que a liderança seja exercida pelo Secretário-Executivo, que é o dirigente em segundo nível na estrutura hierárquica geralmente voltado aos assuntos de natureza técnica e administrativa.

O Comitê estabeleceu diversos mecanismos de coordenação e acompanhamento dos projetos. A cada semana acontece uma reunião de monitoramento dos projetos entre a Secretaria Executiva do Comitê (SLTI/MP), a Presidência da República e os coordenadores dos Grupos de Trabalho de Governo Eletrônico. A Secretaria Executiva também realiza uma avaliação quinzenal com as equipes dos Grupos de Trabalho. O Grupo de Assessoramento Técnico GAT, integrado por especialistas na área de TICs, é convocado sempre que necessário, como por exemplo para a discussão de temas de maior complexidade técnica. As reuniões ordinárias do Comitê são realizadas com mensalmente, com a pauta voltada para a disseminação de

\footnotetext{
${ }^{3}$ Veja a íntegra do decreto de criação do Comitê Executivo de Governo Eletrônico no Anexo H; o decreto n ${ }^{\circ}$ 1.048 de 21 de janeiro de 1994 ao qual o decreto de 18 de janeiro de 2000 se refere encontra-se no Anexo G.
} 
informação, mobilização dos ministérios, acompanhamento dos projetos e deliberação estratégica. Toda a documentação grada durante os trabalhos no âmbito do programa é disponibilizada no portal do Governo Eletrônico (www.governoeletronico.gov.br).

A figura 1 a seguir, apresenta a estrutura atual do programa de Governo Eletrônico.

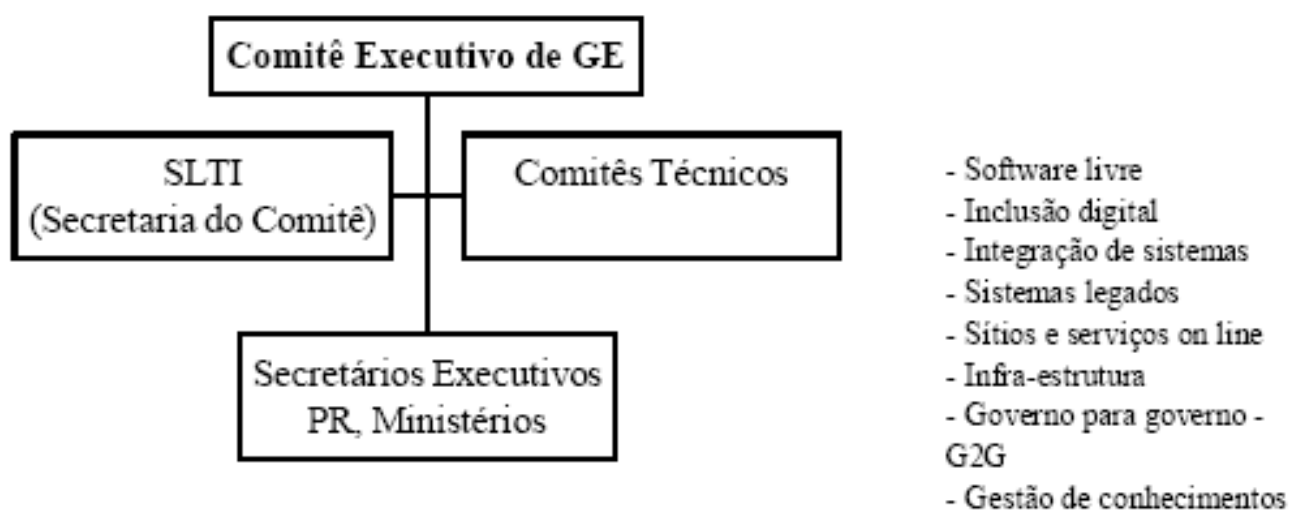

Figura 1 - Estrutura Organizacional do Programa Governo Eletrônico

Fonte: Fernandes (2006)

Os quadros a seguir, construídos por Medeiros (2004), apresentam os aspectos organizacionais e legais da sustentação do governo eletrônico no Brasil, no que diz respeito as principais organizações envolvidas (Quadro 3) e princípios normativos (Quadro 4). 
Quadro 3 - Governo eletrônico no Brasil - principais organizações envolvidas

Fonte: Medeiros (2004)

\begin{tabular}{|c|c|}
\hline \multicolumn{2}{|r|}{ PRINCIPAIS ORGANIZAÇÕES ENVOLVIDAS } \\
\hline Setor Público & $\begin{array}{ll}\text { - } & \text { Casa Civil da Presidência da República } \\
\text { - } & \text { Ministério do Planejamento, Orçamento e Gestão (MPOG) } \\
\text { - } & \text { Secretaria de Logística e Tecnologia da Informação (SLTI/MPOG) } \\
\text { - } & \text { Ministério da Ciência e Tecnologia } \\
\text { - } & \text { Ministério das Comunicações } \\
\text { - } & \text { Instituto Nacional de Tecnologia de Informação (ITI) } \\
\text { - } & \text { Serviço Federal de Processamento de Dados (SERPRO) }\end{array}$ \\
\hline Terceiro Setor & $\begin{array}{l}\text { - ONGs (especialmente aquelas que atuam em projetos de inclusão digital) } \\
\text { - Associações de usuários de serviços de informática } \\
\text { - Associações (sem fins lucrativos) representativas de empresas de processamento de } \\
\text { dados (públicas e privadas), da indústria e do comércio }\end{array}$ \\
\hline Iniciativa Privada & $\begin{array}{l}\text { - Fornecedores de softwares } \\
\text { - Fornecedores de hardware para infra-estrutura de Internet } \\
\text { - Prestadores de serviços em TIC } \\
\text { - Consultorias organizacionais }\end{array}$ \\
\hline Setor Acadêmico & - Instituições acadêmicas \\
\hline
\end{tabular}


Quadro 4 - Governo eletrônico no Brasil - princípios normativos

Fonte: Medeiros (2004)

\section{ESTRUTURA LEGAL - PRINCÍPIOS NORMATIVOS}

\begin{tabular}{|c|c|}
\hline $\begin{array}{l}\text { Leis e Medidas } \\
\text { Provisórias }\end{array}$ & $\begin{array}{l}\text { - Lei no. 9.983, de 14/07/2000 - Altera o Decreto-Lei n. 2.848, de } 7 \text { de dezembro } \\
\text { de } 1940 \text { - Código Penal e dá outras providências (crimes contra sistemas } \\
\text { informatizados da Administração) } \\
\text { - Lei no. 9.998, de 17/08/2000 - Institui o Fundo de Universalização dos Serviços de } \\
\text { Telecomunicações - FUST } \\
\text { - Medida Provisória no. 2.200, de 24/08/2001 - Institui a Infra-Estrutura de Chaves } \\
\text { Públicas Brasileira - ICP-Brasil }\end{array}$ \\
\hline Decretos & 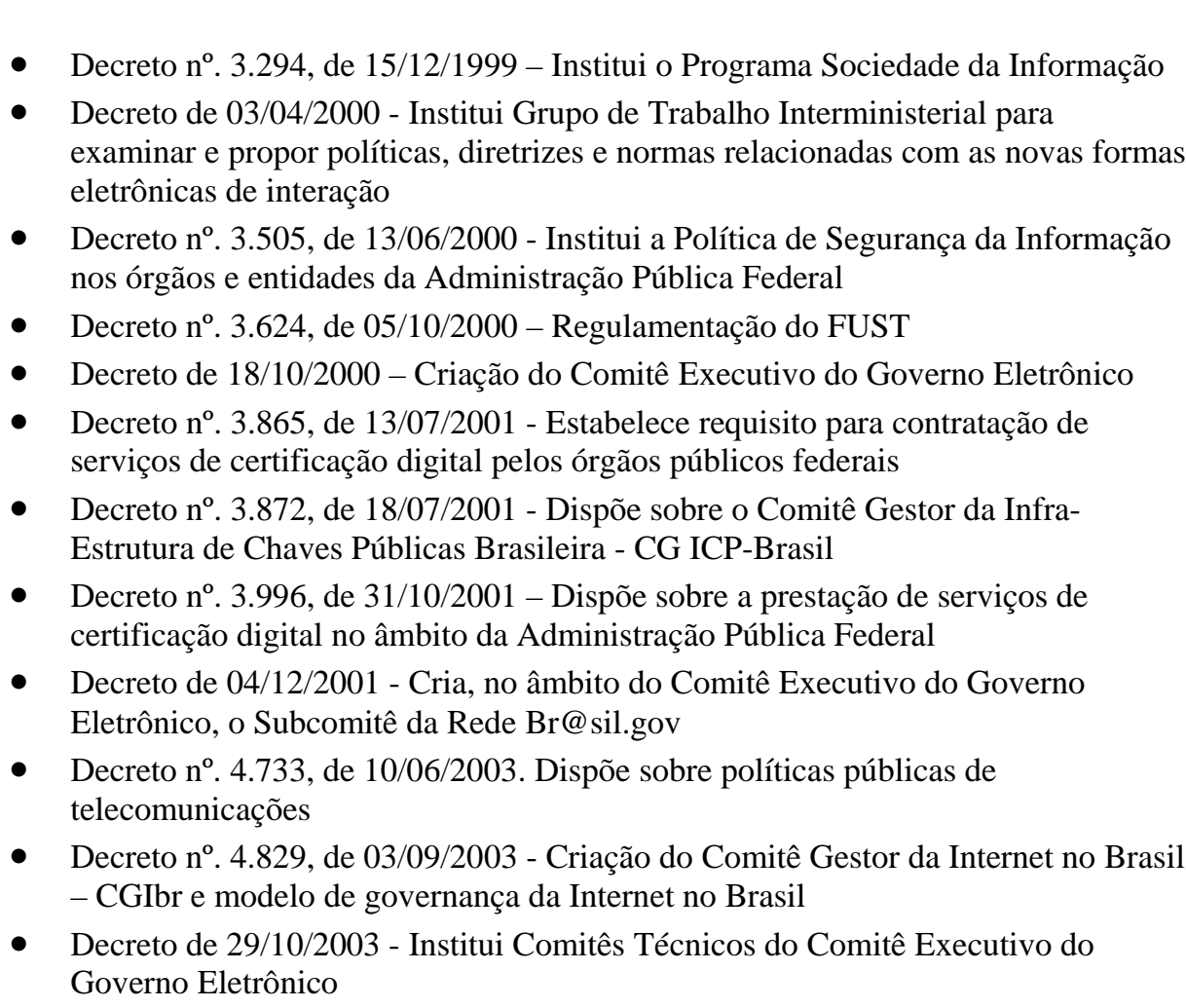 \\
\hline Outros normativos & $\begin{array}{l}\text { - } \quad \text { Livro Verde da Sociedade da Informação } \\
\text { - } \quad \text { Portaria Interministerial no. } 47 / 2000 \text { - Comitê Executivo do Comércio Eletrônico } \\
\text { - } \quad \text { Regimento Interno do Comitê Executivo do Governo Eletrônico } \\
\text { - Instrução Normativa }{ }^{\circ} .31 \text {, de } 10 / 09 / 2003 \text { - Dispõe sobre Marcas e Assinaturas } \\
\text { Publicitárias do Governo Federal }\end{array}$ \\
\hline
\end{tabular}

A fim de elaborar seus documentos e projetos, o Comitê Executivo do Governo Eletrônico instituiu, entre 2000 e 2002, Grupos de Trabalho (GTs) formados por dirigentes e técnicos dos ministérios, agências e autarquias envolvidos com o programa de governo eletrônico. Esses GTs cuidam da elaboração de documentos e projetos, os quais são submetidos à aprovação do 
Comitê. Funcionavam com apoio da SLTI (MPOG) e de consultores contratados, sendo os temas de trabalho, projetos e responsáveis conforme apresentados no Quadro 5.

Quadro 5 - Grupos de Trabalho do Comitê Executivo do Governo Eletrônico - 2000 a 2002

Fonte: Brasil (2002b)

\begin{tabular}{|c|c|c|c|}
\hline $\boldsymbol{n}$ & GRUPO DE TRABALHO & PROJETOS SOB RESPONSABILIDADE & RESPONSAVEL \\
\hline 1 & $\begin{array}{lll}\text { Implantação } & \text { da } & \text { rede } \\
\text { Br@sil.gov } & & \end{array}$ & $\begin{array}{l}\text { - Rede multi-serviço } \\
\text { - Terminais públicos em órgãos da administração } \\
\text { pública } \\
\text { - Serviço de mensageria } \\
\text { - Modernização de Infra-estrutura de redes locais } \\
\text { - Gerência de redes locais }\end{array}$ & SLTI/MPOG \\
\hline 2 & Universalização de serviços & $\begin{array}{l}\text { - Central de Relacionamento (CR) } \\
\text { - Oferta de serviços nos CR conectados à Internet } \\
\text { - Orientação para desenvolvimento de sitios oficiais } \\
\text { - Pagamentos eletrônicos } \\
\text { - Programas (software) para terminais públicos } \\
\end{array}$ & SLTI/MPOG \\
\hline 3 & $\begin{array}{l}\text { Universalização do acesso à } \\
\text { Internet }\end{array}$ & - Projetos de terminais públicos de acesso à Internet & $\begin{array}{l}\text { Ministério das } \\
\text { Comunicações }\end{array}$ \\
\hline 4 & $\begin{array}{l}\text { Normas e padrôes para } \\
\text { prestação de serviços }\end{array}$ & $\begin{array}{l}\text { - Integração dos Sistemas Administrativos do } \\
\text { - Governo Federal } \\
\text { - Sistema de Gestão de Recursos Humanos do } \\
\text { pessoal civil da União } \\
\text { - Sistema de Acompanhamento de Obras Públicas do } \\
\text { Governo Federal } \\
\text { - Gestão de Documentos Eletrônicos } \\
\text { - Catálogo de Informações (Páginas Brancas) } \\
\text { - Política de Divulgação de Informações e de } \\
\text { Prestação de Serviços } \\
\text { - Plano de Serviços e Investimentos em TIC } \\
\text { - Inventário dos Recursos de TIC } \\
\text { - Serviço integrado de documentos e protocolos } \\
\text { - Compartilhamento de Recursos } \\
\text { - Capacitação em TI }\end{array}$ & SLTI/MPOG \\
\hline
\end{tabular}

Em 2003 foram criados oito Comitês Técnicos no âmbito do Comitê Executivo do Governo Eletrônico ${ }^{4}$, com a finalidade de coordenar e articular o planejamento e a implementação de projetos e ações nas respectivas áreas de competência (BRASIL, 2003b). O Quadro 6 apresenta as áreas (temas de trabalho) de cada comitê, além dos respectivos objetivos e órgãos responsáveis.

Um aspecto interessante do decreto que instituiu os comitês técnicos é o fato de que o coordenador de cada comitê pode convidar para participação nas reuniões de seu grupo, representantes de outros órgãos e entidades públicas que não aqueles que formaram inicialmente o comitê e também de empresas privadas ou de organizações da sociedade civil (BRASIL, 2003b).

\footnotetext{
${ }^{4}$ Veja a íntegra do decreto instituindo os Comitês Técnicos no Anexo I.
} 
No período 2000-2002, o Comitê Executivo do Governo Eletrônico (CEGE) funcionou de modo semelhante, em termos de seus temas específicos, por meio de grupos de trabalho compostos por representantes de órgãos e entidades públicas e privadas (BRASIL, 2000b, 2000c). Nota-se, portanto, uma semelhança no modo de permissão à participação de atores externos ao governo no CEGE, desde sua criação até 2002, e na maneira que passou a funcionar a partir de 2003, com a instituição de comitês técnicos.

Quadro 6 - Comitês Técnicos do Comitê Executivo do Governo Eletrônico - 2003 em diante Fonte: Medeiros (2004)

\begin{tabular}{|c|c|c|c|}
\hline$n$ & ARDA DE COMPUTÊNCIA & ORJETIVOS & RESPONSÁVDL \\
\hline 1 & $\begin{array}{l}\text { Implementação do Software } \\
\text { Livre }\end{array}$ & $\begin{array}{l}\text { - Implementar medidas para adoção do software } \\
\text { livre na administração pública federal } \\
\text { - Formular uma politica nacional para o software } \\
\text { livre }\end{array}$ & $\begin{array}{l}\text { Instituto Nacional de } \\
\text { Tecnologia da } \\
\text { Informação (ITI) }\end{array}$ \\
\hline 2 & Inclusão Digital & $\begin{array}{l}\text { - Propor açóes do governo federal em inclusão } \\
\text { digital } \\
\text { - Incentivar inclusão social dentro da autonomia } \\
\text { tecnológica nacional e da sustentabilidade } \\
\text { econômica }\end{array}$ & SLTI/MPOG \\
\hline 3 & Integração de Sistemas & $\begin{array}{l}\text { - Promover a integração dos principais sistemas } \\
\text { estruturadores do Governo Federal, a } \\
\text { padronização de cadastros e tabelas em uso e a } \\
\text { uniformização dos sistemas corporativos que } \\
\text { devem ser integrados aos estruturadores }\end{array}$ & SLTI/MPOG \\
\hline 4 & $\begin{array}{l}\text { Sistemas Legados e Licenças } \\
\text { de Software }\end{array}$ & $\begin{array}{l}\text { - Conter custos na manutenção de sistemas } \\
\text { legados e na aquisição de licenças de softwares } \\
\text { - Promover ganhos de escala decorrentes do } \\
\text { poder de compra do Estado }\end{array}$ & SLTI/MPOG \\
\hline 5 & $\begin{array}{l}\text { Gestão de Sitios e Serviços On- } \\
\text { line }\end{array}$ & $\begin{array}{l}\text { - Disponibilizar um conjunto de serviços e } \\
\text { informações do governo federal na Internet, de } \\
\text { maneira uniforme e com facilidade de acesso } \\
\text { aos brasileiros e ao público estrangeiro }\end{array}$ & $\begin{array}{l}\text { Secretaria de } \\
\text { Comunicação da } \\
\text { Presidência da } \\
\text { República }\end{array}$ \\
\hline 6 & Infra-Estrutura de Rede & $\begin{array}{l}\text { - Estabelecer normas e politicas visando à } \\
\text { integração das diversas redes (voz, dados e } \\
\text { imagem) do governo }\end{array}$ & SLTI/MPOG \\
\hline 7 & Governo para Governo - G2G & $\begin{array}{l}\text { - Definir as ferramentas de governo eletrônico } \\
\text { que possam contribuir na melhora das relaçóes } \\
\text { entre o governo federal, estados e municipios } \\
\text { - Incentivar a implementação de práticas locais } \\
\text { que permitam efetivo controle social do uso } \\
\text { desses recursos }\end{array}$ & SLTI/MPOG \\
\hline 8 & $\begin{array}{l}\text { Gestão de Conhecimentos e } \\
\text { Informação Estratégica }\end{array}$ & $\begin{array}{l}\text { - Identificar e monitorar conhecimentos e } \\
\text { informações estratégicas que deverão ser } \\
\text { compartilhados e integrados entre os órgãos de } \\
\text { governo, tendo como principais produtos } \\
\text { normas e recomendaçóes ao Governo Eletrônico }\end{array}$ & $\begin{array}{l}\text { Ministério das Relaçóes } \\
\text { Exteriores (MRE) }\end{array}$ \\
\hline
\end{tabular}

\subsection{PADRÕES E PADRONIZAÇÃO}

De uma forma ampla, um padrão pode ser definido como um conjunto de especificações para qual todos os elementos de produto, processos, formatos, ou procedimentos sob sua jurisdição 
têm que estar de acordo (TASSEY, 2000). Já para David e Greenstein (1990), um padrão pode ser compreendido como um conjunto de especificações técnicas aderido por um grupo de fornecedores, tacitamente ou como resultado de um acordo formal.

Para a ISO padrões são acordos documentados contendo especificações técnicas ou outro critério preciso para ser usado consistentemente como regras, diretrizes, ou definições de características, para assegurar que materiais, produtos, processos e serviços estão de acordo com o seu propósito.

Para Fomin, Keil e Lyytinen (2003), o processo de criação de um padrão integra as seguintes três atividades entrelaçadas: 1) criação de artefatos que podem satisfazer um conjunto de requisitos embutido no padrão e formulado pelos agentes envolvidos; 2) uma possível divergência da trajetória tecnológica atual na forma de inovação que abre um novo (cognitivo) espaço de projeto; e 3) uma mobilização de um grupo de agentes que está disposto seguir e abraçar tais divergências e soluções.

\subsubsection{Classificações dos padrões}

David e Steinmueller (1994) classificam os padrões em quatro categorias: referência, qualidade mínima, interface e compatibilidade. Os padrões de compatibilidade possuem um papel relevante dentro das TICs, pois são os facilitadores do intercâmbio de dados entre componentes de um sistema em particular ou entre diferentes sistemas interorganizacionais.

Para Williams e outros (2004), o desenvolvimento e implementação de padrões de compatibilidade não só definem tecnicamente um método de interoperação entre os componentes diferentes em uma rede, mas representa principalmente uma proposta para o futuro dos sistemas socio-técnicos complexos que são a forma de uma rede interorganizacional.

Os padrões também podem ser classificados de acordo com os processos por meio dos quais eles surgem. Uma distinção é feita freqüentemente entre formal, de facto e de jure. Padrões formais são criados através de entidades de padronização; os de facto são tecnologias unificadas por mecanismos de mercado, e os de jure são os impostos através de lei (HANSETH e MONTEIRO, 1998). 
De acordo com Graham e outros (1995), o processo de padronização representa uma tentativa para alinhar interesses, práticas de negócios e expectativas de um grupo de pessoas com um interesse para desenvolver e usar o sistema que será padronizado. Então, a padronização não é apenas prover uma solução utilizável, mas, principalmente, articular e alinhar expectativas e interesses (WILLIAMS, 1997).

\subsubsection{Ciclo de vida do processo de padronização}

Visto que o processo de padronização compreende todas as possíveis rotas desde o conceito e definição até a implementação ele necessariamente se apresenta como complexo (SLOANE, 2000). Para Moreton e outros (1995), o processo de padronização pode seguir diferentes rotas entre as fases de necessidade e obsolescência.

Em relação às Tecnologias da Informação (TI), a padronização pode ser definida como o processo pelo qual dois ou mais agentes concordam e aderem a um conjunto de especificações técnicas de um sistema, suas partes ou sua funcionalidade, tacitamente ou como resultado de um acordo formal (DAVID e GREENSTEIN, 1990). Conseqüentemente, os esses padrões habilitam e constrangem concorrentemente o comportamento de vários agentes no futuro (GARUD, JAIN e KUMARASWAMY, 2000). Esses efeitos sobre as ações futuras dos agentes envolvidos devem ser levados em conta pelos seus especificadores, pois podem influenciar o grau de adoção dos referidos padrões.

Assim, os conceitos adotados para analisar a padronização têm que descrever atividades sociais necessárias que identificam e associam os agentes (produtores) e as condições sob as quais eles podem conseguir um acordo (HANSETH, MONTEIRO, e HATLING, 1996). Os estudos sobre padronização têm que descrever interações entre agentes que podem ou não compartilhar interesses em comum. Eles também têm que demonstrar como o projeto de padrões é dependente e influenciado pelos processos ao redor e precedentes de "alcançar um acordo.” Isto exige a capacidade prover razões para fazer assim para cada agente envolvido. Conseqüentemente, é preciso conceituar a padronização como um conjunto de atividades relacionadas que nos conduzem a entender o que é articulado entre os agentes e por que e como eles alcançam acordos como resultado destas comunicações (FOMIN, KEIL e LYYTINEN, 2003). 


\subsubsection{Os estágios de desenvolvimento e implementação de padrões.}

Segundo Williams e outros (2004), os diferentes estágios do ciclo de vida de um padrão se desenvolvem em cenários sociotécnicos bastante diferentes. O lócus onde a padronização ocorre, os agentes envolvidos no processo, e seus atributos são diferentes em seus dois estágios: desenvolvimento e implementação. Contudo, para se entender o processo de maneira efetiva, isto é, como ele evolui, é moldado e estruturado ao longo do tempo, esses diferentes cenários não podem ser considerados dissociadamente. Essa abordagem permite identificar não apenas os fatores que moldam cada um dos dois estágios, mas também os links que se formam entre eles, como resultado da interação entre estes fatores. O nível de formalidade do estabelecimento do padrão pode depender, por exemplo, da cultura organizacional na qual o padrão está sendo implementado. Além disso, o sucesso ou falha da implementação de um padrão pode não depender somente de fatores pertinentes ao contexto da implementação, mas também das características do cenário no qual o padrão está sendo desenvolvido.

Fomin, Keil e Lyytinen (2003), estabelecem que os seguintes pontos devem ser observados de uma forma crítica nos estudos dos processos de padronização: 1) esses processos resultam em acordos que contemplam artefatos técnicos que estão abertos à desafios ao longo do tempo; 2) são processos complexos e envolvem múltiplas atividades heterogêneas que incluem tomada de decisão e construção técnica, 3) os processos se desdobram com o passar do tempo, no espaço e por diversos grupos de agentes que necessariamente não compartilham interesses semelhantes.

De acordo com Graham e outros (1995), o processo de padronização também representa uma tentativa para alinhar interesses, práticas de negócios e expectativas de um grupo de pessoas com um interesse para desenvolver e usar o sistema que será padronizado. Então, a padronização não é apenas prover uma solução utilizável, mas principalmente, articular e alinhar expectativas e interesses (WILLIAMS, 1997).

\subsubsection{As abordagens do desenvolvimento e implementação de padrões.}

Várias são as abordagens já aplicadas ao estudo do desenvolvimento e implementação de padrões: direito, estratégia, marketing, engenharia de operações, teoria política, ciência política e sociologia (SWANN, 2000). 
Embora grande parte da literatura sobre padronização esteja dentro da área de economia, alguns autores, como de Vries (1999), por exemplo, defende que a padronização é na essência um campo interdisciplinar que recebe contribuições de várias outras áreas. Outros, como Verman (1973), argumentam a necessidade da criação de uma nova disciplina para seu estudo.

Relativamente desconectada das literaturas econômicas e das centradas na inovação sobre padronização, surgiu durante as últimas duas décadas uma literatura sociotécnica (WILLIAMS e EDGE, 1996; HANSETH, MONTEIRO e HATLING, 1996) freqüentemente chamada de construção social da tecnologia. Esta linha de abordagem examina a padronização como uma forma de interação social dentro de uma rede de agentes nos quais a tecnologia é introduzida e é estabilizada no sistema social. Os pontos centrais analisados dentro dessa abordagem são (FOMIN, KEIL e LYYTINEN, 2003): por que e como um padrão de TIC específico é criado e que fatores sociais e técnicos influenciam sua criação? Como os agentes envolvidos entendem o significado do projeto e que razões eles buscam para seu envolvimento nos processos de padronização? Como agentes específicos são conectados por artefatos e compromissos durante o processo e por quê? Segundo Mangematin e Callon (1995), os pesquisadores dessa linha analisam por que o processo de padronização segue uma trajetória e exclui outras, e tenta responder por que a tecnologia padronizada adotou essa sua forma.

A literatura sociotécnica complementa assim a literatura econômica e provê uma perspectiva processual da construção da rede relacionada aos agentes da padronização. Ela dá atenção às medidas necessárias e atividades que podem estabilizar a rede. Mas ao mesmo tempo, freqüentemente, não provê uma descrição adequada dos desafios cognitivos e técnicos relacionados aos resultados da padronização. Não responde freqüentemente por racionalidades envolvidas na tomada de decisão dos agentes, como por exemplo, por que uma escolha específica foi feita ou como um projeto foi produzido (FOMIN, KEIL e LYYTINEN, 2003).

\subsubsection{Mecanismos de governança na padronização}

Para Choh (1999), a padronização é um processo social de coordenação num ambiente de conflitos entre os interesses coletivos e individuais privados. Para resolver os problemas de coordenação de padronização, os atores sociais buscam diferentes mecanismos de 
governança. Para o autor, na indústria de TIC podem ser identificados cinco tipos de mecanismos de governança para padronização: Estado, comunidade, associação, rede e mercado. Cada mecanismo de governança possui os seus próprios princípios para a resolução de conflitos entre interesses coletivos e privados.

O mecanismo de mercado é guiado pelo princípio da competição no contexto da maximização do interesse próprio. O princípio que guia o mecanismo de rede é a cooperação voluntária no mercado; Consenso organizado é o princípio guia no mecanismo de associação. A capacidade de coordenação do Estado é baseada na sua legítima coerção na indústria. E, a comunidade exerce seus efeitos de coordenação sobre a indústria com contribuição voluntária baseada na abertura.

Em princípio, o Estado tem o poder impositivo para regular a atividade econômica da inovação tecnológica e padronização. O Estado é assumido então como o elemento para impor o interesse coletivo dos padrões sobre os interesses privados, e seu processo de tomada de decisão tem uma natureza pública. Os padrões produzidos pelo Estado são tecnologias não proprietárias e nesse processo de padronização os padrões podem ser chamados de padrões regulatórios.

A seleção pelo Estado de um padrão tecnológico é um resultado de uma escolha estratégica na trajetória tecnológica. Desde que o estabelecimento de padrões envolve conseqüências irreversíveis para estrutura de mercado é difícil implementar um padrão. Em particular, quando existe rápida mudança de tecnologias, a incerteza do futuro da trajetória tecnológica torna difícil para o Estado decidir sobre uma escolha estratégica para o padrão. Cada mecanismo de governança tem o seu próprio mérito e limites na especificação de padrões. $\mathrm{O}$ mercado estabelece padrões de facto, mas levam os interesses coletivos a serem dissolvidos em competição com os interesses privados. O Estado enfrenta um problema de seleção na competição tecnológica embora ele tenha uma capacidade de imposição. A solução associativa pode ser contaminada pela competição de mercado no processo de estabelecimento do consenso. A rede governa a cooperação entre firmas, mas a competição entre redes não gera um bem comum em nível de indústria.

Algumas vezes um único mecanismo de governança não estabelece uma forma efetiva de produzir a padronização. 
Por outro lado, nem sempre os mecanismos de governança obtêm êxito na resolução dos problemas. Ou seja, eles podem falhar durante a padronização. Nessa situação os atores sociais buscam por um mecanismo de governança alternativo, de modo que é instaurada uma transformação de governança.

As falhas na padronização podem se estabelecer através de várias situações. Numa primeira situação, embora a indústria necessite o processo não resulta num padrão definido. A segunda situação também inclui incompatibilidade no processo de padronização. Embora a indústria crie padrões o problema de incompatibilidade pode surgir nos casos onde existem múltiplos padrões, ou em casos onde empresas não seguem as especificações tecnológicas dadas pelos padrões. A terceira situação é diferente: existe um padrão que resolve o problema da incompatibilidade e a indústria compromete-se em adotá-lo. Mas o padrão pode levar a uma trajetória tecnológica inferior por não acompanhar as inovações que surgem, de modo que é criado um gargalo tecnológico na indústria.

O Estado pode prover o bem coletivo e tem meios impositivos para fazê-lo. Contudo, pode também falhar ao representar os interesses coletivos. Por exemplo, um grupo com interesse especial pode afetar a tomada de decisão. Além disso, o interesse de tecnocratas pode distorcer a tomada de decisão a fim de expandir o poder do Estado sobre a indústria. Nestes casos, a seleção errada de padrões pode prejudicar a indústria como um todo.

\subsubsection{Organizações de desenvolvimento de padrões}

De acordo com Egyedi (2001), deve ser feita uma distinção entre organizações formais e consórcios para desenvolvimento de padrões. Para a autora, a padronização formal se refere processos de especificação de padrões através de consenso voluntário que ocorrem sob a gestão de comitês técnicos sob jurisdição de organizações reguladoras nacionais, regionais ou internacionais. Os procedimentos que guiam esses comitês baseiam-se em valores democráticos, objetivando ser inclusivo e refletem o desejo de um processo técnico e politicamente neutro no estabelecimento dos padrões. Um exemplo dessas corporações é a International Standardization Organization (ISO). Por outro lado, um consórcio para padrões é uma aliança formada por empresas e outras organizações interessadas, financiada por taxas de associação, com o propósito de coordenar o desenvolvimento de tecnologias e/ou as atividades de implementação. Como resultado são geradas especificações ou padrões para 
indústrias. Geralmente seus membros são grandes companhias, o que indica que os padrões resultantes são provavelmente relevantes para o mercado. Por isso, esses consórcios são também chamados de “consórcios orientados ao mercado”. Exemplo de consórcio é o W3C.

Além disso, ainda existem várias organizações que executam atividades objetivando criar comunidades de interesse ao redor de suas tecnologias proprietárias e imitam procedimentos de padronização. Esse é o caso, por exemplo, da Sun's Java Community Process (JCP), que tem obtido sucesso em envolver outras empresas e indivíduos no desenvolvimento e implementação da plataforma Java usando essa estratégia.

\subsection{INTEROPERABILIDADE}

Pode-se definir interoperabilidade como a habilidade de dois ou mais sistemas de interagir e de intercambiar dados de acordo com um método definido, de forma a obter os resultados esperados. No entanto, essa definição não pode ser tomada como um consenso, pois existem muitas outras. O IEEE (2000), por exemplo, apresenta quatro definições:

- a habilidade de dois ou mais sistemas ou elementos de trocar informações entre si e usar essas informações que foram trocadas.

- a capacidade para unidades de equipamentos em trabalhar junto para realizar funções úteis;

- a capacidade, promovida mas não garantida pela adesão a um determinado conjunto de padrões, que possibilita equipamentos heterogêneos, geralmente fabricados por vários fornecedores, trabalhar juntos em rede.

- a habilidade de dois ou mais sistemas ou componentes para trocar informações em uma rede heterogênea e usar estas informações.

De uma forma ampla, interoperabilidade para governo eletrônico pode ser definida como a habilidade do governo e sociedade trabalharem juntos. Do ponto de vista técnico, é a habilidade de dois ou mais sistemas ou componentes de tecnologias de informação e comunicação governamentais de trocar informações de forma transparente e de usar as informações trocadas.

De acordo com Realini (2004), interoperabilidade não significa somente a colaboração entre órgãos para simplificar transações com cidadãos ou melhorar o relacionamento com 
empresas. Além disso, existe a vontade de criar processos mais eficientes e assim diminuir os custos administrativos, e também evitar redundância de dados entre os diversos sistemas usados.

Interoperabiliade é mais do que uma simples conexão entre diferentes computadores em redes com ou sem fios para a transferência de dados. Significa a capacidade de compartilhar dados, informação e conhecimento entre diferentes áreas, envolvendo interações máquina-máquina, homem-máquina e humanas. Também significa a reorganização de processos de trabalho, compatibilidade de significado e compartilhamento de informação a fim de possibilitar a prestação dos serviços eletrônicos de forma transparente para os usuários (COMMISSION OF THE EUROPEAN COMMUNITIES, 2004).

Para o United Nations Development Programme (2007b), a ausência de interoperabilidade pode ser devido a vários fatores. Pode ser por razões de políticas como, por exemplo, de privacidade, tais como as relacionadas com informação pessoal de saúde ou segurança nacional. Pode ser por conta da natureza heterogênea dos sistemas de informação do governo - resultado de decisões passadas sobre hardware, software e sistemas legados. Também vários órgãos podem querer ter seus próprios sistemas e não estão preocupados em compartilhar dados e/ou serviços comuns. Por último, o efeito de rede gerado por algumas empresas que usam padrões proprietários tem ajudado a criar alguns dos problemas atuais. Muitos governos não sabiam que tinham uma escolha, nem estavam atentos aos efeitos de longo prazo de suas aquisiç̧̃es.

Assim, para se alcançar a interoperabilidade, é necessário haver um desejo de transformação e de cooperação de vários órgãos do governo. A menos que o compromisso de conseguir a interoperabilidade seja demonstrado pelos níveis superiores, um excesso de políticas e interesses corporativos burocráticos e minuciosamente construídos sempre podem ser usados para desafiar os esforços de fazer a interoperabilidade acontecer.

Os definidores de políticas precisam desempenhar vários papéis no estabelecimento de uma arquitetura de interoperabilidade. Em relação ao desenvolvimento e implementação, eles são responsáveis por estabelecer:

- uma visão específica do que o governo espera alcançar com o uso das tecnologias. A 
formulação dos aspectos técnicos da arquitetura pode ser delegada ao pessoal técnico;

- um patrocínio político para os processos de desenvolvimento e implementação.

A ausência de demonstração de comprometimento com a interoperabilidade pelo seu alto escalão pode se tornar contraprodutivo ao esforço do governo em aproveitar-se da força das TICs para a boa governança e desenvolvimento nacional.

\subsubsection{Benefícios da interoperabilidade}

A interoperabilidade pode trazer diversos benefícios, tais como maior efetividade, eficiência e responsividade. Os principais aspectos desses benefícios alcançados são os seguintes:

- Efetividade: interconexão em vez de soluções isoladas;

- Eficiência: redução dos custos de transação, aumento da participação dos agentes envolvidos;

- Responsividade: melhor acesso a mais informações, possibilitando a resolução mais rápida dos problemas.

Os governos devem empenhar-se em conseguir a interoperabilidade por diversas razões (UNITED NATIONS DEVELOPMENT PROGRAMME, 2007a). Primeiro, a interoperabilidade de governo eletrônico leva a uma melhor tomada de decisões. Muitas vezes os dados necessários pelos gestores públicos para uma melhor decisão estão disponíveis, mas inacessíveis. Eles enfrentam não apenas superposição e desestruturação de dados, mas também a falta de termos de referência comuns e meios de representar esses dados. Isso resulta em um processo complexo e demorado de comparação de dados que são representados diferentemente. A interoperabilidade permite que dados compilados por diferentes órgãos possam ser usados juntos para a tomada de uma melhor decisão.

A segunda razão é que a interoperabilidade permite uma melhor coordenação dos programas e ações de governo a fim de oferecer melhores serviços para a sociedade. Se as informações sobre o governo forem fáceis de serem obtidas, os gestores públicos podem especificar projetos de forma mais adequada e podem evitar mais facilmente projetos redundantes ou similares. Além disso, esses gestores e os decisores teriam mais informações para avaliar o desempenho dos órgãos e os serviços que eles oferecem. 
A terceira razão é que a interoperabilidade é a base para a oferta se serviços através de um ponto único de acesso voltado para o cidadão, por meio de uma variedade de canais.

A quarta razão é que a interoperabilidade leva à redução de custos. Ao permitir que um sistema “converse” com outro, isso pode evitar a implantação de novos sistemas que anteriormente se fariam necessários. A interoperabilidade ainda possibilita a quebra da dependência de fornecedores únicos e permite ao governo ter mais alternativas para efetuar escolhas nas suas aquisições.

Há ainda a promoção da cooperação internacional. A interoperabilidade entre governos pode ajudar a criar a infra-estrutura necessária para resolver problemas que ultrapassam fronteiras nacionais tais como tráfico de drogas, poluição ambiental, lavagem de direito e comércio ilegal de armas.

A interoperabilidade entre governos pode também significar a prestação de serviços de governos eletrônicos para a sociedade em uma região (como no caso da União Européia) e facilitar o comércio entre um grupo de países e seus parceiros de negócios (como a ALCA, por exemplo).

Além disso, o fluxo sem fronteiras de informações dentro do governo e entre governo e sociedade também aumenta a transparência e a prestação de contas. Em conseqüência, os governos conseguem justificar melhor seus programas e a sociedade fica mais bem informada (UNITED NATIONS DEVELOPMENT PROGRAMME, 2007b).

\subsubsection{Tipos de interoperabilidade}

Existem três tipos de interoperabilidade (COMMISSION OF EUROPEAN COMMUNITIES, 2003; COMMISSION OF THE EUROPEAN COMMUNITIES, 2004):

- Organizacional ou de processos - diz respeito à coordenação e alinhamento dos processos de negócios e arquiteturas de informação que se espalham entre e intraorganizações. Objetiva promover a colaboração das administração que desejam intercambiar informações e que podem ter processos e estruturas internas diferentes. Trata dos métodos comuns, processos e serviços compartilhado para colaboração, incluindo workflow, tomada de decisão e transação de negócios. 
- Semântica ou de informação - preocupa-se em assegurar que o significado preciso da informação intercambiada é entendível por qualquer pessoa ou aplicação que as receberem. Permite aos sistemas combinar informações recebidas com outros recursos de informação e processá-las mantendo seu correto significado. Também provê metodologia, definição e estrutura de informação, junto com serviços compartilhados para recuperação de dados.

- Técnica - Preocupa-se com os aspectos técnicos para conectar sistemas de computadores para o propósito de intercambiar informação ou usar funcionalidades. Refere-se aos padrões e especificações que facilitam o intercâmbio coerente de informação entre sistemas de computadores e envolve estabelecer princípios e diretrizes para um mecanismo comum de transferência, desenvolvendo metadados padronizados e usando uma linguagem comum.

Nem todas as arquiteturas cobrem esses três aspectos da interoperabilidade. A maioria delas foca no aspecto técnico em detrimento do aspecto organizacional ou de semântica. As arquiteturas especificadas pelo governo da Alemanha (SAGA) e pela Comunidade Européia (EIF) são exceções, contemplando todas as dimensões(Quadro 7).

O caminho típico trilhado por vários países é se preocupar com as dimensões técnicas da interoperabilidade em primeiro lugar. De acordo com Riedl (2003), essa é a camada mais fácil de ser implementada e pode ser estabelecida em relativo pouco tempo.

Quadro 7 - Dimensões adotas em algumas arquiteturas de interoperabilidade

\begin{tabular}{|l|c|c|c|}
\hline \multirow{2}{*}{ País / Zona } & \multicolumn{2}{|c|}{ Tipo de interoperabilidade } \\
\cline { 2 - 4 } & Organizacional & Semântica & Técnica \\
\hline Austrália & & & $\checkmark$ \\
\hline Brasil & & & $\checkmark$ \\
\hline Dinamarca & planejada & planejada & $\checkmark$ \\
\hline Alemanha & $\checkmark$ & $\checkmark$ & $\checkmark$ \\
\hline Malásia & & & $\checkmark$ \\
\hline Nova Zelândia & & & $\checkmark$ \\
\hline Reino Unido & & & $\checkmark$ \\
\hline Comunidade Européia & & & $\checkmark$ \\
\hline
\end{tabular}




\subsubsection{Barreiras para a interoperabilidade}

Existem barreiras significativas para se alcançar a interoperabilidade de forma efetiva e ampla. Essas barreiras podem ser classificadas como políticas, organizacionais, econômicas e técnicas (ANDERSEEN e DAWES, 1991):

- Políticas: definição das diretrizes das políticas adotadas; conflitos nas definições dos níveis de privacidade nos acessos às informações; cultura organizacional predominante; ambigüidade da autoridade na coleta e uso das informações; descontinuidade administrativa.

- Organizacionais: falta de experiência e ausência da predisposição de compartilhar; nível de qualificação do pessoal envolvido nos processos; cultura organizacional;

- Econômicas: falta de recursos para disponibilização das informações para outros órgãos; forma de aquisição dos recursos (normalmente adquiridos pelo menor preço e não pelo melhor valor);

- Técnicas: incompatibilidade de hardware e software usados adotados; direitos de propriedade; desconhecimento dos dados gerados e armazenados pelos sistemas; múltiplas definições de dados.

\subsubsection{Benefícios e barreiras do compartilhamento de informações para governo eletrônico.}

Embora o compartilhamento de informações dentro dos órgãos governamentais seja um objetivo comum, a amplitude desse compartilhamento ainda é limitada (DAWES e BLONIARZ, 2001). Mesmo sendo reconhecida a importância do compartilhamento e os benefícios significativos que ele traz para os definidores das políticas públicas, órgãos públicos, e para o público em geral, os órgãos enfrentam várias barreiras tecnológicas, organizacionais, políticas e econômicas (DAWES, 1996; LANDSBERGEN e WOLKEN, 2001; ROCHELEAU, 1997).

O quadro abaixo apresenta um resumo dos benefícios e barreiras no compartilhamento de informações para governo eletrônico, a partir das perspectivas técnica, organizacional e política. 
Quadro 8 - Benefício e barreiras do compartilhamento de informações para governo eletrônico Fonte: Dawes (1996)

\begin{tabular}{|c|c|c|}
\hline Categoria & Benefícios & Barreiras \\
\hline Técnica & $\begin{array}{ll}\text { - } & \text { Melhoria do gerenciamento dos dados } \\
\text { - } & \text { Contribuição para a infra-estrutura de } \\
\text { informação }\end{array}$ & $\begin{array}{ll}\text { - } & \text { Tecnologias incompatíveis } \\
\text { - } & \text { Estrutura de dados inconsistentes }\end{array}$ \\
\hline Organizacional & \begin{tabular}{|l}
$-\quad \begin{array}{l}\text { Exporte para resolução de problemas } \\
\text { - }\end{array}$ \\
profissionais
\end{tabular} & $\begin{array}{ll}\text { - } & \text { Interesses particulares de cada } \\
\text { agência } \\
\text { - } \quad \text { Padrões profissionais dominantes }\end{array}$ \\
\hline \begin{tabular}{|l|} 
Política \\
\end{tabular} & $\begin{array}{ll}\text { - } & \text { Expansão dos contextos de ação dos } \\
\text { - } & \text { programas de políticas públicas } \\
\text { - } & \text { Promoria da prestação de contas públicas } \\
& \text { e serviços }\end{array}$ & $\begin{array}{ll}\text { - } & \text { Influências externas sobre os } \\
\text { decisores } \\
\text { - } & \text { Nível de poder do órgão } \\
\text { - } & \text { Prioridade dos programas }\end{array}$ \\
\hline
\end{tabular}

\subsubsection{Fatores condicionantes de sucesso do compartilhamento de informações em governo eletrônico.}

Essencialmente um processo de interação, o compartilhamento de informações não necessariamente chega ao resultado esperado de modo fácil. Várias variáveis internas e externas ao processo atuam de forma concorrente, e que podem condicionar seu sucesso. Para Landsbergen e Wolken (2001), os principais condicionantes de sucesso para o compartilhamento de informações são os seguintes:

- compartilhar é mais provável quando já existe um histórico de trabalho em conjunto das agências envolvidas;

- projetos de interoperabilidade são mais facilmente implementados quando o foco é no compartilhamento das informações transacionais do que em relação às operacionais e/ou estratégicas;

- os projetos são mais facilmente implementados quando os agentes percebem os resultados em curto espaço de tempo em relação aos de longo prazo;

- em um estado de crise a colaboração e integração podem ser vistas como forma de conseguir capital político necessário para sustentação/progresso

\subsection{ARQUITETURAS DE INTEROPERABILIDADE}

Uma arquitetura de interoperabilidade é uma das maneiras de se conseguir a interoperabilidade em governo eletrônico. É um conjunto de padrões e diretrizes que um governo usa para especificar a maneira preferida que seus órgãos, cidadãos e parceiros interagem uns com os outros. Para Guijarrro (2007), uma arquitetura de interoperabilidade objetiva definir as especificações técnicas básicas as quais todos os órgãos que são relevantes 
na implementação das estratégias de governo eletrônico devem adotar. Essa arquitetura deve possibilitar, no mínimo, a interoperabilidade entre os sistemas de informação de diferentes órgãos a fim de prover serviços aos cidadãos e empresários numa forma integrada (GUIJARRRO, 2007).

Uma arquitetura de interoperabilidade normalmente inclui:

- Contexto;

- Conteúdo técnico;

- Documentação do processo; e

- Esquema de implementação e conformidade

\subsubsection{Seleção de padrões}

No centro de uma arquitetura de interoperabilidade estão os padrões adotados para assegurar a interoperabilidade dentro do governo. De acordo com o United Nations Development Programme (2007), os padrões que melhor promove a interoperabilidade são os padrões abertos.

De acordo com Sliman (2002), interoperabilidade resulta quando os componentes estão aptos a trabalhar junto para completar um processo. Os padrões abertos, ao ajudarem a definir a interface entre componentes, aumentam a interoperabilidade. Isto leva a esforços de integração mais simples e resultados mais rápidos.

Padrões abertos são geralmente contrastados com padrões proprietários - especificações que são pertencentes e/ou controladas por um indivíduo ou uma corporação. Perens (2007) sugere as seguintes características como principais para padrões abertos:

- Disponibilidade - disponível para todos lerem e implementar;

- Maximização da escolha do usuário final;

- Sem royalties;

- Sem descriminação; e

- Sem práticas predatórias

Os mínimos critérios para um padrão ser considerado aberto são: 
- Fácil acessibilidade para todos para ler e usar;

- Desenvolvido por um processo que é aberto e relativamente fácil para qualquer um participar; e

- Sem controles por grupo específico ou fornecedor.

Além de assegurar interoperabilidade, um programa de governo que é construído baseado em padrões abertos permite que os órgãos públicos se mantenham atualizados com inovações tecnológicas e consigam benefícios decorrentes da redução de custos das tecnologias. Os padrões abertos também evitam aprisionamento a fornecedores e possibilita aos governos mais opções em termos de escolhas de tecnologias e de fornecedores.

Existem princípios que definem as prioridades do governo em termo de desenvolvimento das TICs. Esses princípios devem guiar o estabelecimento de uma arquitetura de interoperabilidade e se tornar critérios para a escolha dos padrões que farão parte dela. A maioria das especificações de arquiteturas reconhece sete princípios descritos abaixo (UNITED NATIONS DEVELOPMENT PROGRAMME, 2007):

- Interoperabilidade;

- Escabilidade;

- Reusabilidade;

- Abertura;

- Suporte de mercado;

- Segurança; e

- Privacidade

Enquanto a maioria das arquiteturas favorece padrões abertos, em alguns casos, padrões proprietários são adotados quando não existem padrões abertos para o caso. Por esta razão é importante considerar os princípios que regem a arquitetura durante a seleção dos padrões. É também crucial que a filosofia que suporta a seleção dos padrões seja claramente articulada na arquitetura.

Para o United Nations Development Programme (2007a), ter princípios e critérios bem conhecidos e claros ajuda a prevenir uma adoção de padrões sem crítica, particularmente quando novos padrões emergem e os anteriores ainda não foram aposentados. Especificar uma tecnologia em particular pode não só impedir o governo de usar outras mais novas e melhores, 
mas também destiná-los a usar padrões antigos e até obsoletos. A filosofia por trás da escolha de padrão para a arquitetura deve ser bem definida e entendida por todas as partes relevantes para evitar um uso de padrões sem a devida crítica no governo. Uma forma de conseguir isso é publicar os critérios de seleção dos padrões de modo que todos os interessados tenham conhecimentos deles e que possam levá-los em consideração ao desenvolver novos padrões ou especificações.

\subsubsection{Premissas para o desenvolvimento e implementação}

Uma arquitetura deve ser desenvolvida de forma aberta e inclusiva. A todos os interessados, em seus respectivos e apropriados papéis, dever ser permitido participar no processo.

Para o United Nations Development Programme (2007b), as seguintes premissas devem ser observadas durante os processos de definição e implementação de uma arquitetura de interoperabilidade:

- o desenvolvimento de uma arquitetura deve iniciar com a indicação ou criação de um órgão líder que ficará a cargo de aproveitar habilidades e idéias dentro e fora do governo para produzir um documento tecnicamente competente e politicamente adequado;

- dentro das instituições governamentais, existem dois grupos importantes cujo suporte é crucial para o sucesso da definição da arquitetura: (1) os definidores de políticas e tomadores de decisões, e (2) o pessoal técnico. O primeiro é necessário para fornecer o poder político necessário para suportar os processos de formulação e implementação. O suporte dos que enfrentam os problemas relativos à interoperabilidade no dia-a-dia e que vão eventualmente use os padrões (o pessoal técnico) é também crítico porque eles entendem os problemas sob o ponto de vista operacional e sabem que soluções podem efetivamente funcionar. Para ambos os grupos, é importante incluir representantes dos governos estaduais e municipais, pois conhecem melhor o contexto fora do governo central. Esse último ponto é especialmente importante se as estratégias de governo eletrônico nacionais estiverem focadas na prestação de serviços para áreas pobres e mal servidas.

- as indústrias devem ser incluídas pois elas atuam no ponto limite de aplicação das tecnologias e podem ter uma extensa experiência em implementação de 
interoperabilidade em corporações e empresas privadas. Elas desempenham um importante papel em sugerir, vetar e corrigir os elementos necessários da arquitetura;

- o público em geral, que são os usuários finais dos serviços potenciais que serão viabilizados pela adoção da arquitetura, deve ter a oportunidade de comentar o seu esboço através de um processo claro e transparente. Embora possam não ser capazes de comentar sobre os aspectos técnicos, suas visões são certamente importantes na determinação de prioridades. Em áreas marginalizadas e mal servidas, o engajamento com organizações não governamentais ou da sociedade civil locais pode ser decisivo para alcançar tais setores e oferecer os serviços básicos.

Além dessas premissas sobre a atuação dos participantes, ainda existem os seguintes pontos a serem considerados no processo de estabelecimento da arquitetura, (UNITED NATIONS DEVELOPMENT PROGRAMME , 2007b):

- é necessário no mínimo um orçamento para o órgão que for encarregado de liderar o desenvolvimento da arquitetura, e também para o grupo de governança para que ele efetivamente possa cumprir suas funções;

- a seleção, implementação e a substituição de padrões requerem um razoável número de pessoas tecnicamente habilitadas no governo;

- é essencial ensinar e treinar o pessoal do governo para assegurar que os padrões de interoperabilidade ocupem seu lugar apropriado tanto no nível estratégico como no prático;

- também é preciso investimentos para estabelecer as habilidades em TICs necessárias para a efetiva implementação dos serviços de governo eletrônicos baseados nos padrões.

Outro ponto que deve ser levado em consideração é a necessidade de articular claramente a estrutura subjacente que suporta os padrões selecionados, pois isso estabelece flexibilidade na arquitetura. E flexibilidade é importante em parte porque todos os padrões eventualmente se tornam obsoletos. Como se torna inevitável que os padrões sejam alterados ao longo do tempo é importante cuidar como a estrutura pode ser projetada para antecipar e acomodar mudanças. 
Para uma arquitetura ser bem sucedida também deve atender às realidades que os governos enfrentam. Por exemplo, o uso de padrões obrigatórios ou recomendados (ou ambos) depende de condições particulares, como o nível de desenvolvimento do país que a está implementando.

A arquitetura também deve ter um modelo de governança claramente definido, incluindo o controle do financiamento do projeto. Para o United Nations Development Programme (2007a), a governança do estabelecimento de uma arquitetura deve focar em quatro itens:

- especificação dos direitos de decisão - identificar as decisões que precisam serem tomadas e quem pode tomá-las;

- determinação dos mecanismos de observância - entender as ligações dos processos e políticas, tais como as políticas de aquisição, para assegurar que os órgãos devem aderi-las;

- gerenciamento do ciclo de vida dos padrões - aposentar os padrões que não são mais úteis ou que se tornaram obsoletos, e incorporar outros novos; e

- medição da efetividade - definir métricas de sucesso (tais como reuso de código e melhoria do nível de prestação de serviços), e usar métricas para avaliar os progressos.

\subsubsection{Atores envolvidos no desenvolvimento e implementação}

Para o United Nations Development Programme (2007a), os principais atores no desenvolvimento de uma arquitetura de interoperabilidade são: o órgão líder, a secretaria executiva e o(s) grupo(s) de trabalho.

Definir o órgão líder do projeto assegura que o desenvolvimento da arquitetura tenha uma base institucional para suportar as suas atividades. Esse suporte significa disponibilização de pessoal, orçamento e outras necessidades de logística. Além do suporte organizacional, o órgão líder tem poderes para recomendação final na aprovação da arquitetura. Também age como centro de convergência de todos os esforços para implementá-la.

A secretaria executiva serve como a base organizacional do projeto. O órgão líder pode criar uma unidade e indicar pessoal do seu próprio quadro para a secretaria executiva ou formar uma secretaria com outros órgãos. Resumidamente, a secretaria supervisiona as operações do documento referência da GIF do desenvolvimento à aprovação à revisão, etc. 
A secretaria é também responsável por traduzir a visão do grupo de liderança sobre a arquitetura em um plano de ação. O formato da arquitetura, divisão das tarefas e cronograma são normalmente responsabilidade da secretaria. Contudo, o trabalho efetivo das definições técnicas pode ser alocado para os grupos de trabalho. A secretaria também é responsável pelas preparações de logística para atividades do desenvolvimento da arquitetura como, por exemplo, workshops ou conferências.

Além do trabalho operacional, a secretaria também coordena os agentes envolvidos no processo de desenvolvimento da arquitetura. Isso envolve a seleção dos membros dos grupos de trabalho que são de outros órgãos do governo. Se houver outros agentes que serão envolvidos no processo, como representantes da indústria ou organizações não governamentais (NGOs), a secretaria tem que assegurar suas participações. Quando o esboço do documento referência é apresentado para consulta pública, este processo também é administrado pela secretaria.

Além disso, a secretaria executa também as funções relacionadas a documentação do projeto. Ela recebe e organiza as recomendações submetidas pelos grupos de trabalho e também prepara as versões da arquitetura para lançamento para o público.

O grupo de trabalho, formado por especialistas de vários órgãos de governo, é o órgão técnico que trabalha na seleção dos padrões. No caso do Reino Unido, o grupo de trabalho repartiu várias funções da secretaria. Foi, por exemplo, o grupo de trabalho, não a secretaria que escolheu o formato e conteúdo da arquitetura. Nesse caso, a secretaria se torna um órgão coordenador e o grupo de trabalho assume o papel de direção dos trabalhos.

Em outro cenário, as funções de secretaria e de grupo de trabalho são agrupadas e desempenhadas por um mesmo grupo, como no caso da Dinamarca, através do IT Architecture Committee e da Malásia, pela Malaysia’s ICT Policy and Planning Division.

Além do órgão líder, da secretaria e do(s) grupo(s) de trabalho, outros órgãos e organizações fazem um papel de suporte no desenvolvimento de uma arquitetura de interoperabilidade por duas razões: assegurar apoio para o documento (acreditação) e para controle de qualidade. 
Se é verdade que um padrão bem sucedido é um que é extensamente usado, então é prudente envolver todos os órgãos de governo no desenvolvimento das especificações. Os representantes de órgãos do setor público podem participar do processo de desenvolvimento por vários mecanismos. A Malásia efetuou consultas internas em seus próprios órgãos. Na Austrália e Dinamarca, a liderança do projeto é exercida por representantes de diferentes órgãos do governo. Na Nova Zelândia e o Reino Unido, os órgãos do governo agem como contribuintes individuais submetendo comentários ou questionamentos sobre as especificações contidas na arquitetura.

Alguns países têm usado os serviços grupos de consultores no desenvolvimento dos seus projetos. A Austrália, Alemanha e o Reino Unido têm grupos especialistas fora dos seus grupos de trabalho. Estes grupos especialistas podem ser formados por pessoal seniores de TIC, como no caso do Reino Unido, ou é um grupo de consultoria privado, como no caso de Austrália. Estes grupos de especialista funcionam como um grupo aconselhador ou como um comitê de revisão independente para o documento da arquitetura.

Uma participação ampla de outros interessados, envolvendo indústria, NGOs e cidadãos, também é importante para o desenvolvimento do projeto.

Como mencionado anteriormente, a indústria de TIC tem desempenha um papel importante no desenvolvimento e na implementação de uma arquitetura de interoperabilidade, tendo em vista que ela normalmente atua no auge do progresso de desenvolvimento tecnológico. No Reino Unido, representantes de indústrias participam dos grupos de trabalho. Na Austrália, uma organização privada atuou como consultoria externa para revisar os conteúdos do projeto. Também mecanismos de consulta como websites, e-mails e fóruns de discussão podem ser usados para receber contribuições da indústria.

A participação de NGOs também pode ser bastante relevante. NGOs normalmente articulam as visões dos usuários e consumidores de serviços de governo on-line, e levar em conta essas visões poderia ajudar formular melhor os padrões.

Os cidadãos podem participar do desenvolvimento do projeto por mecanismos de consulta públicos que são disponibilizados pela secretaria. A perspectiva dos cidadãos é importante 
para avaliar o impacto e a utilidade das especificações definidas para o usuário final. Os mecanismos que podem ser usados para a participação pública são:

- websites e e-mails;

- audiências públicas; e

- pedidos para comentários e pedidos para propostas.

\subsubsection{Exemplos de arquiteturas de interoperabilidade em implementação}

Vários países, e também a União Européia têm estabelecido seus padrões de interoperabilidade para governo eletrônico. Dessas iniciativas, a considerada com maior nível de maturidade é a e-Government Interoperability Framework (e-GIF), definida pelo governo do Reino Unido a partir de 2000, e que atualmente está na versão 6.1. As diretrizes de padronização dessa arquitetura determinam um conjunto de especificações e políticas que cobrem quatro áreas: interconectividade, integração de dados, acesso à serviços eletrônicos e gerenciamento de conteúdo (E-GOV UNIT, 2004).

A França publicou sua versão 2.1 da Le Cadre Commun d'Intéroperabilité (CCI) em setembro de 2003. A CCI define as recomendações para o fortalecimento da convergência dos sistemas eletrônicos públicos e para possibilitar a prestação de serviços eletrônicos através de múltiplas agências (ADAE, 2003).

A Coordenação Federal de Governo para Tecnologias da Informação da Alemanha publicou a versão 2.0 do documento Standards and Architectures for e-Government Applications (SAGA) em Dezembro de 2003. O SAGA é um conjunto de diretrizes que serve de orientação para os gestores de governo eletrônico da Alemanha (KBST, 2003).

Também o Federal Chief Information Officers (CIO) Council, nos Estados Unidos, lançou a Federal Enterprise Architecture Framework (FEAF) em setembro de 1999 (CIOC, 1999), e publicou sua segunda versão do e-Gov Enterprise Architecture Guidance (CIOC EAG) em julho de 2002, para guiar as iniciativas de governo eletrônico (CIOC, 2002).

A Comissão Européia, através do projeto Interoperable Delivery of European eGovernment Services to public Administrations, Business and Citizens (IDABC), publicou o documento Architecture Guidelines (versão 4.1) em Março de 1999. Esse documento foi lançado como suporte para o programa "Interoperability and access to Trans-European Networks for the 
electronic Interchange of Data between Administrations”. A versão 7.1 foi lançada em Setembro de 2004 (IDABC, 2004a). As diretrizes desse documento estabelecem conceitos e referência para interoperabilidade entre agências e instituições européias, e também com as administrações nos seus estados membros. Posteriormente, ainda como fruto do projeto IDABC, foi publicada a versão 1.0 do European Interoperability Framework (IDABC EIF) em novembro de 2004 (IDABC, 2004b). Este documento recomendou o estabelecimento de uma arquitetura de interoperabilidade, enfatizando os tópicos que deviam ser levados em consideração quando da implementação de serviços de governo eletrônico na dimensão transEuropéia.

O Quadro 9 apresenta alguns dos principais projetos de padrões de interoperabilidade para governo eletrônico em andamento. 
Quadro 9 - Projetos de padrões de interoperabilidade para governo eletrônico em andamento

Fonte: adaptado de United Nations Development Programme (2007)

\begin{tabular}{|c|c|c|}
\hline PAIS / ÁREA & PADRÃO & $\begin{array}{l}\text { VERSÃO } \\
\text { ATUAL }\end{array}$ \\
\hline Alemanha & Standards and Architectures for e-government applications & 2.0 \\
\hline Arábia Saudita & Yesser Framework for Interoperability & \\
\hline Austrália & Australian Government Technical Interoperability Framework & 2.0 \\
\hline Canadá & $\begin{array}{l}\text { Government of Canada's (GC) enterprise architecture (EA) - } \\
\text { Treasury Board information or technology standards }\end{array}$ & \\
\hline Dinamarca & Danish e-Government Interoperability Framework & 1.2 .14 \\
\hline Estados Unidos & FEA Consolidated Reference Model Document & 2.0 \\
\hline Estônia & Estonian IT Interoperability Framework & 2.0 \\
\hline Filipinas & Draft Philippine Government Interoperability Framework & \\
\hline França & Le CadreCommund’Intéroperabilité(CCI) & 2.1 \\
\hline Hong Kong & The HKSARG Interoperability Framework & 4.0 \\
\hline Ilhas Maurício & e-Government Interoperability Framework & 1.0 \\
\hline Índia & Draft Interoperability Framework for e-Governance & 2.1 \\
\hline Malásia & $\begin{array}{l}\text { Standards, Policies and Guidelines - Malaysian Government } \\
\text { Interoperability Framework }\end{array}$ & 1.0 \\
\hline Nova Zelândia & New Zealand E-government Interoperability Framework & 3.0 \\
\hline Reino Unido & e-Government Interoperability Framework & 6.1 \\
\hline Sirilanka & Lanka Interoperability Framework Version & 0.9 \\
\hline Tailândia & $\begin{array}{l}\text { Thailand Interoperability Framework: Interoperability Systems } \\
\text { for a Connected Government }\end{array}$ & \\
\hline União Européia & $\begin{array}{l}\text { European Interoperability Framework for Pan-European e- } \\
\text { Government Services }\end{array}$ & 1.0 \\
\hline
\end{tabular}




\section{CAPÍTULO 3 - METODOLOGIA DE PESQUISA}

\subsection{PARADIGMA DE PESQUISA}

O paradigma de pesquisa é o interpretativismo. De acordo com Walsham (1993), os métodos interpretativos de pesquisa partem do princípio que o nosso conhecimento da realidade, incluindo o domínio da ação humana, é uma construção social por atores humanos e que isso se aplica também aos pesquisadores. Segundo essa perspectiva, não há uma realidade objetiva a ser descoberta por pesquisadores e replicada por outros, em contraste com a suposição da ciência positivista. Em outras palavras, o pesquisador procura construir sua visão da realidade a partir da visão dos atores.

Burrel e Morgan (1979) explicam que o paradigma interpretativo procura compreender o mundo como ele é, criado por significados intersubjetivos em um processo social. Objetiva-se entender um fenômeno social sob o ponto de vista da percepção dos indivíduos nele envolvidos, dentro do ambiente natural. Em um estudo interpretativo, o pesquisador não impõe seu entendimento prévio sobre a situação pesquisada.

De acordo com Orlikowski e Baroudi (1991) o objetivo de uma pesquisa baseada nesse paradigma não é a generalização a partir de um determinado contexto para uma população. A intenção é compreender a estrutura profunda de um fenômeno que, se acredita, pode ser usado para informar outro ambiente. Ainda segundo esses autores, os pressupostos da filosofia de pesquisa interpretativista são os seguintes:

- Crenças sobre a realidade física e social: a perspectiva interpretativista enfatiza a importância dos significados subjetivos e sócio-políticos, assim como ações simbólicas na forma como as pessoas constroem e reconstroem sua própria realidade. A realidade é reproduzida por meio de interações sociais; ela não é algo “dado”, à espera de uma descoberta, mas sim, só é passível de interpretação.

- Crenças sobre o conhecimento: o conhecimento sobre os processos sociais não pode ser construído a partir de deduções hipotéticas ou cálculos de relações entre variáveis. A compreensão dos processos sociais pressupõe um 'mergulho' no mundo no qual eles são gerados. Isso envolve conhecer como as práticas e os significados são 
formados e informados pela linguagem e por normas tácitas compartilhadas em um determinado contexto social. Os modelos de causalidade são sempre circulares ou reciprocamente interativos. Os métodos sob o paradigma interpretativista mais apropriados são os estudos de campo, nos quais o pesquisador evita a imposição de categorias para o estudo de um fenômeno. Ao invés de ir a campo com um conjunto bem definido de construtos ou instrumentos para medir a realidade, o pesquisador deriva seus construtos a partir do trabalho de campo, visando captar aquilo que é mais significativo segundo a perspectiva das pessoas no contexto pesquisado. Aos participantes é permitido usar suas próprias palavras e imagens, se basear em seus próprios conceitos e experiências.

- Crenças sobre o relacionamento entre teoria e prática - a abordagem Interpretativista assume que o pesquisador nunca possui uma posição neutra, mas sim que suas pressuposições, crenças, valores e interesses sempre intervém na modelagem de suas investigações. Recontar precisamente a história de um ator não é completamente possível, pois os esquemas interpretativos do pesquisador sempre intervêm.

De acordo com Castells (2001), as TICs são construídas socialmente. Por isso, precisamos compreender em profundidade o ambiente no qual essas tecnologias estão sendo utilizadas, por meio de uma abordagem qualitativa e interpretativista.

A pesquisa também possui um caráter contextualista (PETTIGREW, 1985; AVGEROU, 2001, 2002), o que pressupõe o entendimento de porque mudanças ocorrem em diferentes contextos organizacionais, culturas e sistemas políticos, sob diferentes condições sócioeconômicas, ao longo do tempo. Isso implica compreender a contínua interação entre o contexto de mudança (ambiente externo e interno da organização onde as mudanças ocorrem), o processo da mudança (como as mudanças ocorrem) e o conteúdo da mudança (novas tecnologias introduzidas em uma organização).

Avgerou (2001) argumenta que esses elementos são extremamente interconectados e sobrepostos. Ela utiliza o termo “estudos situados" (situated studies) significando a compreensão das dinâmicas locais de mudança, como as pessoas interagem com a tecnologia e como as mudanças ocorrem. Ela propõe uma abordagem contextualista em estudos sobre inovações de TI em países em desenvolvimento, com as seguintes características: considerase a inovação em relação a mudanças sócio-organizacionais; consideram-se não só as decisões 
e ações técnicas e racionais envolvidas no processo de mudança, mas também os elementos culturais, políticos, sociais e cognitivos envolvidos.

\subsection{MÉTODO DE PESQUISA}

Para a classificação da pesquisa, toma-se como base a taxionomia apresentada por Vergara (1997), que a classifica em relação a dois aspectos: quanto aos fins e quanto aos meios.

Quanto aos fins, a pesquisa é considerada exploratória e descritiva. ${ }^{5}$ Exploratória porque, embora os processos de padronização em TI já tenham sido alvo de pesquisas em diversas áreas de investigação, não se verificou a existência de estudos que abordem o tema com o ponto de vista pelo qual essa pesquisa abordou. E descritiva, porque visou descrever o processo, suas fases, suas fontes e seus efeitos.

Quanto aos meios, a pesquisa foi bibliográfica e de campo. ${ }^{6}$ Bibliográfica, pois para a fundamentação teórico-metodológica do estudo foram necessárias a investigação em livros, periódicos, dissertações, teses, etc., sobre padronização, integração de sistemas, interoperabilidade, e outros tópicos relativos à adoção de padrões de TI. A investigação foi também de campo, onde foram coletados dados primários em documentos e através de entrevistas semi-estruturadas.

O método de pesquisa utilizado foi o estudo de caso em profundidade. O propósito fundamental deste tipo de pesquisa é analisar uma unidade social, que pode ser um indivíduo, um grupo deles, uma organização, uma instituição ou até mesmo uma comunidade (GODOY, 1995).

Já Yin (1994) afirma que o estudo de caso é uma forma de pesquisa empírica que investiga os fenômenos contemporâneos dentro do seu contexto de vida real, em situações em que as fronteiras entre o fenômeno e o contexto não estão claramente estabelecidas, ou se utiliza de múltiplas fontes de evidência.

\footnotetext{
${ }^{5}$ A investigação exploratória é realizada em área na qual há pouco conhecimento acumulado e sistematizado; a pesquisa descritiva expõe características de determinado fenômeno. Pode também estabelecer correlações entre variáveis e definir sua natureza Vergara (1997).

6 Pesquisa bibliográfica é o estudo sistematizado desenvolvido com base em material publicado em livros, periódicos, dissertações, teses, redes eletrônicas, isto é, material acessível ao público em geral; investigação documental é a realizada em documentos conservados no interior de órgãos públicos e privados de qualquer natureza, ou com pessoas; pesquisa de campo é a investigação empírica realizada no local onde ocorre ou ocorreu um fenômeno ou que dispõe de elementos para explica-lo - pode incluir entrevistas, aplicação de questionários, testes e observação participante ou não (Vergara, 1997).
} 
Para Godoy (1995), os estudos de caso têm se tornado uma estratégia de pesquisa preferida pelos pesquisadores quando eles procuram responder "por que e como" certos fenômenos ocorrem, quando há pouca possibilidade de controle sobre os eventos estudados e quando o foco de interesse é sobre fenômenos atuais, que só poderão ser analisados dentro de um contexto de vida real. Os estudos de caso permitem também uma interação mais direta entre o objeto e o sujeito da pesquisa, possibilitando a busca específica de significados que particularizam a realidade em questão.

Para Roesch (1999), existem alguns aspectos que caracterizam o estudo de caso como uma estratégia de pesquisa, como por exemplo, a possibilidade de se estudar fenômenos em profundidade dentro de seu contexto, sua especial adequação ao estudo de processos e permitir a exploração dos fenômenos com base em vários ângulos.

O estudo do objeto em seu ambiente natural é uma vantagem do estudo de caso e uma diferença básica em relação ao experimento, que é conduzido num ambiente artificial, controlado. O estudo de caso difere também de uma survey, que agrega os dados de dezenas ou centenas de casos, analisando-os fora de seu contexto. É apropriado, então, quando a ênfase da pesquisa for analisar fenômenos ou processos dentro de seu contexto e não traços, opiniões ou ações de indivíduos como no caso de uma survey (ROESCH, 1999).

Para Hartley (1994), o ponto forte dos estudos de caso reside em sua capacidade de explorar processos sociais à medida que eles se desenrolam nas organizações. Seu emprego permite, entre outros, uma análise processual, contextual e longitudinal das várias ações e significados que se manifestam e são construídos dentro das organizações.

Benbasat, Goldstein e Mead (1987) destacam que o estudo de caso é um método apropriado quando a pesquisa e a teoria sobre um determinado assunto estão em seu estágio inicial, quando a experiência e perspectivas dos atores são importantes e quando a consideração do contexto de ação é crítica. Logo, todas essas condições são válidas em relação a pesquisa realizada. O tema é relativamente recente, o campo teórico ainda é pouco consistente, especialmente no Brasil e, dada a abordagem interpretativista, a perspectiva dos atores e contextualização são fundamentais. 
Benbasat, Goldstein e Mead (1987) descrevem as características-chave do método de estudo de caso:

- é um método útil para estudar questões como "por que” e “como”, pois foca processos ao longo do tempo e não intensidades de freqüência ou incidências

- o foco recai sobre eventos contemporâneos

- o fenômeno sob investigação é estudado em seu contexto natural

- os dados são coletados por múltiplos meios

- uma ou mais entidades são investigadas (pessoas, grupos ou toda a organização)

- o pesquisador deve ter uma atitude receptiva e exploratória

- não há controles experimentais ou manipulações envolvidas

- o investigador não precisa especificar um conjunto de variáveis dependentes ou independentes a priori

- os resultados dependem fortemente da habilidade integradora do pesquisador

- mudanças de locais e métodos de coleta de dados podem ocorrer durante o processo de investigação, dependendo das hipóteses que vão sendo desenvolvidas

A pesquisa foi realizada através de um estudo de caso único. Essa opção encontra respaldo na lógica interpretativista, segundo a qual, a validade das inferências feitas a partir de um ou mais casos não depende de representatividade estatística, mas da plausibilidade e validade da argumentação lógica usada para descrever os resultados obtidos, e das conclusões que podem ser desenhadas a partir de um ou mais casos (WALSHAM, 1993, KLEIN e MEYERS, 1999). Além disso, considerou-se que, ao optar por um estudo de caso único, ele deve consistir em um caso crítico e representativo do fenômeno que se deseja investigar (BENBASAT, GOLDSTEIN e MEAD, 1987; YIN, 2001).

O estudo de caso segue o que Stake (1995) chama de instrumental, que examina um caso particular para estabelecer um ponto de vista sobre determinado assunto.

A escolha da metodologia de estudo de caso pode ser argumentada com base em duas razões. Primeiro, um estudo de caso evidencia o papel que o contexto desempenha no entendimento do fenômeno que está sendo estudado, permitindo assim examinar o processo de desenvolvimento de um padrão como uma construção social em vez de apenas uma questão técnica. Segundo, permite capturar descrições densas (STAKE, 1995), possibilitando captar 
detalhes do rico processo social que permeia o desenvolvimento de uma tecnologia e também explicar a forma pela qual as escolhas dos atores envolvidos foram feitas e as condições sob as quais um determinado resultado foi produzido (RUSSEL e WILLIAMS, 2002).

O objeto de estudo foi a arquitetura e-PING, um conjunto de padrões de interoperabilidade definido pelo governo federal brasileiro, que abrange cinco principais áreas: interconectividade, segurança, meios de acesso, organização e intercâmbio de informações (BRASIL, 2004). A e-PING é considerada como uma estrutura básica para a estratégia de governo eletrônico no Brasil e sua elaboração teve como base o projeto e-GIF (Government Interoperability Framework), implementado pelo governo britânico a partir do ano de 2000, atualmente já na 6a . Versão (e-GIF, 2004). A e-GIF, pelo seu tempo já de implementação e constante evolução, tem se tornado referência de padrão de interoperabilidade em governo eletrônico.

A e-PING traça diretrizes para padronizações no governo eletrônico brasileiro a partir das experiências dos EUA, Canadá, Reino Unido, Austrália e Nova Zelândia - países que têm investido intensivamente em políticas e processos para o estabelecimento de padrões de TI e estruturas dedicadas para atingir interoperabilidade e assim prover melhor qualidade e menor custo para os serviços públicos prestados.

Inicialmente aplicada no âmbito do Poder Executivo do Governo Federal brasileiro, a arquitetura prevista para a e-PING cobre o intercâmbio de informações entre o Poder Executivo e cidadãos, governos estaduais e municipais, os Poderes Legislativo e Judiciário do governo federal, o Ministério Público, organizações internacionais, governos de outros países, empresas nacionais e internacionais e também organizações do terceiro setor. Na sua concepção, a e-PING é especificada como de uso compulsório para os órgãos do Poder Executivo (inclusive as empresas públicas e outras entidades federais) para todos os novos sistemas de informação, para os sistemas legados que incorporem a previsão de serviços de governo eletrônico ou integração entre sistemas, e também para outros sistemas que envolvam prestação de serviços eletrônicos (BRASIL, 2004; BRASIL, 2007a).

\subsubsection{Dinâmica da pesquisa}

Em um estudo interpretativista, as técnicas de coleta de dados incluem entrevistas em profundidade, observações diretas, não possuindo categorias de análise a priori, mas 
procurando captar em profundidade a perspectiva dos atores que estão sendo pesquisados (FISH, 1990).

Baseado nessa premissa, as técnicas de coleta de dados utilizadas compreenderam entrevistas semi-estruturadas com o grupo de coordenação do projeto, assim como outros atores envolvidos no processo de desenvolvimento e implementação da e-PING. Foi também efetuada análise documental e realizadas observações diretas com a geração de anotações de campo.

Outros dados foram coletados de fontes secundárias como bibliografias, artigos em periódicos, etc., visando compreender todo o contexto no qual o caso estava inserido.

O estudo de caso foi conduzido ao longo do período de maio de 2004 a dezembro de 2007, com as observações realizadas durante todo o período e as entrevistas em datas agendadas em função de alguns eventos do projeto considerados relevantes. Esses eventos incluíram, por exemplo, o lançamento das versões da arquitetura, divulgação das pesquisas de diagnóstico de adoção do padrão e finalização das análises das contribuições submetidas nas consultas e audiências públicas realizadas pelo grupo de coordenação do projeto.

Como já anteriormente mencionado, em um estudo interpretativista, todo o processo de investigação deve ser flexível, aberto à visão dos atores pesquisados e à sensibilidade do contexto no qual o caso está inserido. No entanto, cabe destacar que isso não significa que o estudo não tenha diversos critérios metodológicos a seguir. Uma pesquisa interpretativista exige uma considerável preparação por parte do pesquisador, e uma série de princípios a serem buscados visando garantir sua seriedade, profundidade e robustez.

Nesse sentido, foram considerados na pesquisa os princípios para a condução de estudos de campo interpretativos, propostos por Klein e Meyers (1999):

1. Princípio do círculo Hermenêutico - Este é um princípio chave, que serve de base para todos os demais e é válido para estudos interpretativistas que tomam como base a Hermenêutica e a Fenomenologia. A Hermenêutica preocupa-se com a compreensão, a interpretação e a tradução de signos e sinais. Já a Fenomenologia procura compreender a essência de um fenômeno, evitando o parcelamento de uma pesquisa e a atomização dos dados, mas a sua consideração enquanto um todo (GIL, 1995). Esse princípio 
sugere que os seres humanos compreendem um todo complexo a partir de préconcepções a respeito de cada uma de suas partes e seus inter-relacionamentos. Logo, para compreender uma história, por exemplo, é preciso compreender cada uma de suas partes ou episódios, para então formar o todo, e retornar ao estudo de cada parte novamente, para se chegar a uma compreensão profunda do que ela significa. Com isso, formam-se círculos concêntricos de entendimento, das partes para o todo e novamente do todo para as partes.

2. Princípio da Contextualização - De acordo com esse princípio, a consideração e a reflexão crítica sobre o contexto histórico e social do objeto de pesquisa são fundamentais. Os interpretativistas partem do pressuposto que o contexto e o padrão de conduta de uma organização muda constantemente; as organizações não são estáticas, assim como não são estáticos os relacionamentos entre pessoas, instituições e tecnologia. Logo, a pesquisa interpretativa é ideográfica, isto é, ela visa ao entendimento de um fenômeno considerando o contexto em que ele ocorre (BENBASAT, GOLDSTEIN e MEAD, 1987; BURREL E MORGAN, 1979). Além disso, o pesquisador precisa ver as pessoas como produtores, e não só como produtos da história, e a descrição do contexto histórico precisa refletir isso (KLEIN e MEYERS, 1999, p. 74).

3. Princípio da Interação entre pesquisadores e pesquisados - Esse princípio requer que o pesquisador se coloque como sujeito, em uma perspectiva histórica. De acordo com a lógica interpretativista, os dados não estão "sentados, esperando por serem coletados, como pedras no litoral” (KLEIN e MEYERS, 1999, p. 74); os fatos são produzidos como parte da interação social entre pesquisadores e pesquisados. Logo, o pesquisador precisa reconhecer que suas pré-concepções a respeito do fenômeno investigado e dos pesquisados também afeta a construção, documentação e organização de todos os dados coletados na pesquisa.

4. Princípio da Abstração e generalização - Como já foi dito, as abstrações e generalizações em um estudo interpretativista não ocorrem por inferência estatística, mas sim, pela plausibilidade, coerência, consistência e clareza da argumentação que descreve os resultados do estudo e as conclusões geradas. Logo, abstrações e generalizações precisam ser cuidadosamente relacionadas a detalhes e dados obtidos 
em campo, da forma como eles tenham sido coletados ou vivenciados pelo pesquisador, para que os leitores possam acompanhar a linha de raciocínio do pesquisador e como ele chegou a tais resultados. Quanto à fundamentação teórica e o seu significado para a pesquisa, ela é muito mais um meio para a sensibilização do pesquisador do que algo a ser falsificado. Klein e Meyers (1999) afirmam que, em geral, os pesquisadores da área de Sistemas de Informação tendem a fazer generalizações considerando teorias sociais específicas, como a Teoria da Estruturação (o que é o caso desta proposta) do que generalizações sobre categorias filosoficamente abstratas.

5. Princípio do raciocínio dialógico - Esse princípio requer que o pesquisador confronte as suas pré-concepções e preconceitos que guiaram o desenho original de pesquisa, ou suas “lentes de análise” originais, à medida que a pesquisa se desenvolve. Antes de tudo, o pesquisador precisa declarar quais foram as suas suposições e bases filosóficas de pesquisa, tanto para o leitor quanto para ele próprio. Ele precisa esclarecer qual a linha de estudo que escolheu, bem como as suas forças e fraquezas. Isso tudo precisa ser clarificado, pois é possível que os resultados da pesquisa não ofereçam suporte às pré-concepções existentes. Isso não significa que essas pré-concepções não sejam importantes. Ao contrário do Positivismo, a Hermenêutica reconhece que as préconcepções e pré-conceitos são pontos de partida necessários para a nossa compreensão dos fenômenos, porém o seu reconhecimento e a sua suspensão diante de evidências em contrário são necessários.

6. Princípio de Múltiplas Interpretações - Esse princípio requer que o pesquisador examine as influências que o contexto social tem sobre as ações que estão sendo pesquisadas, ao buscar considerar múltiplos pontos de vista e suas possíveis contradições, revisando a sua compreensão de acordo com eles. Esse confronto entre diferentes pontos de vista é essencial até mesmo para a revisão das pré-concepções do pesquisador.

7. Princípio da Suspeita - Esse princípio ressalta a necessidade de se aprofundar a compreensão dos dados coletados, procurando identificar distorções e contradições, mantendo-se sempre uma visão crítica do assunto pesquisado, questionando-se a superfície dos significados que são expostos pelos pesquisados. O pesquisador precisa 
ler uma realidade indo além das palavras utilizadas pelos atores, mergulhando no mundo social que se caracteriza por estruturas de poder, interesses pessoais, etc.

Esses princípios são interdependentes, e muito embora seja opção de cada pesquisador seguilos ou não na íntegra (KLEIN e MEYERS, 1999), acredita-se que eles contribuem para guiar o estudo a ser realizado, e evidenciam a complexidade do método Interpretativo e da necessidade de preparo do pesquisador para a realização da pesquisa. Esses princípios orientam todo o desenho de pesquisa, mas especialmente a análise dos dados a serem coletados.

Objetivando obter um discurso mais natural dos respondentes acerca do projeto e das decisões tomadas ao longo do seu curso, apenas a última entrevista (onde foram feitas checagem de pontos específicos para fechamento da pesquisa) foi gravada. Em todas as outras anteriores foram tomadas notas e realizadas análises preliminares imediatamente seguidas de notas expandidas, a fim de preservar detalhes considerados relevantes para a análise final.

As análises dos dados foram iniciadas logo após suas coletas. Embora esse procedimento possa criar eventuais vieses nas coletas posteriores, ele está de acordo com a abordagem interpretativista, onde a compreensão do fenômeno se dá por sucessivas observações através de interações entre pesquisador e objeto ao longo da pesquisa.

De acordo com Maxwell (1996) um dos problemas mais comuns em estudos qualitativos é deixar as notas de campo e as transcrições de entrevistas de lado, tornando a tarefa de análise final muito mais difícil e desencorajadora. Para o autor os pesquisadores ao adotarem uma abordagem qualitativa para sua pesquisa, devem começar a análise dos dados imediatamente após finalizar a primeira entrevista ou observação, e continuar a analisar os dados enquanto estiver trabalhando na pesquisa. 


\section{CAPÍTULO 4 - APRESENTAÇÃO DOS DADOS: A ARQUITETURA e-PING}

Este capítulo apresenta os dados sobre o objeto do estudo de caso dessa pesquisa, a arquitetura de interoperabilidade e-PING. As informações aqui apresentados refletem os dados coletados através de pesquisa e análise documental, entrevistas com os coordenadores do projeto e observação direta em seminários e workshops promovidos sobre o padrão.

\subsection{CONCEPÇÃO}

A arquitetura e-PING - Padrões de Interoperabilidade de Governo Eletrônico - define um conjunto mínimo de premissas, políticas e especificações técnicas que regulam a utilização das Tecnologias de Informação e Comunicação (TIC) na interoperabilidade de serviços de governo eletrônico, estabelecendo as condições de interação com outras instituições governamentais (inclusive estados e municípios) e com a sociedade. Esses padrões englobam cinco segmentos: (1) interconexão, (2) segurança, (3) meios de acesso, (4) organização e intercâmbio de informações e (5) áreas de integração para governo eletrônico. O Quadro 10 apresenta os segmentos definidos e os seus respectivos tópicos contemplados (BRASIL, 2007).

Quadro 10 - Definição dos segmentos da e-PING

\begin{tabular}{|l|l|}
\hline Segmentos & Tópicos contemplados \\
\hline Interconexão & $\begin{array}{l}\text { Estabelece as condições para que os órgãos de governo se interconectem, } \\
\text { além de fixar as condições de interoperação entre governo e a sociedade. }\end{array}$ \\
\hline Segurança & $\begin{array}{l}\text { Trata dos aspectos de segurança para assegurar a validade e privacidade } \\
\text { das operações. }\end{array}$ \\
\hline Meios de acesso & $\begin{array}{l}\text { Define as questões relativas aos padrões dos dispositivos de acesso aos } \\
\text { serviços de governo eletrônico. }\end{array}$ \\
\hline $\begin{array}{l}\text { Organização e intercâmbio de } \\
\text { informações }\end{array}$ & $\begin{array}{l}\text { Aborda os aspectos relativos ao gerenciamento e à transferência de } \\
\text { informações nos serviços de governo eletrônico. }\end{array}$ \\
\hline $\begin{array}{l}\text { Áreas de integração para Governo } \\
\text { Eletrônico. }\end{array}$ & $\begin{array}{l}\text { Compreende as diretrizes para novas formas de integração e intercâmbio } \\
\text { de informações baseados nas definições do e-PING. }\end{array}$ \\
\hline
\end{tabular}

Cada segmento foi subdividido em componentes, para os quais foram estabelecidas as políticas e especificações técnicas a serem adotadas. O Quadro 11 a seguir apresenta as especificações estabelecidas na versão 3.0 da e-PING (BRASIL, 2007). 
Quadro 11 - Especificações contempladas nos segmentos da e-PING

\begin{tabular}{|c|c|}
\hline Segmentos & Especificações contempladas \\
\hline Interconexão & $\begin{array}{l}\text { - Protocolo de Transferência de Hipertexto; } \\
\text { - Transporte de Mensagem Eletrônica; } \\
\text { - Segurança de Conteúdo de Mensagem Eletrônica; } \\
\text { - Acesso à Caixa Postal; } \\
\text { - Acesso Seguro à Caixa Postal; } \\
\text { - Diretório; } \\
\text { - Serviços de Nomeação de Domínio; } \\
\text { - Endereços de Caixa Postal Eletrônica; } \\
\text { - Protocolo de Transferência de Arquivos; } \\
\text { - Intercomunicação LAN / WAN; } \\
\text { - Transporte; } \\
\text { - Web Services: SOAP, UDDI e WSDL. }\end{array}$ \\
\hline Segurança & $\begin{array}{l}\text { - Segurança de IP; } \\
\text { - Segurança de Correio Eletrônico; } \\
\text { - Criptografia; } \\
\text { - Desenvolvimento de Sistemas; } \\
\text { - Serviços de Rede; } \\
\text { - Coleta e arquivamento de evidências. }\end{array}$ \\
\hline Meios de acesso & $\begin{array}{l}\text { Padrões para acesso via estações de trabalho: } \\
\text { - Navegadores (browsers); } \\
\text { - Conjunto de Caracteres e Alfabetos; } \\
\text { - Formato de Intercâmbio de Hipertexto; } \\
\text { - Arquivos do Tipo Documento; } \\
\text { - Arquivos do Tipo Planilha; } \\
\text { - Arquivos do Tipo Apresentação; } \\
\text { - Arquivos do Tipo Banco de Dados para Estações de Trabalho; } \\
\text { - Especificação de Intercâmbio de Informaços Gráficas e Imagens Estáticas; } \\
\text { - Gráficos Vetoriais; } \\
\text { - Especificação de Padrões de Animação; } \\
\text { - Arquivos do Tipo Áudio e do Tipo Vídeo; } \\
\text { - Compactação de Arquivos de Uso Geral; } \\
\text { - Arquivos para georeferenciamento. } \\
\text { Cartões Inteligentes / Tokens / Outros : } \\
\text { - Definição de Dados; } \\
\text { - Aplicações (inclusive multi-aplicações); } \\
\text { - Componentes Elétricos; } \\
\text { - Protocolos de Comunicação; } \\
\text { - Padrões de Interface Física; } \\
\text { - Segurança; } \\
\text { - Infra-estrutura do Terminal }\end{array}$ \\
\hline $\begin{array}{l}\text { Organização e } \\
\text { intercâmbio de } \\
\text { informações }\end{array}$ & $\begin{array}{l}\text { - Linguagem para intercâmbio de dados; } \\
\text { - Linguagem para transformação de dados; } \\
\text { - Definição dos dados para intercâmbio; } \\
\text { - Catálogo de Padrões de Dados (CPD); } \\
\text { - Lista de Assuntos do Governo: Taxonomia para Navegação (LAG); } \\
\text { - Padrão de Metadados do Governo (e-PMG). } \\
\end{array}$ \\
\hline $\begin{array}{l}\text { Áreas de } \\
\text { integração para } \\
\text { Governo } \\
\text { Eletrônico }\end{array}$ & $\begin{array}{l}\text { - XML Schemas referentes a aplicações voltadas a Áreas de Atuação de Governo, que } \\
\text { serão organizados na forma de Catálogo, disponível no sítio da e-PING, e apresentado com } \\
\text { os conteúdos atuais em tópico a seguir; } \\
\text { - Componentes relacionados a temas transversais a Áreas de Atuação de Governo, cuja } \\
\text { padronização seja relevante para a interoperabilidade de serviços de Governo Eletrônico, } \\
\text { tais como Processos e Informações Geográficas. }\end{array}$ \\
\hline
\end{tabular}


Para cada um desses segmentos, existe um processo para análise dos padrões que irão compor a arquitetura. Esse processo compreende a seleção, aprovação e classificação das especificações selecionadas em cinco níveis (BRASIL, 2007, p. 15):

Adotado (A): item adotado pelo governo como padrão na arquitetura e-PING, tendo sido submetido a um processo formal de homologação realizado por parte de uma instituição do governo ou por uma outra instituição com delegação formal para realizar o processo. Também é considerado homologado quando baseado em uma proposição devidamente fundamentada pela coordenação do segmento, publicada no sítio e aprovado pela Coordenação da e-PING;

Recomendado (R): item que atende às políticas técnicas da e-PING, é reconhecido como um item que deve ser utilizado no âmbito das instituições de governo, mas ainda não foi submetido a um processo formal de homologação;

Em Transição (T): item que o governo não recomenda, por não atender a um ou mais requisitos estabelecidos nas políticas gerais e técnicas da arquitetura; é incluído na e-PING em razão de seu uso significativo em instituições de governo, tendendo a ser desativado assim que algum outro componente, em uma das duas situações anteriores venha a apresentar condições totais de substituí-lo. Pode vir a ser considerado um componente "recomendado" caso venha a se adequar a todas as políticas técnicas estabelecidas. Convém salientar que o desenvolvimento de novos serviços ou a reconstrução de partes significativas dos já existentes deve evitar o uso de componentes classificados como transitórios;

Em Estudo (E): componente que está em avaliação e será enquadrado numa das situações acima, assim que o processo de avaliação estiver concluído;

Estudo Futuro (F): componente ainda não avaliado e que será objeto de estudo posterior.

Na sua versão 3.0, de dezembro de 2007, a e-PING especificou 193 padrões. A tabela a seguir apresenta suas classificações, agrupados por segmentos.

\begin{tabular}{|c|c|c|c|c|c|c|}
\hline \multirow[b]{2}{*}{ Segmento } & \multirow{2}{*}{$\begin{array}{c}\text { Total de } \\
\text { padrões } \\
\text { especificados }\end{array}$} & \multicolumn{5}{|c|}{ Classificação } \\
\hline & & (A) & (R) & $(\mathrm{T})$ & (E) & (F) \\
\hline Interconexão & 26 & 4 & 15 & 1 & 6 & - \\
\hline Segurança & 35 & 1 & 25 & - & 6 & 3 \\
\hline Meios de acesso & 118 & 21 & 51 & 33 & 2 & 11 \\
\hline $\begin{array}{l}\text { Organização e } \\
\text { intercâmbio de } \\
\text { informações }\end{array}$ & 7 & 2 & 3 & - & 1 & 1 \\
\hline $\begin{array}{l}\text { Áreas de integração } \\
\text { para Governo } \\
\text { Eletrônico. }\end{array}$ & 7 & 3 & 2 & - & 2 & - \\
\hline Total & 193 & 31 & 96 & 34 & 17 & 15 \\
\hline
\end{tabular}

Tabela 1 - Classificação dos padrões da e-PING versão 3.0 
Inicialmente aplicada no âmbito do Poder Executivo do Governo Federal brasileiro, a arquitetura prevista compreende o intercâmbio de informações entre o Poder Executivo e cidadãos, governos estaduais e municipais, os Poderes Legislativo e Judiciário do governo federal, o Ministério Público, organizações internacionais, governos de outros países, empresas nacionais e internacionais e também organizações do terceiro setor (Figura 2). Na sua concepção, a e-PING é especificada como de uso compulsório para os órgãos do Poder Executivo do Governo Federal (inclusive as empresas públicas e outras entidades federais).

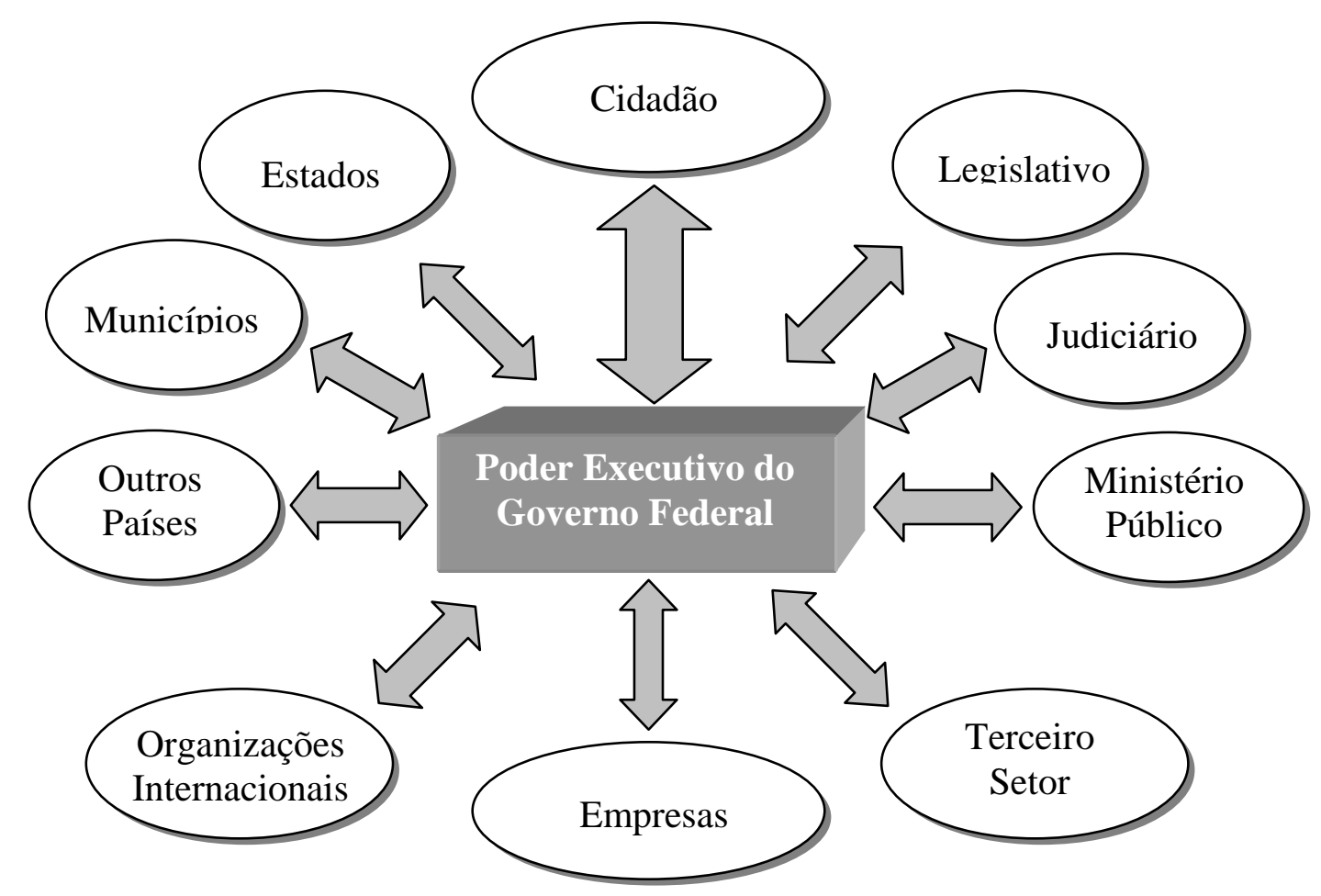

Figura 2 - Relacionamentos do e-PING.

O Poder Executivo do Governo Federal brasileiro inclui: os órgãos da Administração Direta (Ministérios, Secretarias e outras entidades governamentais de mesma natureza jurídica, ligados direta ou indiretamente à Presidência da República do Brasil) e as autarquias e fundações.

Para essas entidades, as especificações contidas na e-PING são obrigatórias para (BRASIL, 2007, p.8):

- $\quad$ todos os novos sistemas de informação que vierem a ser desenvolvidos e implantados no governo federal e que se enquadram no escopo de interação, dentro do governo federal e com a sociedade em geral; 
- sistemas de informação legados que sejam objeto de implementações que envolvam provimento de serviços de governo eletrônico ou interação entre sistemas;

- outros sistemas que façam parte dos objetivos de disponibilizar os serviços de governo eletrônico.

Segundo as diretrizes estabelecidas no documento referência, a adesão ocorrerá de maneira gradativa, de acordo com plano de implementação, que considerará a situação de cada uma das instituições em relação à possibilidade de se adequar às especificações e recomendações da e-PING.

Outro ponto específico sobre a questão de conformidade com e-PING definido no documento referência é que todas as compras e contratações do governo federal - Poder Executivo, relativas a desenvolvimento de serviços de governo eletrônico e para atualizações de sistemas legados devem estar em consonância com as especificações e políticas estabelecidas.

Existe ainda a recomendação para que os responsáveis por sistemas de informação de governo que estiverem fora do escopo de obrigatoriedade delimitado considerem a adequação aos padrões da e-PING sempre que forem planejados esforços significativos de atualização.

Para a divulgação dos padrões e especificações estabelecidos na arquitetura o governo brasileiro adotou o esquema de versionamento. É prevista a elaboração de uma versão anual, com publicação intermediária de atualizações, sempre que existirem modificações significativas.

\subsection{FINALIDADE}

A arquitetura e-PING tem por finalidade ser o padrão de referência para interoperabilidade no Governo Federal, inicialmente no âmbito do Poder Executivo. A iniciativa de especificação e implementação da arquitetura está a cargo de três órgãos da esfera federal (BRASIL, 2007):

- Ministério do Planejamento, Orçamento e Gestão, por meio da sua Secretaria de Logística e Tecnologia da Informação (SLTI/MP);

- Instituto Nacional de Tecnologia da Informação, da Presidência da República (ITI); e

- Serviço Federal de Processamento de Dados (SERPRO), empresa pública ligada ao Ministério da Fazenda. 
O desenvolvimento e implementação da e-PING objetiva promover as condições para suporte às transações de governo eletrônico. Sua especificação baseia-se na seguinte premissa defendida pelo Governo Federal (BRASIL, 2005):

[...] necessidade de assegurar a operação integrada entre equipamentos, programas e sistemas de informática, visando o pleno aproveitamento dos potenciais de intercâmbio de dados e informações no âmbito da Administração Pública Federal direta, autárquica e fundacional, o avanço na constituição da infra-estrutura para o desenvolvimento do Governo Eletrônico e a racionalização de custos.

A e-PING traça diretrizes para padronizações no governo eletrônico brasileiro a partir das experiências dos EUA, Canadá, Reino Unido, Austrália e Nova Zelândia - países que têm investido intensivamente em políticas e processos para o estabelecimento de padrões de TI e estruturas dedicadas para atingir interoperabilidade e assim prover melhor qualidade e menor custo para os serviços públicos prestados.

Essa arquitetura é considerada como uma estrutura básica para a estratégia de governo eletrônico no Brasil e sua elaboração teve como base o projeto e-GIF (Government Interoperability Framework), implementado pelo governo britânico a partir do ano de 2000, atualmente já na versão 6.1 (e-GIF, 2004). O e-GIF, pelo seu tempo já de implementação e constante evolução, tem se tornado referência de padrão de interoperabilidade em governo eletrônico.

\subsection{HISTÓRICO}

A fim de obter uma referência para a especificação da e-PING, um comitê do Governo Brasileiro visitou o Reino Unido em junho de 2003, com o propósito de conhecer a e-GIF, a arquitetura de interoperabilidade implementada pelo Governo Britânico a partir de 2000.

Posteriormente, em novembro do mesmo ano, os três órgãos coordenadores do projeto organizaram um seminário com participação de outras entidades do Governo Federal, no âmbito do Poder Executivo, tendo como objetivo a formação de um comitê inter órgãos denominado Comitê Constituinte - para conduzir os trabalhos iniciais de especificação da arquitetura.

Esse comitê estabeleceu o seguinte programa de trabalho:

- definição da forma inicial de elaboração e gestão da arquitetura e-PING; 
- definição da segmentação dos assuntos a serem cobertos pela e-PING;

- criação de cinco grupos de trabalho responsáveis pelas definições iniciais de políticas e especificações técnicas para cada um dos segmentos;

- estabelecimento de um cronograma de trabalho com o objetivo de construção e divulgação da versão inicial da arquitetura, denominada versão 0;

- realização de consulta pública e audiências públicas em RS, SP, DF, RJ, MG e PE, de modo a colher contribuições, da sociedade em geral, sobre o conteúdo proposto na versão 0;

- publicação da versão 1, juntamente com a resolução de institucionalização da e-PING no âmbito da Administração Pública Federal - Poder Executivo;

- realização de consulta pública e audiências públicas de modo a colher contribuições, da sociedade em geral, a cada nova versão do documento de referência;

- publicação de versão anual, contendo as atualizações e revisões das especificações técnicas e da visão geral da e-PING.

Mas tarde, após a sua institucionalização por intermédio da Portaria Normativa ${ }^{0}$. 5 de 14 de julho de $2005^{7}$, o Comitê Constituinte passou a se denominar Coordenação da e-PING.

Em dezembro de 2003 foram criados os cinco grupos de trabalho, sendo todos formados por funcionários efetivos de vários órgãos governamentais, um para cada segmento coberto pela arquitetura.

Os grupos de trabalho começaram as discussões em janeiro de 2004 para especificar a versão preliminar da arquitetura (versão 0) que foi publicada em maio. No período de junho a agosto o documento foi submetido a consulta pública via internet. Nesse mesmo período foram realizadas seis audiências públicas das quais participaram mais de 600 pessoas. Essas consultas e audiências públicas trouxeram as contribuições de órgãos públicos, pesquisadores e fornecedores de TICs, com mais de 90 sugestões submetidas. Depois da análise das sugestões apresentadas, o documento foi atualizado e a versão 1.0 foi publicada em março de 2005 e em julho, foi publicada a portaria normativa do Governo Federal institucionalizando o uso da arquitetura (BRASIL, 2005).

\footnotetext{
${ }^{7}$ Ver Anexo D
} 
Em seu conteúdo, a versão 1.0 do documento referência da e-PING estabeleceu as diretrizes para implementar a interoperabilidade entre as diversas soluções tecnológicas usadas pelo Governo Brasileiro. Essas diretrizes contemplam questões como segurança de redes, infraestrutura computacional, requisitos tecnológicos, padrões de desenvolvimento de softwares e acessos a dados e informações (BRASIL, 2004; BRASIL, 2007a).

O documento de referência da e-PING contém (BRASIL, 2007):

- os fundamentos de concepção, implantação e administração da e-PING, relacionando os benefícios esperados com o trabalho, definindo os limites da abrangência da arquitetura e-PING e destacando as premissas consideradas e as políticas estabelecidas;

- o modelo de gestão da e-PING, discriminando responsabilidades, critérios de verificação de conformidade, gestão de mudanças, divulgação e orientação para capacitação;

- as políticas e as especificações técnicas estabelecidas para todos os componentes de cada um dos segmentos da e-PING;

- glossário de termos técnicos referenciados;

- relação dos integrantes e colaboradores da presente versão deste documento.

Como resultado das discussões conduzidas pelos grupos de trabalho, duas outras versões foram publicadas: a versão 1.5 em dezembro de 2005 e a versão 1.9 em agosto de 2006, sendo essa última submetida também à audiências e consulta públicas. Depois da avaliação das sugestões dadas, foi publicada a versão 2.0 em novembro de 2006. Posteriormente foram lançadas as versões 2.01 em espanhol e inglês em dezembro de 2006, e a versão 2.9 em outubro de 2007, sendo esta objeto de audiências e consulta públicas. Após a análise das contribuições recebidas o documento referência foi alterado e então publicada a versão 3.0 em dezembro de 2007. A figura 3 apresenta a linha to tempo do lançamento das versões da e$\mathrm{PING}^{8}$.

\footnotetext{
${ }^{8}$ Para uma lista completa do histórico dos eventos do projeto ver o anexo E
} 


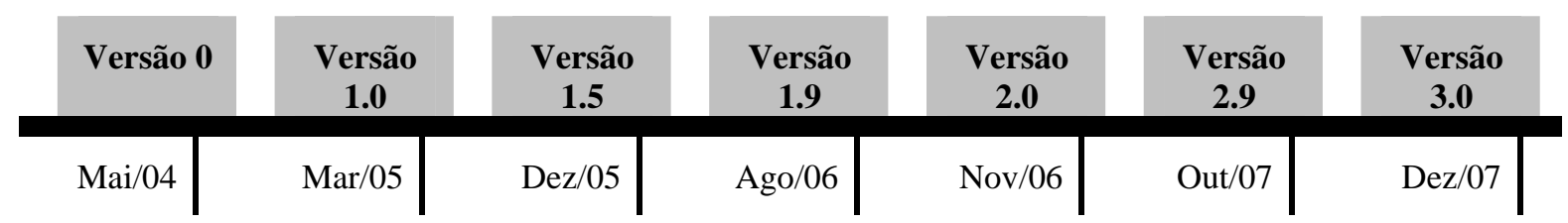

Figura 3 - Linha do tempo das versões da e-PING

\subsection{ESTRUTURA DE GOVERNANÇA}

A estrutura adotada para a gestão do projeto da e-PING segue o modelo sugerido pelo United Nations Development Programme (2007a). Especificadamente, existem três órgãos coordenadores (SLTI/MP, SERPRO e ITI), o grupo de coordenação que executa as funções de secretaria executiva, e os grupos de trabalho.

A Secretaria de Logística e Tecnologia da Informação do Ministério do Planejamento, Orçamento e Gestão, através do instrumento do Sistema de Administração dos Recursos de Informação e Informática (SISP), instituído pelo Decreto 1.048, de 21 de janeiro de 1994, é a responsável pela institucionalização e pela definição do formato jurídico da Coordenação da e-PING (BRASIL, 2005).

A atuação da Coordenação da e-PING é pautada pelos seguintes pontos (BRASIL, 2007a):

- implantação da arquitetura e-PING, providenciando as atividades necessárias para consolidação da versão atual e dinâmica da sua evolução;

- gestão da arquitetura e-PING;

- estabelecimento e gestão das normas e dos instrumentos institucionais e legais que garantam a efetividade das recomendações e especificações da e-PING;

- administração dos padrões considerados na e-PING;

- garantia de manutenção da atualização dos diversos catálogos da e-PING;

- gestão dos processos de comunicação e divulgação dos padrões, das decisões e das atividades da e-PING, incluindo a publicação de novas versões e das atualizações intermediárias; 
- fornecimento de critérios e subsídios para a elaboração da Lei Orçamentária Anual do Governo Federal;

- gestão dos processos de contratação dos serviços e de estabelecimento de convênios para realização das atribuições necessárias para consolidação dos padrões, como, por exemplo, avaliação de propostas de projetos de governo eletrônico voltados para a Administração Pública Federal, homologação de padrões e verificação de conformidade;

- estabelecimento dos pontos de contato com os diversos órgãos da Administração Pública Federal;

- administração dos Grupos de Trabalho - GTs, definindo sua composição e determinando as diretrizes de trabalho, baseadas nas políticas técnicas, gerais e especificas, nas necessidades de governo e na monitoração do cenário tecnológico.

O grupo de coordenação é responsável por supervisionar as atividades realizadas pelos grupos de trabalho assim como também apresentar e discutir o projeto com outras instituições dos setores público e privado (figura 4). Esse grupo também se reporta ao Comitê Executivo de Governo Eletrônico sobre a progressão do projeto, através da sua Secretaria Executiva.

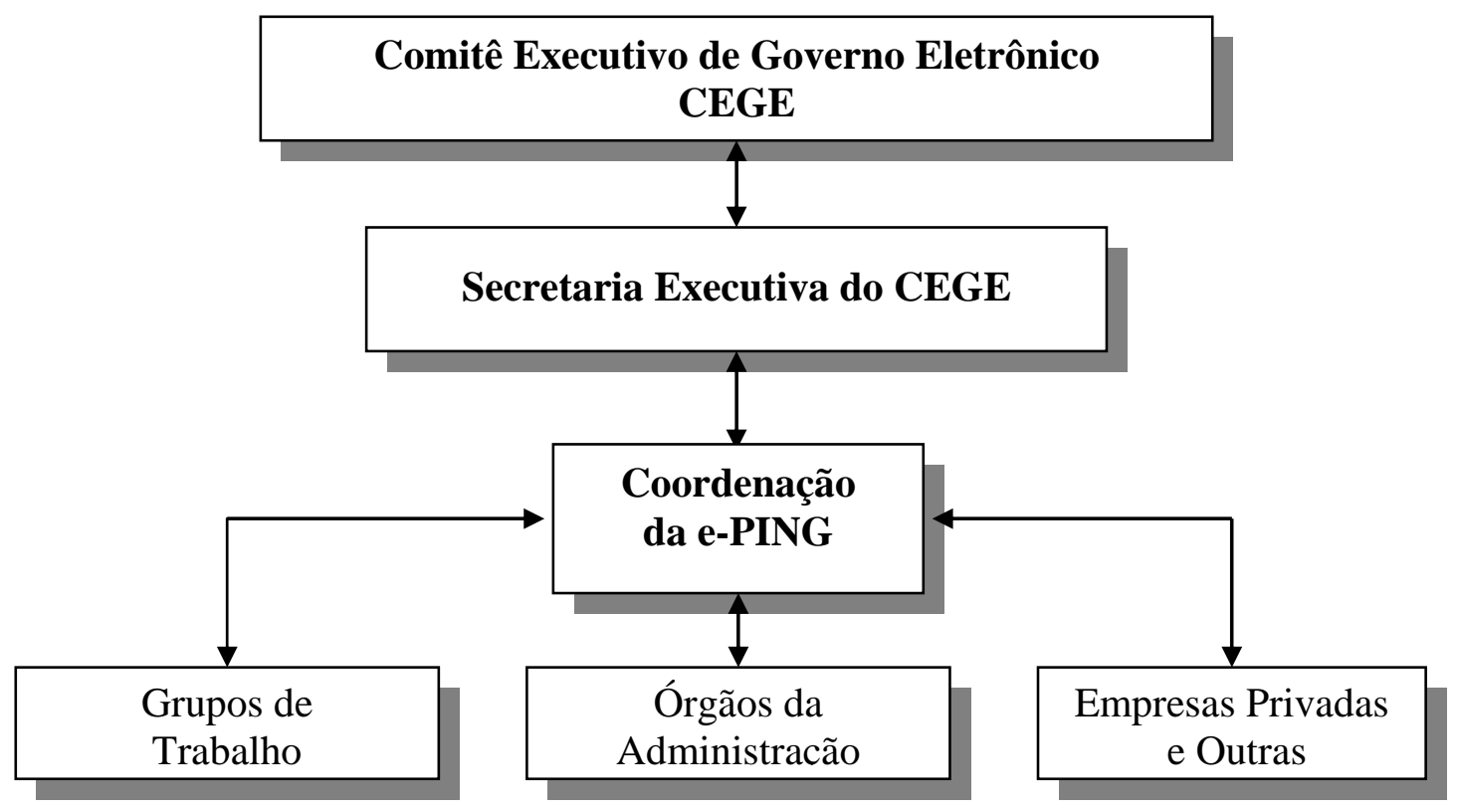

Figura 4 - Modelo de gestão da e-PING. 
Além da SLTI/MP, do SERPRO e do ITI, participam ainda do grupo de coordenação os seguintes órgãos: Presidência da República, Ministério das Relações Exteriores, Ministério da Saúde, Banco do Brasil, Caixa Econômica Federal, DATAPREV - Empresa de Tecnologia i Informações da Previdência Social e ABEP - Associação Brasileira de Empresas Estaduais de Processamento de Dados.

Cada um dos cinco grupos de trabalho é responsável por promover os encontros e discussões da sua área e apresentar os resultados para os outros grupos durante as reuniões com a coordenação. Seus representantes são indicados pelos vários órgãos da Administração Pública Federal e por representantes de instituições de outras esferas de governos, e são responsáveis por (BRASIL, 2007a):

- tratar os assuntos que compõem os segmentos da e-PING;

- monitorar sistematicamente o mercado, especificamente para os segmentos sob sua responsabilidade, com o objetivo de detectar as necessidades de atualização tecnológica das políticas e especificações técnicas; e

- subsidiar a atuação da Coordenação da e-PING, no desempenho de suas atribuições administrativas e técnicas.

Cada um dos grupos de trabalho possui um coordenador que tem assento no grupo de coordenação da e-PING.

\subsection{POLÍTICAS GERAIS}

Cada um dos segmentos da e-PING contém um conjunto de políticas técnicas que norteia o estabelecimento das especificações dos seus componentes. Esses conjuntos específicos de cada segmento estão fundamentados nas seguintes políticas gerais (BRASIL, 2007a):

- Alinhamento com a INTERNET: todos os sistemas de informação da administração pública deverão estar alinhados com as principais especificações usadas na Internet e com a World Wide Web.

- Adoção do XML como padrão primário de intercâmbio de dados para todos os sistemas do setor público.

- Adoção de navegadores (browsers) como principal meio de acesso: todos os sistemas de informação de governo deverão ser acessíveis, preferencialmente, por 
meio de tecnologia baseada em browsers; outras interfaces são permitidas em situações específicas, como em rotinas de atualização e captação de dados onde não haja alternativa tecnológica disponível baseada em navegadores.

- Adoção de metadados para os recursos de informação do governo.

- Desenvolvimento e adoção de um Padrão de Metadados do Governo Eletrônico e-PMG, baseado em padrões internacionalmente aceitos (http://www.eping.e.gov.br).

- Desenvolvimento e manutenção da Lista de Assuntos do Governo: Taxonomia de Navegação (LAG), que contemple, numa estrutura de diretório, os assuntos relacionados com a atuação de governo (http://www.eping.e.gov.br).

- Suporte de mercado: todas as especificações contidas na e-PING contemplam soluções amplamente apoiadas pelo mercado. O objetivo a ser alcançado é a redução dos custos e dos riscos na concepção e produção de serviços nos sistemas de informações governamentais.

- Escalabilidade: as especificações selecionadas deverão ter a capacidade de atender alterações de demanda no sistema, tais como, mudanças em volumes de dados, quantidade de transações ou quantidade de usuários. Os padrões estabelecidos não poderão ser fator restritivo, devendo ser capazes de fundamentar o desenvolvimento de serviços que atendam desde necessidades mais localizadas, envolvendo pequenos volumes de transações e de usuários, até demandas de abrangência nacional, com tratamento de grande quantidade de informações e envolvimento de um elevado contingente de usuários.

- Transparência: os documentos da e-PING estarão à disposição da sociedade, via Internet, sendo previstos mecanismos de divulgação, recebimento e avaliação de sugestões. Nesse sentido, serão definidos - e divulgados para amplo conhecimento prazos e compromissos para implantação e gestão de sítio dedicado na Internet (http://www.eping.e.gov.br).

- Adoção preferencial de Padrões Abertos: a e-PING define que, sempre que possível, serão adotados padrões abertos nas especificações técnicas. Padrões proprietários são aceitos, de forma transitória, mantendo-se as perspectivas de 
substituição assim que houver condições de migração. Sem prejuízo dessas metas, serão respeitadas as situações em que haja necessidade de consideração de requisitos de segurança e integridade de informações. Quando disponíveis, soluções em Software Livre são consideradas preferenciais, conforme política definida pelo Comitê Executivo de Governo Eletrônico (CEGE).

- Garantia à privacidade de informação: todos os órgãos responsáveis pelo oferecimento de serviços de governo eletrônico devem garantir as condições de preservação da privacidade das informações do cidadão, empresas e órgãos de governo, respeitando e cumprindo a legislação que define as restrições de acesso e divulgação.

Além de se pautar nessas políticas gerais, todo o conteúdo do documento referência foi produzido em consonância com as diretrizes do Comitê Executivo de Governo Eletrônico (CEGE), criado pelo Decreto de 18 de outubro de 2000, e está publicado em uma página específica na internet (http://www.eping.e.gov.br), garantindo acesso público às informações de interesse geral e transparência à iniciativa (BRASIL, 2007).

\subsection{MODELO DE GESTÃO}

\subsubsection{Atribuições}

Segundo a versão 3.0 do documento de referência da e-PING, sua gestão compreende o desempenho de atribuições de ordem administrativa e de ordem técnica:

a) atribuições de caráter administrativo:

- Definir os objetivos estratégicos e de gestão de governo para o estabelecimento dos padrões;

- Administrar a arquitetura de interoperabilidade do governo brasileiro, provendo a infra-estrutura gerencial necessária para sua correta utilização e garantindo sua atualização, considerando: as prioridades e metas de governo, as necessidades da sociedade e a disponibilidade de novas tecnologias maduras e suportadas pelo mercado de TIC;

- Atuar como centro de coordenação da arquitetura e-PING, buscando alinhamento dos esforços de interoperabilidade, assegurando a coerência das iniciativas empreendidas pelos órgãos de governo; 
- Especificamente para os segmentos de Interoperabilidade, administrar o relacionamento do Poder Executivo do Governo Federal com as demais instâncias definidas no escopo de abrangência da arquitetura;

- Gerenciar e operacionalizar a divulgação dos padrões da e-PING, considerando:

o Criação e administração de um site na internet (http://www.eping.e.gov.br);

o Coordenação do processo de consultas públicas;

o Coordenação do processo de recebimento e avaliação de proposições de alteração e complementação;

o Coordenação do processo de solicitação de sugestões;

o Publicação das versões atualizadas e das atualizações intermediárias;

- Gerenciar a interação com iniciativas de mesmo propósito, conduzidas por outros governos, no país e no exterior;

- Incentivar a capacitação das equipes do governo federal, atuando em conjunto com os órgãos, tanto na consideração da e-PING nos planos específicos de treinamento de cada um deles como na realização de eventos corporativos direcionados para disseminação dos padrões;

- Estabelecer, implantar e divulgar indicadores de acompanhamento dos resultados obtidos com a implantação da e-PING;

- Gerenciar a interação com organismos de especificação (W3C, IEEE, BSI, OMG, OGC, OASIS, IETF, Institutos Normativos de segmentos específicos, como ABNT, INMETRO, ISO, NIST, etc.), sendo estes organismos escolhidos a critério da coordenação da e-PING levando em consideração o seu notório reconhecimento internacional, competência em sua área de atuação e o estabelecimento de padrões abertos.

- Gerenciar a interação com órgãos de fomento nacionais e internacionais, para canalizar recursos, visando atender as necessidades de criação de infra-estrutura da ePING e promover a pesquisa e desenvolvimento;

- Viabilizar a implantação e gerenciar o processo de homologação dos padrões a serem estabelecidos para o governo;

- Viabilizar a implantação e gerenciar processos de auditoria realizados com a finalidade de verificar o nível de adesão às recomendações e especificações da ePING; 
- Atuar cooperativamente, como apoio aos órgãos de governo, na realização dos processos necessários para adequação aos padrões e-PING; avaliar a possibilidade de patrocinar programas abrangentes que promovam a utilização intensiva dos padrões propostos.

b) atribuições de caráter técnico:

- Estabelecer as formas de elaboração e de manutenção das políticas e especificações técnicas que compõem a e-PING, considerando:

o Identificação, criação e gestão de grupos de trabalho específicos;

o Estabelecimento de convênios e definição de instituições de governo como responsáveis pelas políticas e especificações técnicas de componentes específicos dos segmentos de interoperabilidade;

o Identificação e implementação de formas alternativas de gerenciamento técnico dos assuntos contemplados na abrangência de atuação da e-PING;

- Coordenar o desenvolvimento e manutenção, no âmbito do Governo Federal - Poder Executivo, de:

o Padrão de Metadados de Governo (e-PMG);

o Lista de Assuntos do Governo: Taxonomia para Navegação (LAG);

o Catálogo de Padrões de Dados (CPD);

o Catálogo de Referência dos XML Schemas;

o Demais padrões de Organização e Intercâmbio de Informações;

o Padrões de Interconexão;

o Padrões de Segurança;

o Padrões de Meios de Acesso a serviços eletrônicos de governo;

o Padrões de uso de Cartões Inteligentes, Tokens e outros tipos de cartão;

- Garantir a unicidade de concepção, conceitos, definições e estabelecimento de padrões por parte dos responsáveis pelos segmentos técnicos definidos para a e-PING.

\subsubsection{Seleção e homologação dos padrões}

O processo de seleção dos padrões adotados pela e-PING e sua conseqüente classificação nos cinco níveis adotados (adotado, recomendado, em transição, em estudo e estudo futuro), é de responsabilidade dos grupos de trabalho compostos por profissionais especialistas com atuação no governo e em instituições com as quais seja estabelecido algum tipo de convênio ou contrato especificamente para essa finalidade. 
A seleção é feita a partir de sugestões formalizadas, demandas internas dos órgãos do governo federal e de pesquisas realizadas pelos grupos de trabalho ou indicação do grupo de coordenação.

Já a homologação é objeto de estudo mais aprofundado por parte dos coordenadores da ePING. Por conta do grande número de padrões tratados pela arquitetura, existe uma sistemática de homologação que contempla desde processos em que é necessária a avaliação de características físicas de determinados componentes (Smart Cards - Cartões Inteligentes, por exemplo) até outros em que exige o de estudo de aspectos que envolve o uso do componente no desenvolvimento e construção de serviços (organização e intercâmbio de informações e segurança, por exemplo).

Nesse caso, o governo pode estabelecer convênios ou credenciar instituições para elaboração de testes de conformidade, sempre definindo quais componentes devem ser submetidos a processos de homologação, quais os critérios de avaliação dos resultados e quais as condições de realização dos procedimentos.

A definição completa do processo de seleção e homologação, levando em consideração as especificidades dos segmentos, é de responsabilidade da coordenação da e-PING.

\subsubsection{Auditoria de conformidade}

Cabe a coordenação da e-PING a recomendarão a realização de processos de auditoria para verificação do atendimento às especificações e políticas da arquitetura. Em alguns casos, é possível delegar responsabilidades para equipes especialmente montadas para essa finalidade, compostas por técnicos de governo com experiência em procedimentos dessa natureza.

Mas, preferencialmente serão utilizadas as estruturas próprias nos órgãos responsáveis por auditoria de sistemas para a realização desses tipos de procedimentos. A coordenação da ePING atuará no sentido de sugerir os critérios básicos a serem seguidos pelos órgãos.

Existe ainda a possibilidade de colaboração de órgãos de governo atuantes na área, prevendose contatos com instituições de outros poderes e até mesmo outras esferas de governo. 


\subsection{PROCESSO DE CRIAÇÃO DA e-PING}

As atividades dos grupos de trabalho consistiram na execução de pesquisas sobre tecnologias de governo eletrônico e necessidades existentes, sugerindo princípios e critérios de seleção dos padrões, e classificando padrões específicos e especificações nas categorias apropriadas. Com base nesse trabalho e discussões internas, foi publicado o esboço da e-PING (versão 0), e submetido à consulta e audiências públicas. Sugestões e críticas foram recebidas de vários interessados (gestores e técnicos de TIC do governo, consultores, e representantes de fornecedores de serviços e produtos). Os grupos de trabalho discutiram e incorporaram as mudanças sugeridas e a versão atualizada do esboço foi discutida em reunião do grupo de coordenação para ajustes considerados necessários e, após aprovação, foi publicada e liberada a versão 1.0. O Quadro 12 apresenta uma síntese das atividades realizadas e seus respectivos executantes durante o processo de elaboração da especificação preliminar e da primeira versão do documento referência da e-PING.

\subsection{PROCESSO DE REVISÃO DA e-PING}

Além do cuidado de definir uma arquitetura de interoperabilidade inicial adequada à sua realidade, os governos enfrentam também o desafio de ter que revisá-la periodicamente. Alcançar a interoperabilidade é um processo interativo onde especificar, testar e implementar traz os subsídios para os melhoramentos do padrão. A maioria das arquiteturas de interoperabilidade governamentais existentes estipula um processo de revisão e atualização anual. Este processo de atualização é estabelecido para assegurar que os padrões e diretrizes incluídas na arquitetura permaneçam relevantes ao ambiente tecnológico em que ela está sendo adotada. O Quadro 13 apresenta as atividades e seus executores para o processo adotado como base para as atualizações da e-PING. 
Quadro 12 - Atividades e seus executantes para a elaboração da e-PING

\begin{tabular}{|c|c|}
\hline Atividade & Executante \\
\hline Criação do Grupo de Coordenação & SLTI \\
\hline Criação do plano de ação, cronograma e Grupos de Trabalho & Grupo de Coordenação \\
\hline $\begin{array}{l}\text { Revisão de documentos referência de padrões de outros } \\
\text { governos, das necessidades internas e da estratégia de governo } \\
\text { para TIC }\end{array}$ & Grupo de Coordenação \\
\hline Elaboração do esboço da estrutura da arquitetura & Grupo de Coordenação \\
\hline Esboço dos princípios, definições, metas e critérios de seleção. & Grupo de Coordenação e Grupos de Trabalho \\
\hline $\begin{array}{l}\text { Seleção dos padrões e especificações a serem adotados na } \\
\text { arquitetura }\end{array}$ & Grupos de Trabalho \\
\hline Análise dos padrões sugeridos pelos Grupos de Trabalho & Grupo de Coordenação \\
\hline $\begin{array}{l}\text { Liberação da versão } 0 \text { da arquitetura para submissão à } \\
\text { consulta e audiências públicas }\end{array}$ & Grupo de Coordenação \\
\hline Elaboração de consulta e audiências públicas & SLTI \\
\hline $\begin{array}{l}\text { Análise das contribuições apresentadas na consulta e } \\
\text { audiências públicas }\end{array}$ & Grupo de Coordenação e Grupos de Trabalho \\
\hline $\begin{array}{l}\text { Alteração do documento referência para incorporação das } \\
\text { contribuições apresentadas na consulta e audiências públicas } \\
\text { que foram acatadas; refinamento dos princípios e do conteúdo } \\
\text { do documento }\end{array}$ & Grupos de Trabalho \\
\hline $\begin{array}{l}\text { Aprovação das alterações e liberação da versão } 1.0 \text { do } \\
\text { documento referência }\end{array}$ & Grupo de Coordenação \\
\hline Aprovação do documento e liberação para uso público & SLTI \\
\hline
\end{tabular}


Quadro 13 - Atividades e seus executantes para as revisões da e-PING

\begin{tabular}{|c|c|}
\hline Atividade & Executante \\
\hline $\begin{array}{l}\text { Recebimento de demandas via mecanismos de consultas ou } \\
\text { por sugestão interna dos membros dos grupos }\end{array}$ & Grupo de Coordenação \\
\hline Monitoração e compilação das contribuições & Grupo de Coordenação \\
\hline $\begin{array}{l}\text { Consulta a documentos referências de arquiteturas de outros } \\
\text { governos e acompanhamento da agenda interna de governo } \\
\text { eletrônico }\end{array}$ & Grupo de Coordenação e Grupos de Trabalho \\
\hline Elaborar as listas de tópicos a serem revisados & Grupo de Coordenação e Grupos de Trabalho \\
\hline $\begin{array}{l}\text { Revisão das políticas em relação aos aspectos técnicos e } \\
\text { especificações }\end{array}$ & Grupos de Trabalho \\
\hline $\begin{array}{l}\text { Redação das versões intermediárias com as incorporações } \\
\text { realizadas para publicação }\end{array}$ & Grupos de Trabalho \\
\hline $\begin{array}{l}\text { Revisão das versões intermediárias com as incorporações } \\
\text { realizadas para publicação }\end{array}$ & Grupo de Coordenação \\
\hline Publicação das versões intermediárias & SLTI \\
\hline Execução de audiências e consultas públicas & SLTI \\
\hline $\begin{array}{l}\text { Avaliação das contribuições sugeridas nas audiências e } \\
\text { consultas públicas }\end{array}$ & Grupo de Coordenação \\
\hline $\begin{array}{l}\text { Elaboração do relatório com as respostas às contribuições } \\
\text { sugeridas nas audiências e consultas públicas }\end{array}$ & Grupo de Coordenação e Grupos de Trabalho \\
\hline $\begin{array}{l}\text { Incorporação das alterações aprovadas para inclusão na nova } \\
\text { versão do documento referência }\end{array}$ & Grupos de Trabalho \\
\hline $\begin{array}{l}\text { Revisão do relatório com as respostas às contribuições } \\
\text { sugeridas nas audiências e consultas públicas }\end{array}$ & Grupo de Coordenação \\
\hline $\begin{array}{l}\text { Revisão da nova versão do documento referência com as } \\
\text { contribuições sugeridas nas audiências e consultas públicas e } \\
\text { aprovadas para incorporação }\end{array}$ & Grupo de Coordenação \\
\hline $\begin{array}{l}\text { Publicação do relatório com as respostas às contribuições } \\
\text { sugeridas nas audiências e consultas públicas }\end{array}$ & SLTI \\
\hline $\begin{array}{l}\text { Publicação da nova versão do documento referência com as } \\
\text { contribuições sugeridas nas audiências e consultas públicas e } \\
\text { aprovadas para incorporação }\end{array}$ & SLTI \\
\hline
\end{tabular}




\section{CAPÍTULO 5 - ANÁLISE E DISCUSSÃO DOS DADOS}

Conforme já mencionado anteriormente, de acordo com Williams e outros (2004), os diferentes estágios do ciclo de vida de um padrão são estabelecidos em cenários sociotécnicos bastante diferentes. O lócus onde a padronização ocorre, os agentes envolvidos no processo, e seus atributos são diferentes em seus dois estágios: desenvolvimento e implementação.

Embora seja reconhecida claramente a existência desses estágios, identificar os limites de escopo das atividades desenvolvidas dentro do processo de padronização como um todo em relação a esses estágios não é uma tarefa fácil. Como é um processo contínuo, uma mesma atividade ora pode estar relacionada ao desenvolvimento do padrão, ora à implementação e, por vezes, aos dois estágios ao mesmo tempo.

É necessário também definir a abrangência desses estágios no processo. No caso específico dessa pesquisa, considera-se desenvolvimento a fase de discussão e especificação dos padrões que comporão a arquitetura, enquanto que a implementação corresponde a fase de publicação e avaliação do documento referência, e liberação da versão para adoção pelos interessados.

O processo de construção da arquitetura e-PING pode ser visto de uma forma simplificada como composto de três estágios, conforme figura abaixo.

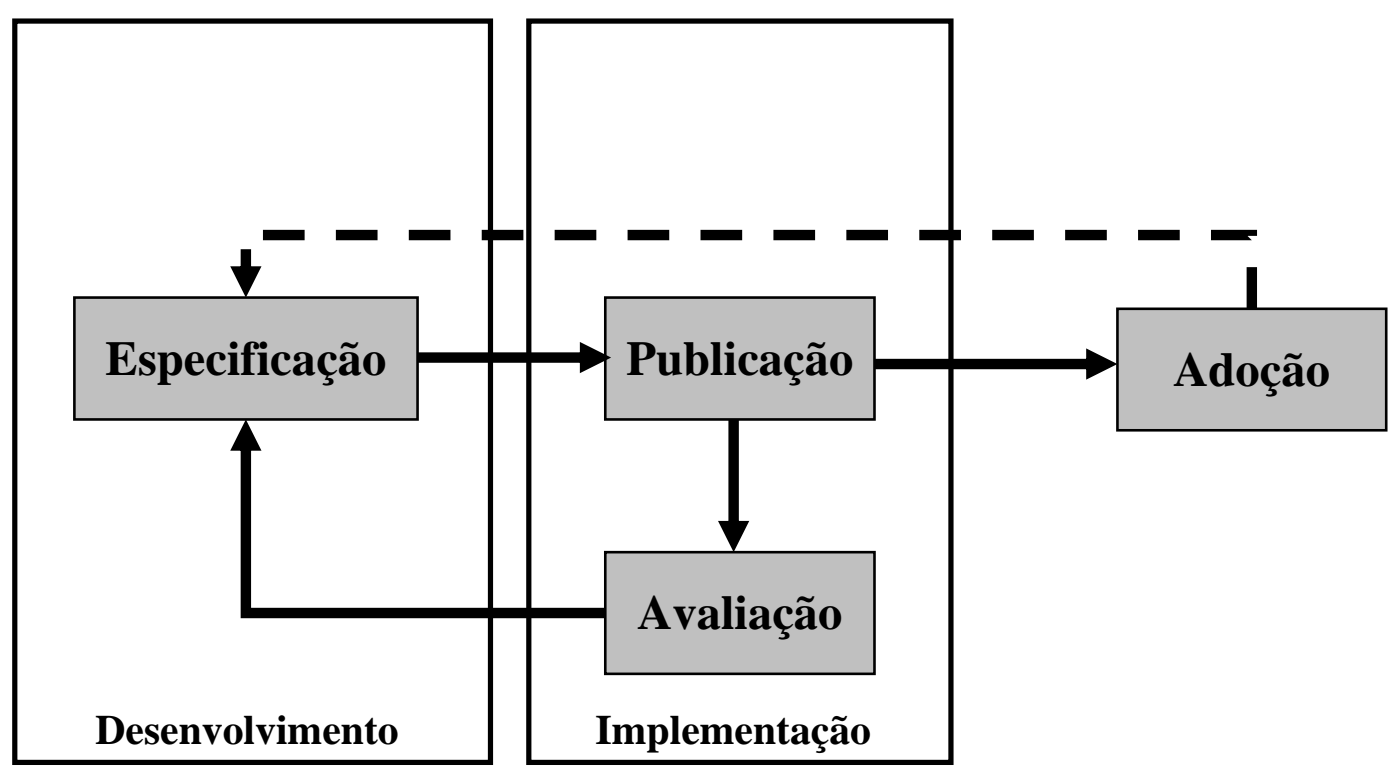

Figura 5 - Estágios do processo simplificado de construção da e-PING 
O desenvolvimento da e-PING ocorre num ambiente que, embora seja heterogêneo, pode ser considerado como fechado. Os grupos de trabalho são compostos de técnicos e gestores de TIC de vários órgãos do Governo Federal, que podem ser classificados como stakeholders apenas internos. Seus interesses na padronização, embora possam ser divergentes em algum momento em relação a determinado ponto de vista, representam idealizações e expectativas relativas apenas ao âmbito dos seus escopos de trabalho dentro do governo. A resolução de possíveis conflitos se dá através da discussão direta dos componentes do grupo com seu coordenador ou dentro do grupo de coordenação do projeto, onde a solução adotada é fruto de consenso decorrente dessas discussões.

A sua implementação, por sua vez, possui um ambiente mais heterogêneo e em parte aberto, onde ocorrem interações com outros agentes afetados pelo processo de padronização. As audiências e consultas públicas estabelecem uma interface com o público externo, tais como empresários, fornecedores, consultores e sociedade em geral. Nessa fase, os interesses na padronização tendem a serem mais divergentes pois refletem pontos de vistas baseados na obtenção de benefícios de ordem também pessoal dos interessados. Fabricantes e fornecedores, por exemplo, buscam influenciar na tomada de decisões do grupo de coordenação do projeto em relação a especificações dos padrões a serem homologados, tendo em vista a representatividade da participação do governo como consumidor no mercado de produtos e serviços de TICs. A resolução dos conflitos passa a ser através de uma estratégia de mediação, onde as sugestões e questionamentos submetidos são avaliados internamente pelos grupos de trabalho e pelo grupo de coordenação e posteriormente as respostas são divulgadas em documento específico na página da internet do projeto. A solução adotada nesse estágio, embora sofra certa influência externa, é decidida internamente e posteriormente comunicada.

Enquanto é fácil designar que todos os órgãos do governo obedeçam aos padrões especificados, não existe nenhuma garantia que essa exigência seja seguida. O escopo da arquitetura e o processo como ela foi estabelecida influencia na sua adesão. Mas, além disso, ter uma acreditação inicial ajuda a ter uma maior adesão futura.

Nesse sentido, as audiências e consultas públicas exercem um papel importante no processo de desenvolvimento da arquitetura. Elas são, na realidade, estratégias para promover a legitimação das decisões tomadas pela coordenação da e-PING. Ao efetuar as consultas e 
audiências, os interessados e/ou impactados pela padronização são chamados a opinar sobre as especificações definidas. Com isso, é dada a oportunidade de validação ou contestação dessas definições. A divulgação das versões dos documentos referência da arquitetura estabelece a condição de conhecimento do seu teor e das implicações decorrentes de sua aplicação. A possibilidade de participação dos interessados no processo, inclusive com a incorporação de suas sugestões e contribuições cria condições de estabelecer uma acreditação no padrão, conferindo-lhe uma percepção de relevância para potenciais adotantes. A legitimidade das decisões, nesse caso, baseia-se na participação coletiva dos membros dos grupos de trabalho, do grupo de coordenação e dos outros interessados que se manifestaram.

A execução dessas consultas e audiências públicas segue um processo de interação entre os grupos de trabalho, grupo de coordenação e interessados específico para cada um dos casos:

No caso das consultas... A pessoa se cadastra, o documento está todo divido em capítulos, ela escolhe onde quer contribuir e lança a contribuição dela. As pessoas podem fazer comentários em cima da contribuição dela, A gente lê as contribuições e os comentários, mas só responde as contribuições. Esse sistema está lá no site do governo eletrônico e ai os coordenadores têm um login e uma senha. Só os coordenadores dos grupos de trabalho, então são 5 e, normalmente, eu [o assessor técnico do projeto] e o Leandro [o coordenador geral do projeto na época da entrevista] a gente também tem uma senha. $\mathrm{E}$ antes de responder tem o processo de publicação da contribuição. Não é nenhuma censura, é um critério. A única restrição é se o cara colocar algum xingamento, alguma coisa que não tenha nada a ver com a consulta, aí a gente não publica. [...] Quando tem uma contribuição, a gente tem um botão publicar e não publicar. Quando você coloca o publicar fica disponível para todo mundo ler. O não publicar não vai aparecer. Só que o não publicar a gente é obrigado a dar uma resposta do porquê. Os coordenadores podem publicar ou não, mas essa parte fica mais aqui a critério meu e do Leandro. A gente deixa a parte dos coordenadores para responder as contribuições. Mas eles poderiam entrar ali publicar ou não. Todo mundo que tem acesso a senha tem acesso a essa funcionalidade. Ai o programa vai listar pra você todas as contribuições feitas. Você só consegue responder as contribuições quando acaba a consulta. Ai pra adiantar o trabalho a gente pede que os coordenadores vão entrando, olhando as contribuições e respondendo em um documento texto ... perguntas e respostas. A gente marca sempre logo depois que fecha a consulta pública uma reunião da coordenação coisa de uma semana depois, para discutir alguma contribuição que o grupo ficou em dúvida... Nesse meio período, as vezes vem uma contribuição pro GT1, mas que não tem nada a ver, que era pro GT2, então a gente já vai fazendo esse trabalho de divisão, de reencaminhar as contribuições através de aviso aos coordenadores. Aí fechamos tudo e damos um prazo para os coordenadores fechar tudo e nos encaminhar todas as respostas. Cada coordenador poderia, sem problema nenhum, responder diretamente no site. Só que pra poder padronizar a gente até encaminha pra ele uma sugestão. Tipo na resposta vamos fazer assim. Mas, pra facilitar o trabalho dos coordenadores, eles me enviam e eu publico tudo. [...] Só que ai depois de publicar, eu organizo em texto e disponibilizo em PDF no site tanto no site da e-PING, quanto no portal governo. Isso fica funcionando como histórico também.

Audiência pública... Como a gente faz? É presencial. O cara vai lá se inscreve e faz a contribuição dele. O bom da audiência é que já estão lá todos os coordenadores e já respondem ali na hora. Se for alguma pergunta cabeluda a gente diz que vai discutir com o resto do GT e depois te dá uma resposta. Pra facilitar o trabalho dos coordenadores, dos GTs e da coordenação do e-PING, o que a gente fez o ano passado... A gente recebia a pergunta e tentava responder, e pedia para todo mundo, a fim de tornar a coisa mais pública, que eles entrassem na consulta e publicasse a mesma pergunta. Por dois motivos: primeiro pra tornar pública e as pessoas poderem contribuir em baixo e segundo, para ficar mais fácil a resposta. Pra tentar não perder a informação e pra tentar fazer a 
resposta mais clara possível a gente pede que vocês entrem no site e publiquem. É até mais um ponto positivo para a gente tentar movimentar a consulta. [...] o ano passado a gente fez dois meses. O primeiro mês foi meio parado. O segundo mês, nas duas últimas semanas, chegaram várias perguntas. Mas esse mês meio parado a gente teve as audiências. E ai foi movimentando um pouco o site da consulta, porque as pessoas que participavam da audiência ia entrando e publicando. Então tem esses dois mecanismos: a gente tenta responder na hora e responde depois de novo na consulta.

Baseado nas diretrizes adotadas como políticas gerais, no item transparência, todo o processo de consultas públicas é documentado no portal do projeto (www.eping.e.gov.br), inclusive o relatório contendo todas as perguntas e respostas para cada consulta. No relatório da consulta de 2007 ao final de cada pergunta consta o nome, data e hora da submissão, e após a resposta, existe uma indicação se a esta foi dada pelo grupo de coordenação ou pelo coordenador do grupo de trabalho ao qual a questão submetida está relacionada, de acordo com os segmentos estabelecidos na arquitetura. Uma informação ausente, e relativamente importante, é a filiação do autor da submissão - alguma indicação se este representa alguma empresa ou organização, por exemplo.

Embora o projeto seja conduzido pela SLTI, SERPRO e ITI, a portaria normativa que institucionalizou a e-PING especifica a SLTI como coordenadora executiva das atividades de implantação, manutenção e disseminação da arquitetura. Tal posição lhe dá a competência para aprovar as políticas, as diretrizes e as especificações que a compõem, e supervisionar técnica e normativamente os órgãos na sua aplicação, entre outras incumbências (BRASIL, 2005). Essa condição dá um destaque maior da SLTI dentro do projeto em relação aos outros órgãos coordenadores, o que pode proporcionar na sua percepção pelos interessados na padronização como um agente de maior nível de poder de decisão dentro do processo.

A participação da SLTI no grupo de coordenação também é bastante expressiva. O coordenador geral tem sido um funcionário desta secretaria desde o início do projeto e a maioria dos membros do grupo é pertencente ao seu quadro. Na ocasião dos trabalhos para lançamento da versão 3.0 do padrão, dos 30 componentes, 9 eram da SLTI, ou seja, 30\% do total. Os outros participantes eram: 5 do SERPRO, 3 do ITI, 3 da DATAPREV, 3 do Ministério da Saúde, 2 da ABEP, 1 do Banco do Brasil, 1 da Caixa Econômica Federal, 1 do Ministério da Justiça, 1 do Ministério das Relações Exteriores e 1 da Presidência da República 9 .

\footnotetext{
${ }^{9}$ Veja relação completa dos membros do grupo de coordenação e também dos grupos de trabalho no Anexo F
} 
Por outro lado, a manutenção dos sistemas estruturadores do Governo Federal é feita pelo SERPRO. Com isso, ele torna-se o maior impactado pelo estabelecimento da arquitetura o que, em uma análise inicial, poderia ser indicador de prováveis pontos de tensão. No entanto, a legitimação dada pela portaria normativa em relação ao papel da SLTI de coordenação executiva do projeto termina se sobrepondo à questão dos reflexos da adoção dos padrões.

Outro ponto que colabora para a atenuação do surgimento de conflitos é o fato que a coordenação da e-PING tem adotado em grande parte padrões de facto para compor a arquitetura (tais como XML e Webservices, por exemplo), o que pode levar os gestores a serem mais propensos a adotá-la.

Dados da $1^{\text {a }}$. pesquisa diagnóstico de adoção da e-PING promovida pela coordenação do projeto demonstraram que mais de $58 \%$ dos sistemas de informações em uso estavam alinhados com as principais especificações usadas na internet e com os padrões para Web. Cerca de 44\% dos pesquisados já adotavam o XML como padrão de intercâmbio de dados e mais de $82 \%$ adotavam navegadores (browsers) como principal meio de acesso, sendo que destes, aproximadamente 78\% empregavam um padrão mínimo de navegador para poder operar em múltiplas plataformas. Esses níveis de adoção desses padrões sugerem a possibilidade de um alto nível de aderência a e-PING, visto que existe um relativo baixo nível de incompatibilidade das tecnologias já implementadas pelos órgãos com as especificações definidas na arquitetura.

Por um lado, ao definir o uso de padrões de mercado, valendo-se do mecanismo de isomorfismo mimético, a coordenação do projeto reduz incertezas e legitima as suas decisões. Entretanto, essas opções podem fazer alguns potenciais adotantes se desinteressar pela arquitetura como um todo, caso considerem esse fato como uma forma de redução da relevância das suas especificações, mesmo reconhecendo sua legitimidade.

Definir no documento referência um escalonamento do escopo para adesão à arquitetura também se revela uma estratégia de certa forma eficiente de quebrar resistências e superar alguns obstáculos mais imediatos. As barreiras para adoção são reduzidas pelo fato de esta poder ser efetuada gradualmente, e não de uma única vez, conforme o documento referência estabelece: "A adesão ocorrerá de maneira gradativa, de acordo com plano de implementação, 
que considerará a situação de cada uma dessas instituições em relação à possibilidade de se adequar às especificações e recomendações da e-PING" (BRASIL, 2007a, p. 8).

Os membros dos grupos de trabalho são funcionários prioritariamente do Governo Federal ${ }^{10}$ (existem membros da Companhia de Processamento de Dados do Estado do Paraná CELEPAR, como exemplo de exceção), indicados pelos seus órgãos de origem em resposta às solicitações por ofício feitas pela SLTI. São pré-requisitos para a participação nos GTs que os funcionários sejam efetivos (concursados) e sejam gestores ou técnicos de TI. De acordo com a coordenação da e-PING:

[...] todo início de ano, a gente pega a lista de todos os servidores, a gente coloca esse critério, a pessoa tem que ser servidor público para participar. Lógico, sociedade, empresas, terceirizados podem participar, mas em momentos específicos, nas audiências públicas, nas consultas públicas, enviando e-mails e aí a gente considera todas as sugestões na mesa, sem problema algum. Agora no trabalho mesmo dos grupos, foi uma recomendação do secretário que só participassem servidores públicos. Aí isso nos da uma dificuldade maior, porque as coordenações de TI dos ministérios tem muita gente terceirizada.

Como já mencionado, os integrantes dos grupos participam do processo por conta das indicações de seus órgãos de origem. Em termos práticos, embora esse técnicos estejam representando suas instituições no processo de especificação dos padrões, suas manifestações e decisões refletem bem mais suas concepções pessoais sobre as tecnologias em questão do que o posicionamento das suas organizações. Segundo a coordenação da e-PING, alguns deles até argumentam defendendo um posicionamento mais específico de seu órgão, mas na maior parte das vezes, os membros dos grupos é que levam os resultados das discussões para serem conhecidas na organização. Embora existam atas das reuniões, com registros das discussões e decisões, as definições são consideradas como fruto de consenso e, consequentemente, não são associadas formalmente nem aos técnicos nem aos órgãos os quais eles representam.

Os membros dos GTs e do GC não possuem dedicação exclusiva, e dividem seu tempo alocado ao projeto com suas atividades do dia-a-dia nos seus órgãos de origem. Essa forma de dedicação parcial termina provocando uma grande variação do número de participantes nos grupos, com uma significativa evasão por conta, principalmente, do surgimento de outras atividades e/ou projetos considerados mais prioritários dentro do órgão ao qual o técnico está

\footnotetext{
${ }^{10}$ Veja relação completa dos membros dos grupos de trabalho e de coordenação com suas respectivas vinculações institucionais no Anexo F.
} 
vinculado. Isso é evidenciado pelo seguinte relato do Assessor Técnico da coordenação da ePING:

Todo começo de ano, a gente encaminha um ofício para todos os ministérios e para outros órgãos que já vinham participando. E nesse ofício a gente pede, por exemplo, Ministério da Fazenda, “encaminhe este ofício para todos os seus órgãos vinculados" aí ele manda. Lógico, B(anco do) B(rasil), Caixa (Econômica Federal), SERPRO, estes órgãos principais a gente já manda direto. E aí a gente coloca todos os critérios: que tem que ser servidor público, que tem que ter a dedicação de tantas horas por mês, que tem que participar de pelo menos uma reunião por mês.

[...]

Mas o problema é assim: no começo do ano está todo mundo animado. A gente recebe a indicação de 200 pessoas. Chega no final do ano tem, sei lá, 50 pessoas, normalmente, ficam em torno de 60 pessoas trabalhando.

$[\ldots]$

Para compor o grupo de coordenação, o procedimento é o mesmo. A gente faz um ofício e envia para os ministérios e pede para os órgãos indicar representantes para a coordenação e para cada um dos GTs. A gente explica direitinho que a coordenação já é um nível mais decisório, tem que ter a parte técnica, lógico porque a gente discute as especificações na coordenação também. Mas, é mais no nível decisório, então o perfil já muda um pouco. Enquanto que no GT o cara tem que ser técnico, na coordenação é mais gerencial. Mas, acaba que quem indica, indica só para um GT ou só para a coordenação, ai fica em aberto. A gente pede para indicar para todos... nunca sobra disponibilidade ai fica essa variação.

Também não existe nenhuma forma de incentivo para participação dos técnicos nos grupos. É apenas mais uma atividade de trabalho que é alocada dentro das suas agendas do dia a dia por conta de determinação superior. Em algumas poucas exceções, existe participação voluntária, desde que o solicitante preencha os requisitos estabelecidos.

Dentro dos grupos de trabalho e do grupo de coordenação não existem níveis hierárquicos definidos. Existem apenas membros e um deles faz o papel de coordenador, sendo a escolha deste feita por votação entre os próprios componentes do grupo.

O processo de formação e manutenção dos grupos pode ser entendido como evidência de um baixo nível de priorização do projeto dentro dos programas do governo. Um projeto considerado de grande impacto na reestruturação do ambiente de TICs e, consequentemente, de governo eletrônico, precisaria de uma atenção maior em relação à definição de prioridades. Por conta da rotatividade de pessoal, o andamento do processo sofre variações de produtividade. Os novos membros têm que se interar do que já foi discutido e em que ponto as discussões estão, e isso leva tempo. E mesmo com a coordenação do projeto mantendo um portal com todos os documentos gerados, inclusive as atas das reuniões realizadas, só o acesso a essas informações não permite um enquadramento imediato dos novos membros no 
processo. Por isso, a coordenação tem utilizado seminários internos para reduzir esse tempo de alinhamento, conforme pode ser confirmado nesse depoimento:

Esse ano nós fizemos assim: como tinham muitos servidores que não vinham participando da ePING, a gente fez um seminário de nivelamento que ai todos os coordenadores dos grupos se apresentaram, que as pessoas não conheciam. Eles fizeram uma apresentação de quais trabalhos estavam sendo desenvolvidos, quais eram os objetivos daquele ano, quais os pontos que eles pretendiam desenvolver, aprofundar.

Outro aspecto a ser considerado como resultado da rotatividade dos membros dos grupos é que, durante o tempo de alinhamento dos novos participantes, as decisões tomadas tendem a serem mais concentradas no ponto de vista dos membros remanescentes, mais antigos. E esse deslocamento temporário do núcleo de decisão pode implicar em vieses que não necessariamente seria o melhor caminho para a definição de determinados padrões.

Ao optar por um modelo de gestão inclusivo, possibilitando a participação de todos os interessados através de consulta e audiências públicas a coordenação da e-PING, por um lado, consegue obter, como já mencionado anteriormente, um endosso da legitimidade de suas ações. Mas, por outro lado, essa participação também acarreta o surgimento de alguns obstáculos para o andamento mais fluido do projeto. Fornecedores de produtos e serviços ou representantes da indústria de TICs, e comunidades e grupos de discussão, por exemplo, têm questionado algumas vezes de forma incisiva o posicionamento do grupo de coordenação sobre determinados padrões inclusos na arquitetura. Algumas discussões sobre os critérios e o processo de seleção e classificação dos padrões têm se arrastado ao longo de todas as consultas e audiências públicas realizadas.

Esses embates se intensificam por conta do compromisso da coordenação em responder a todos os questionamentos que, em alguns casos, se repetem nas consultas seguintes, mesmo tendo sido respondidas anteriormente. Outras são de cunho apenas ideológico, não tendo nenhum suporte racional em torno da discussão da adequação da tecnologia em questão, como algumas relacionadas à adoção de software livre X proprietário. Como exemplo, seguem trechos do relatório "Respostas aos questionamentos encaminhados à Consulta Pública 2007", publicado pela coordenação da e-PING no site do projeto. 
Retirar a limitação imposta aos padrões proprietários como Transitórios, bem como a referência a soluções de Software Livre

Justificativa: No Documento de Referência da e-PING V 2.9 é declarada a preferência por padrões abertos, em detrimento dos padrões proprietários, bem como a preferência por soluções de Software Livre. A adequabilidade de sua inclusão na especificação da arquitetura e-PING merece uma avaliação cuidadosa.

Aparentemente, essa política trata como disjuntos os padrões abertos e os padrões proprietários, mas existem padrões que são ao mesmo tempo abertos e proprietários. O conceito de padrão aberto pode se fundamentar em princípios jurídicos, comerciais ou eminentemente técnicos, e uma definição consensual desse conceito é improvável de se conseguir, pelo menos em um futuro próximo. Supostamente, esse conceito foi evocado dentre as políticas gerais na e-PING para conduzir à construção de certas características técnicas nos padrões a serem adotados. Em vez de sustentar a especificação dos padrões da e-PING em um conceito difuso como o dos padrões abertos, pode ser mais apropriado explicitar as características técnicas desejadas para que um padrão seja adotado. Quanto à preferência por soluções de Software Livre, ela poderia ser retirada da e-PING, pois está fora de contexto: a e-PING trata da especificação de padrões para interoperabilidade, e definitivamente não trata e não deve tratar da especificação dos aplicativos que irão interagir com base nesses padrões. Qualquer manifestação de preferência ou indução ao uso de aplicativos com quaisquer características específicas contraria o princípio que tem motivado o desenvolvimento dos padrões para interoperabilidade expressos na e-PING.

A inclusão da preferência de uso de aplicativos de código livre na especificação do protocolo de interoperabilidade da e-PING suscita uma discussão que está fora do contexto desse protocolo, e pode induzir à vinculação da Referência e-PING e sua utilização a políticas de adoção de aplicativos para uso interno nos órgãos do governo federal, o que pode implicar em atrasos desnecessários na implantação ampla e efetiva da arquitetura e-PING.

Considerando que o objetivo da e-PING é a interoperabilidade, essa diretriz parece mais adequada. Alem do mais, a referência a produtos ou soluções específicas são itens que deveriam estar presentes somente como parte do projeto de implementação, pois já aponta para questões de natureza comercial. Essas preocupações deveriam ser parte somente dos itens que envolvem o processo de desenvolvimento da solução e nunca na política de interoperabilidade. Portanto, tais referências deveriam ser retiradas da e-PING.

Responsável: Raimundo Nonato da Costa

Enviada em: 15/11/2007 17:24

\section{RESPOSTA:}

Caro Senhor Raimundo,

Obrigado por contribuir no processo de aperfeiçoamento da versão 2.9 do documento de referência da e-PING.

Em resposta à sua proposta de retirada da limitação imposta aos padrões proprietários no documento de referência, reiteramos nossa compreensão de que a atual redação, alinhada às políticas gerais de todos os governos que têm trabalhado o tema da interoperabilidade, apresentase como aspecto estratégico para a defesa do interesse público. Afinal, os riscos em estabelecer dependência de fornecedor exclusivo em temas tão críticos para a gestão pública e sociedade, quanto aos sistemas de informação, são conhecidos e documentados.

Relevante destacar que os aspectos contidos em seu comentário em relação às dificuldades de estabelecer definição consensual e "perfeita” do que sejam padrões abertos são pertinentes e neste sentido buscaremos aperfeiçoar as referências ao termo em versões futuras.

Quanto à escolha preferencial de soluções em Software Livre, isto ocorre em função das diretrizes, dos objetivos e das ações prioritárias do governo federal no Planejamento Estratégico produzido pelo Comitê Técnico de Implementação de Software Livre.

Lembramos também que a e-PING não faz “(...) qualquer manifestação de preferência ou indução ao uso de aplicativos com quaisquer características específicas (...)” já que a arquitetura e-PING faz referência a padrões e não a produtos ou fabricantes. Desta forma, qualquer produtor ou fabricante que trabalhe com os componentes indicados no documento de referência da e-PING poderá participar de qualquer processo de compra e contratações do governo federal, Poder 
Executivo, direcionado para o desenvolvimento de serviços de governo eletrônico e para atualizações de sistemas legados, conforme recomendações da e-PING.

Atenciosamente,

Coordenação da e-PING

Respostas Relativas ao GT - Meios de Acesso

01) CONTRIBUIÇÃO:

Gostaria de reforçar a sugestão do colega Daniel Fernandes (SERPRO/TIFLA) que sugeriu a promoção do formato ODF para o status de Adotado.

Justificativa: O impacto desta medida não seria impedimento a meu ver, uma vez que grande parte dos documentos produzidos no governo hoje não está no formato Adotado, muito menos em formato Recomendado, e sim no formato MicroSoft Office que tem status Transitório.

Responsável: Emmanuel Nazareno de Lima Ferro

Enviada em: 13/11/2007 17:47

RESPOSTA:

Caro Senhor Emmanuel,

Obrigado por contribuir no processo de aperfeiçoamento da versão 2.9 do documento de referência da e-PING.

Quanto ao seu questionamento, consideramos prematura a homologação do ODF como um formato adotado neste momento. O formato ODF contribui efetivamente para a interoperabilidade entre sistemas e atende às políticas gerais da e-PING, especialmente no que diz respeito à adoção preferencial de padrões abertos. Entendemos, entretanto, que o impacto de sua adoção é considerável, justamente devido à prevalência de outros formatos proprietários, devendo ser objeto de estudo cuidadoso. Reconhecemos as vantagens oferecidas pelo formato ODF e continuaremos avaliando a possibilidade de sua homologação futura.

Atenciosamente,

Coordenador do GT3 da e-PING

2) CONTRIBUIÇÃO:

Reforço minha fala durante a consulta pública realizada no SERPRO, em 3/11/2007, para que os formatos ODF (Open Document Format odt, ods, odp e odb) sejam classificados como "Adotado (A)".

Justificativa: Os formatos ODF são padrões ISO/IEC 26300 (padrão aberto, conforme orientação da e-PING) e são utilizados por uma boa gama de aplicativos de escritórios livres, entre os quais se destacam o OpenOffice.org/BrOffice.org. Além disso, por possibilitarem formatações complexas, são claramente mais adequados que os formatos "texto puro", atualmente classificados como "Adotado". Essa classificação seria ainda uma forma de incentivar ainda mais o uso de software livre pelos órgãos de governo.

Responsável: Daniel Lima Fernandes

Enviada em: 14/11/2007 19:39

\section{RESPOSTA:}

Caro Senhor Daniel,

Obrigado por contribuir no processo de aperfeiçoamento da versão 2.9 do documento de referência da e-PING. 
Quanto ao seu questionamento, consideramos prematura a homologação do ODF como um formato adotado neste momento. O formato ODF contribui efetivamente para a interoperabilidade entre sistemas e atende às políticas gerais da e-PING, especialmente no que diz respeito à adoção preferencial de padrões abertos. Entendemos, entretanto. que o impacto de sua adoção é considerável, devido à prevalência de outros formatos proprietários, devendo ser objeto de estudo cuidadoso. Reconhecemos as vantagens oferecidas pelo formato ODF e continuaremos avaliando a possibilidade de sua homologação futura.

Como o foco da e-PING é a interoperabilidade, julgamos absolutamente justificada a adoção dos formatos de "texto puro". Documentos nesses formatos podem ser manipulados por todos os aplicativos de escritório e em quaisquer sistemas operacionais. Aplicações desenvolvidas pelos diversos órgãos de governo podem implementar facilmente a leitura e geração desses documentos. Entendemos que documentos em "texto puro" não competem com os formatos "ricos" (como o ODF e outros) e devem ser preferíveis sempre que suas limitações não sejam um impedimento importante.

Atenciosamente,

Coordenador do GT3 da e-PING

Uma das particularidades da e-PING é que, embora seja especificada como compulsória, a portaria normativa que instituiu sua obrigatoriedade não indica nenhuma forma de sanção para o seu não cumprimento.

Segundo a coordenação da e-PING, embora exista a definição de mandatoriedade na portaria, a idéia é de orientação para o uso e não de punição. Além disso, existem alguns mecanismos que estão sendo implementados de forma a auxiliar o monitoramento da aderência ao padrão, como visto a seguir.

A gente não pode falar assim, usa a e-PING, se não a gente vai cortar seus recursos. Só fala que tem que seguir. Agora e se não seguir, o que vai acontecer? Não fala. Então com a CGU (Controladoria Geral da União) e o TCU (Tribunal de Contas da União) começando a cobrar, começando a observar o que é e-PING, a tendência é... Uma coisa é o TCU chegar para um órgão, “oh, por que você não”... "justifique aqui” “quem foi o gestor dessa compra? Por que não seguiu o que estava na e-PING?”. O cara vai prestar mais atenção nos outros editais.

$[\ldots]$

É o que também está no texto da e-PING. A adoção não é imediata, ela é gradativa. A gente não quer que o órgão chegue e jogue tudo fora e compre tudo novo. Não, a medida que for comprando ou adicionando novas coisas ao sistema, ele já tem que está observando a e-PING

[...]

Tem aquela idéia que, em princípio seria mais educativa do que punitiva, que é essa conversa que a gente está tendo com a CGU. A CGU agora tem uma equipe interna especializada em TI. Tivemos algumas conversas com ele para nas vistorias colocarem algumas questões básicas sobre a e-PING. Questões básicas para fazer um levantamento, tipo usa "isso" usa "aquilo". Agente ainda está tentando bolar as questões, mas seriam questões mais amplas. Talvez a daqui a vários anos a gente possa chegar a um nível maior de detalhamento.

Para dar suporte a essa regulamentação, poderia ser interessante o governo adotar uma abordagem baseada em incentivos para a adesão à arquitetura. A versão mais comum desta 
abordagem é associar a adesão com o a gestão dos orçamentos: somente projetos de governo eletrônico em conformidade com os padrões recebem dotação orçamentária e financiamentos.

Uma variação desse mecanismo é a criação de um fundo central para governo eletrônico que completa ou aumenta recursos de um órgão para projetos de TICs. Desde que esse procedimento ainda permite que projetos sem conformidade sejam financiados, ele pode ser visto pelos órgãos como uma abordagem menos arbitrária para a adesão aos padrões.

Mas isto só é particularmente efetivo se todos os projetos de TICs forem gerenciados centralmente e se o órgão líder do projeto tiver real controle sobre a destinação do orçamento e do uso e desembolso dos fundos de financiamento, o que não é o caso do governo federal brasileiro, conforme declarado pela coordenação da e-PING:

O orçamento de TI não é centralizado. Cada ministro deve brigar pelos seus recursos. O MP [Ministério do Planejamento] influi no orçamento dos órgãos, contudo indiretamente, já que a Secretaria é órgão central do SISP - Sistema de Administração dos Recursos de Informação e Informática. Conforme competência da Secretaria:

"À Secretaria de Logística e Tecnologia da Informação compete planejar, coordenar, supervisionar e orientar normativamente as atividades do SISP e do SISG, bem como propor políticas e diretrizes a eles relativas, no âmbito da administração federal direta, autárquica e fundacional".

Essa situação onde não há mecanismos de auditorias nem de sanções definidos, possibilita que surjam dois tipos de situações que implicam diretamente na efetividade da adoção dos padrões. Como não existem mecanismos de auditoria, alguns órgãos podem simplesmente afirmar que adotaram a arquitetura, quando na realidade não o fizeram. Outros, valendo-se da inexistência de sanções, poderão decidir por não seguir as especificações, pois não há punições formais resultantes dessa opção.

$\mathrm{Na} 1^{\mathrm{a}}$ pesquisa realizada pela coordenação do projeto para diagnóstico da disseminação da ePING, mais de $82 \%$ dos gestores declararam que conheciam as especificações da arquitetura e cerca de 53\% afirmaram já tê-la adotado ao menos parcialmente. Mas apenas pouco mais de $2 \%$ não tiveram nenhuma dificuldade em adotar os padrões, enquanto o resto enfrentou algum tipo de restrição. Mais de 33\% tiveram limitações de recursos técnicos ou de qualificação profissional para implementar as especificações e cerca de $28 \%$ afirmaram não ter conhecimento do que está sendo realizado nos demais órgãos. Aproximadamente 17\% possuem dificuldades com relação ao tempo para implementação de projetos mais de $12 \%$ declararam não conhecer a arquitetura. Esses resultados apontam barreiras para a efetiva 
adoção dos padrões, visto que os órgãos não dispõem de recursos para implementar a arquitetura e, principalmente, gerir as mudanças decorrentes do processo.

Embora tenha sido mencionado na pesquisa por alguns respondentes o desconhecimento sobre o assunto e também a falta de qualificação do pessoal para a implantação dos projetos em conformidade com os padrões, não existe nenhum plano de ação formal especificado pela coordenação do projeto para alterar esse quadro de forma mais abrangente. Vale salientar, no entanto, que o documento referência especifica que será feita capacitação dos gestores de TICs sobre o padrão.

É imprescindível empreender esforços para disseminar informação como também treinar o pessoal sobre a arquitetura e os padrões que ela define. Isso permite assegurar que a interoperabilidade aconteça tanto no nível estratégico como no prático.

Não efetuar os investimentos necessários em desenvolvimento de capacidade em gestão, e em sistemas e serviços de aquisição, como também em habilidades de TICs que são requeridas para uma efetiva implementação de serviços de governo eletrônico baseados no padrão trazem um grande risco de fracasso da arquitetura.

Em relação aos esforços para disseminar a informação sobre a e-PING, um ponto que se pode destacar do projeto tem sido sua estratégia de publicação e discussão. Desde o seu início até o lançamento da versão 3.0, foram feitas 39 apresentações nacionais e internacionais em seminários, workshops e conferências ${ }^{11}$. Isso trouxe visibilidade ao projeto, tornando possível um alto nível de conhecimento sobre suas diretrizes não só para os gestores públicos, mas também para a sociedade em geral. No entanto, essas ações parecem não estar sendo efetivas, tendo em vista o que tem sido apurado nas pesquisas. A segunda pesquisa apontou, por exemplo, redução no percentual de respondentes que afirmaram que a organização na qual trabalhavam usava os padrões e também redução do número de respondentes que conheciam as políticas de especificações técnicas da e-PING. Questionada sobre o assunto, a coordenação do projeto respondeu:

A gente sabe que a amostra que a gente pegou é significativa, contudo, não é exatamente a mesma amostra da pesquisa do ano anterior. Então a gente sabe que nas pessoas pesquisadas teve essa redução, agora a gente não sabe o porquê. Podem ser vários motivos. Como a gente estava pesquisando gestores dos vários ministérios e tem uma movimentação grande desses

\footnotetext{
${ }^{11}$ Para saber as datas e eventos onde ocorreram as apresentações consulte o Anexo E - Histórico da e-PING
} 
coordenadores [...] do ano passado pra cá vários órgãos trocaram os coordenadores. Então pode ter acontecido desde tenha chegado coordenador novo e nunca tenha ouvido falar de e-PING...

Sobre a redução de pessoas que conhecem as políticas de especificações técnicas da e-PING: aqui também pode ter acontecido a mesma coisa com "trabalha ou não com e-PING". Chegou um coordenador de informática novo não conhece e-PING e não tem a menor idéia se o órgão dele trabalha com e-PING ou não. A gente não pode desmerecer a pesquisa, mas também a gente não pode afirmar com certeza a causa dessa variação.

Ainda em relação à disseminação de informações, existe uma outra iniciativa do governo que, através do site de governo eletrônico, disponibilizou um fórum para discussão de tópicos relativos a e-PING (https://www.governoeletronico.gov.br/forum/e-ping-padroes-deinteroperabilidade-de-governo-eletronico/). No entanto, em um acesso em 25/01/2008, consta que a última atualização na página de acesso foi feita em 24/07/2007 e que não há nenhuma discussão cadastrada (Figura 6).

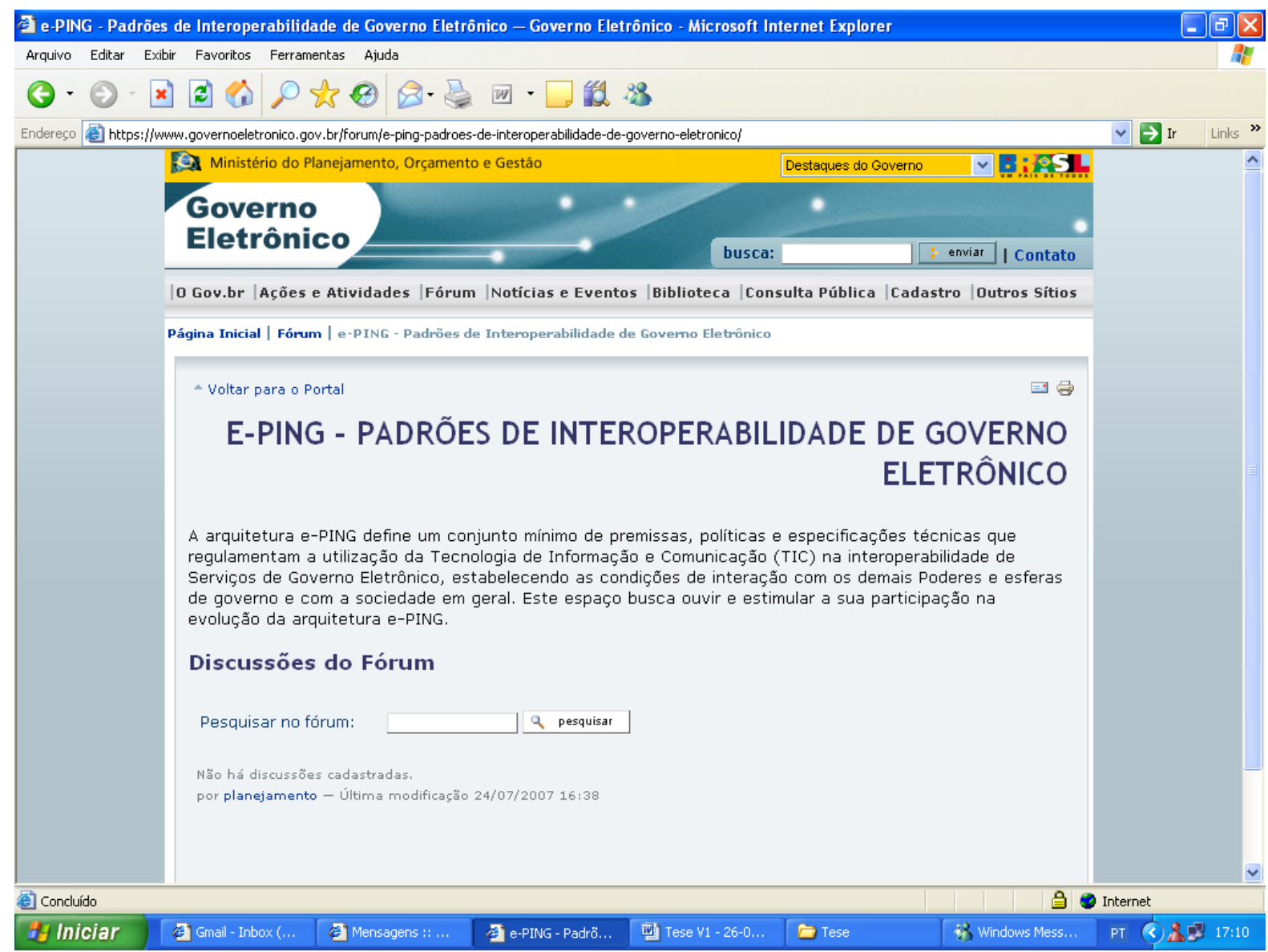

Figura 6 - Tela de acesso ao fórum de discussão da e-PING

Dos 193 padrões especificados na versão 3.0 da e-PING, apenas 31 estão definidos como adotados (A), ou seja, 15,82 \%, e 96 estão classificados como recomendados (R), o que corresponde a 49,74 \% do total. Isso significa que embora o projeto já esteja sendo conduzido 
por quase quatro anos (janeiro de 2004 a dezembro de 2007), o nível de padrões definidos como adotados ainda pode ser considerado relativamente baixo. Essa situação pode ser considerada pelos gestores de TIC como um fator inibidor, visto que apenas uma pequena parte dos padrões especificados está formalmente homologada.

Para a coordenação da e-PING essa situação é resultado do contexto do próprio processo, mas também uma estratégia de institucionalização do padrão:

[...] o número de padrões adotados (homologados) em minha opinião é que está de ideal a talvez a aquém. E por que não tem mais? Porque tem ainda essa parte de catequização dos órgãos. Então eu acho que não adianta nada a gente adotar um monte de padrão se não tem ninguém usando, $\mathrm{A}$ partir do momento que a gente tiver essa consciência solidificada nos órgãos que eles têm que seguir o que está aqui, aí acho que dá pra avançar até mais rápido um pouco.

[...] a fase mais crítica é a passagem de recomendado para adotado. Mais crítica nem tanto pelas dificuldades do processo, mais em função do que aquela decisão vai resultar. A partir do momento que você coloca como adotado, segundo o documento, todos os órgãos são obrigados a seguir. Então você está influenciando todos os órgãos. Colocar como recomendado também é crítico, mas não tanto como adotado. Colocar como em estudo e em estudo futuro, assim, o grupo está estudando mais não afeta tanto. Colocar como recomendado tem um peso, mas colocar como adotado tem um peso maior ainda.

Todo esse processo de desenvolvimento e implementação da e-PING ocorre num contexto amplamente desfavorável. A gestão dos investimentos de TICs dos órgãos no governo é descentralizada, com cada um tendo autonomia de definição de suas aquisições. A SLTI interfere nesses investimentos de forma indireta e muito superficial, usando como instrumento a análise e aprovação dos orçamentos a serem fixados no Planejamento Plurianual - PPA pelo Ministério do Planejamento. Mas a SLTI não tem nenhuma inferência sobre a aquisição efetiva das tecnologias a serem implantadas nos órgãos. Aliado a esse aspecto, ainda existem as questões relativas aos contextos institucional, econômico e político nos quais esse projeto está sendo conduzido.

Fernandes (2007), ao analisar a construção da agenda, o planejamento, a estrutura organizacional e a implementação do governo eletrônico brasileiro que vêm sendo realizada desde 2000, afirma que a trajetória do governo eletrônico registra importantes realizações na formulação de uma visão estratégica, na condução da política e na definição de uma agenda de projetos transversais. No entanto, ressalva que embora mantida a sua estrutura de coordenação inserida na Presidência da República e ampliada através da criação de comitês técnicos, a implementação foi afetada pelo enfraquecimento da capacidade de liderança e 
mobilização sobre os ministérios, decorrente principalmente das mudanças no arranjo de poder que deu sustentação inicial à política. Além disso, o autor apresenta vários outros fatores que têm dificultado o programa de governo eletrônico em aprofundar a implementação dos projetos, como a emergência de agendas concorrentes, a desconexão entre a agenda de governo eletrônico e a agenda da gestão pública, a dificuldade de coordenação dos projetos setoriais de informatização de grande porte, a pulverização dos investimentos em TI e a inadequação do perfil e da estrutura organizacional dessa área nos órgãos da administração federal.

O relatório de Avaliação do Programa de Governo Eletrônico publicado pelo TCU em 2006 também reitera esse contexto desordenado. Segundo o relatório, foram identificados os seguintes problemas, entre outros: ausência de coordenação e articulação do programa na implementação da prestação de serviços públicos eletrônicos; falta de formalização das diretrizes do programa; enfraquecimento das instâncias de discussão e formulação da política de governo eletrônico; descompasso na implementação de serviços eletrônicos, pelos órgãos da Administração Pública Federal, com base nas diretrizes do programa; ausência de monitoramento e avaliação da prestação de serviços públicos eletrônicos; inexistência de monitoramento e avaliação por parte da coordenação do programa; insuficiência de monitoramento e avaliação sistemáticos no âmbito interno dos órgãos da APF; ausência de indicadores de desempenho para o programa, e inobservância de recomendações propostas nos documentos gerados pelo Programa que facilitariam o acesso e o uso de serviços públicos eletrônicos pelo cidadão (BRASIL, 2006b).

Em "Organização do governo eletrônico no Brasil: situação atual, problemas e propostas", Fernandes (2007) apresenta uma análise sobre as mudanças que ocorreram nos contextos político e institucional onde os programas e ações de governo eletrônico estão sendo conduzidos:

Até o final de 2002, até o final de 2002, o CEGE foi fortalecido pelo ativismo e liderança exercidos pelo então Ministro Chefe da Casa Civil - Pedro Parente - com experiência e envolvimento pessoal nos temas de informática e de modernização do Estado. O envolvimento direto de um dirigente com inserção privilegiada na estrutura de poder contribuiu de forma decisiva para a centralidade alcançada pela política na agenda governamental. As redes informais que impulsionaram o governo eletrônico na administração federal foram articuladas a partir da atuação da SLTI, do SERPRO e das unidades de informática e de comunicação social da Presidência da República. Esses atores buscaram a interlocução e o envolvimento de gerentes nas áreas de informática dos órgãos responsáveis pelos programas transversais e setoriais.

A mudança de governo, desde 2003, trouxe modificações nesse arranjo: a liderança na condução da política deixou de apoiar-se no envolvimento direto e mobilizador exercido até então por um 
ministro estrategicamente posicionado. Verifica-se a ampliação da atuação e visibilidade do ITI e do ativismo de algumas empresas estatais em projetos sociais, impulsionando agendas emergentes nas áreas de software livre e de inclusão digital. Além disso, constata-se a mudança de perfil e o maior número de técnicos e gerentes arregimentados nos comitês interministeriais que coordenam os projetos. O novo perfil é influenciado pela entrada de técnicos recrutados em administrações estaduais e municipais com vocação para as temáticas da inclusão digital e do software livre. Há evidências de maior freqüência de interlocução de entidades da sociedade civil que atuam na área de inclusão digital.

A manutenção do arranjo institucional baseado na atuação de uma instância de coordenação estratégica com participação de altos dirigentes de todos os ministérios vinculada à Presidência da República tem sido importante componente organizacional de sustentação ao governo eletrônico. Os resultados obtidos em projetos e ações de amplo escopo e transversalidade se deveram em grande medida À viabilização de mecanismos de consulta e de participação junto aos ministérios. A perda de um forte patrocinador político debilitou a capacidade de liderança do programa sobre o conjunto de órgãos e entidades da administração federal. De forma concomitante, a atuação do CEGE refluiu enquanto os comitês técnicos, expandidos e fortalecidos, têm exercido com maior autonomia a coordenação dos projetos. A interrupção da realização periódica de reuniões desse conselho, de forma mais evidente a partir de 2003, é demonstração preocupante de certo desalinhamento estratégico da política de governo eletrônico, em relação às prioridades do governo como um todo.

Apesar de relevantes realizações nos projetos de infra-estrutura e de integração de sistemas, não há avanços no aprofundamento da colaboração entre os órgãos e, de forma mais evidente, no desenvolvimento dos serviços ao cidadão. Esses avanços dependem de forma crucial da capacidade de mobilização exercida por intermédio do CEGE e dos dirigentes e redes de relacionamento que nele convergem. Nesse sentido, a implementação do programa tem trilhado um caminho de maior descentralização ao custo de dispersão e acomodação a arranjos de tipo incrementalista.

...dois itens emergentes na agenda do governo eletrônico [...] ganharam presença autônoma e certa centralidade na agenda governamental: a inclusão digital e o software livre. As agendas emergentes atropelaram o esforço de formulação estratégica e de compatibilização entre espaços de atuação, papéis e planejamento de ações no âmbito do governo eletrônico, acarretando dispersão de recursos e capacidades, especialmente de mobilização e coordenação transversal sobre o conjunto da administração federal. Esse efeito de diluição se deu ao mesmo tempo em que a atuação da CEGE refluía e o programa governo eletrônico perdia visibilidade política. A ênfase conferida a esses temas na agenda reflete diferentes visões que, não são antagônicas, divergem em relação a opções estratégicas, estilos e arranjos para a implementação dos projetos. Assim, a perspectiva de construção de uma agenda específica para a inclusão digital ganhou corpo, resultando na criação de um programa específico para a área, coordenado a partir do MP, o qual disputa espaços de atuação com outros projetos, na área de inclusão digital.

O tema software livre emergiu com força e foi incorporado às diretrizes do governo eletrônico, para implementação progressiva, iniciando-se pelos projetos novos e pela modernização dos sistemas corporativos da administração federal. Entretanto, a implementação de ações nesse sentido foi pressionada todo o tempo por uma visão alternativa que preconizava o planejamento e a indução mais forte junto aos órgãos e entidades, da fixação de metas de transição para a disseminação generalizada do software livre. Essa estratégia alternativa, explicitada no ativismo do ITI entre 2003 e 2005, não foi bem sucedida em viabilizar o apoio político e os recursos necessários à sua implementação. A substituição do dirigente máximo da autarquia e a perda de apoio no âmbito da Presidência da República marcam uma inflexão desde 2006 que indica a conformação de uma estratégia de implementação mais incremental e direcionada aos sistemas corporativos.

Além das circunstâncias relacionadas com estratégia, lideranças e construção de agendas, a organização do governo eletrônico convive com estruturas organizacionais nas áreas de informática que necessitam de atualização. Essas estruturas são significativo obstáculo à operacionalização dos projetos e ao alinhamento das áreas de tecnologia da informação com a visão estratégica do governo eletrônico. De forma geral, não existem instâncias capazes de coordenar projetos de maior complexidade, no âmbito de cada ministério. As unidades administrativas responsáveis pela gestão de informação e informática permanecem subordinadas a estruturas organizacionais que não estão alinhadas às características inovadoras pretendidas pelo governo eletrônico. A realização de projetos de alcance interministerial, voltados para a gestão interna, encontra dificuldades de mobilização e de coordenação junto aos ministérios. 
A implementação do governo eletrônico foi também severamente afetada por restrições orçamentárias, de forma que mesmo projetos formalmente definidos como prioritários são submetidos a contingenciamento de recursos com forte impacto sobre sua viabilização. Os resultados mais expressivos e de maior impacto junto ao cidadão foram alcançados no âmbito dos programas setoriais, sendo seu sucesso decorrência de trajetórias específicas em cada área, com baixa integração e aproveitamento de oportunidades de sinergia, obtenção de escala e alinhamento estratégico entre projetos.

Essas mudanças ocorridas nesse período têm se materializado em mudanças constantes na formalização dos objetivos, metas e ações da área de governo eletrônico. Em relação especificadamente ao projeto e-PING, durante sua execução, várias alterações têm ocorrido em termos de classificação do projeto dentro do orçamento e dos programas de governo, conforme relato da coordenação do projeto:

Em 2003 o projeto da e-PING era uma ação. Logo depois teve uma mudança que fundiram várias ações, se não me engano quatro ações, e a e-PING ficou dentro dessas ações. A e-PING não era mais uma ação isolada. Eram ações abaixo do Governo Eletrônico mais fundiram as ações e os recursos destinados para essas ações também fundiram. Isso aí foi mais uma decisão política.

Por fim, outro ponto a ser mencionado é que o nível de adoção da e-PING não é totalmente conhecido. Desde que a adoção é compulsória apenas para o Poder Executivo Federal, os órgãos adotantes dos outros poderes e de outras esferas não são facilmente identificáveis. Por outro lado, os coordenadores do projeto têm recebido solicitações de diversas instituições para ajudá-las nas suas implementações, o que pode significar um aumento da adoção dos padrões.

Para Rogério Santanna, Secretário da SLTI, a grande dificuldade na área de governo eletrônico é lidar com processos, sistemas, plataformas e tecnologias introduzidas em épocas diferentes e que precisam ser integrados e racionalizados. Ele defende a idéia de para a melhoria dos serviços é necessário executar ações para permitir que essa integração ocorra segundo um método que leve à progressiva redução de dependência de fornecedores proprietários, que ao longo do tempo sempre controlaram a cadeia de valores dos negócios do governo.

No entanto, o próprio Rogério Santanna reconhece que a integração dos sistemas do governo é um processo muito demorado. Segundo ele,

[...] porque são milhares de sistemas e processos complexos construídos ao longo de 30 anos de trabalho. Sistemas públicos estruturadores da Administração Pública levam entre quatro a cinco anos para serem implantados, cerca de dez anos para atingir a sua maturidade e entre 20 a 25 anos para serem substituídos por uma nova versão. Então, não é possível integrá-los de uma hora para outra porque além das questões técnicas há também questões culturais envolvidas. Mesmo assim, 
esse esforço deve ser prioritário porque os sistemas estruturadores do governo contêm informações vitais sobre compras governamentais, programas sociais, recursos patrimoniais, orçamentários, servidores públicos, empreendimentos, entre outros e que, apesar de terem sido feitos em épocas e com tecnologias diferentes, precisam conviver e se integrar.

Para viabilizar tecnicamente essa integração, desenvolvemos os Padrões e-PING, pois permitem que mesmo sistemas desenvolvidos em épocas diferentes e com tecnologias distintas possam trocar informações em tempo real. Portanto, a maior dificuldade hoje não está relacionada às questões tecnológicas, mas sim à integração dos processos, sobretudo das pessoas, e das dificuldades culturais relacionadas ao rompimento dos feudos da burocracia tradicional, da percepção dos processos paralelos que ocorrem em outros ministérios. Geralmente um sistema nasce por demanda de um ministério, mas ele interfere na vida de outros e acaba se tornando mais abrangente. Como acaba envolvendo muitos problemas de grande complexidade e também muitas pessoas, tende a ser um processo lento.

Mas para que a integração realmente ocorra, esse processo deve ser permanente e ter uma direção que conheça essas dificuldades para que o trabalho não se perca ao longo do tempo. Quando vemos um serviço de Governo Eletrônico que é um sucesso, só enxergamos a parte do processo que foi publicada na internet, quando a interface web ficou pronta. Mas para que isso pudesse ocorrer $90 \%$ do trabalho foi feito nos bastidores integrando diferentes sistemas e processos. Veja o caso da Receita Federal do Brasil que tem um sistema muito robusto de Governo Eletrônico envolvendo a declaração de imposto de renda pela internet. São mais de 500 sistemas diferentes com mais de 20 anos de implantação que estão por trás dessa facilidade e que hoje é possível graças a um trabalho realizado anteriormente, sistemático e que passou de governo para governo até atingir esse nível de maturidade dos serviços. Nesse sentido, o desafio da arquitetura e-PING é sua adoção por todos os órgãos, mantendo-se atualizada e possibilitar que tenhamos sistemas e processos integrados. 


\section{CAPÍTULO 6 - CONCLUSÃO}

Retomando justificativas apresentadas para a execução dessa pesquisa, reitera-se aqui que padrões são difíceis de serem desenvolvidos e implementados e que alguns deles não passam da fase de desenvolvimento, em decorrência de problemas no processo de articulação das discussões e definições. Outros embora especificados, não são adotados, alguns por conta do processo de construção ou institucionalização.

Também foi colocado anteriormente que o caráter dinâmico da padronização, um processo contínuo de evolução e adaptação, apresenta uma constante tensão entre suas definições e a flexibilidade e generalização necessárias para que o padrão possa se tornar robusto e adotado. É necessário, portanto, uma completa institucionalização dos processos de seu desenvolvimento e implementação, além de uma percepção de legitimidade por parte dos agentes afetados pelo estabelecimento da padronização em relação às ações que foram executadas durante as especificações do referido padrão.

Tendo em vista os resultados obtidos através das análises documentais, entrevistas e observações diretas realizadas e confrontando esses resultados com a literatura revisada, acredita-se ter atingido o objetivo proposto dessa presente pesquisa que foi o de compreender os processos de desenvolvimento e implementação de uma arquitetura de interoperabilidade para governo eletrônico e identificar prováveis implicações da condução desses processos na posterior adoção dos padrões especificados.

Para delinear a pesquisa e se alcançar seu objetivo foram definidas questões de partida, que serão reapresentadas a seguir, juntamente com a argumentação de suas respostas:

(1) como ocorrem os processos de desenvolvimento e implementação de um padrão de interoperabilidade em um ambiente de governo eletrônico, visto que estes se caracterizam por constituírem-se de agentes múltiplos e de ações inter-relacionadas?

Em relação aos processos de desenvolvimento e implementação do padrão, estes ocorrem em ambientes heterogêneos, mas necessariamente precisam ser realizados através de forma inclusiva. Embora atores externos possam de certa forma causar dispersão em algumas etapas dos processos por conta de seus interesses particulares, 
sua participação, conjuntamente com os internos, é imprescindível para um efetivo exercício de discussão voltada para o interesse público. No entanto, no caso da e-PING essa participação ainda pode ser considerada relativamente fraca, com poucos interressados, e sem ter representantes de todos os grupos implicados pela padronização (organizações do terceiro setor e da sociedade civil, por exemplo).

Tendo em vista ser um processo de seleção entre alternativas cuja escolha pode implicar em conseqüências para vários agentes ao redor do padrão especificado e, além disso, coordenado por um grupo composto por membros de vários órgãos do governo, seria de se esperar a ocorrência de conflitos de interesses e de poder. No entanto, a adoção de mecanismos e estratégias de legitimação e a influência dos processos de isomorfismo fazem com que esse nível de conflitos termine sendo atenuado, pelo menos no que se refere aos órgãos do governo obrigados a adotar a arquitetura.

(2) que mecanismos e estratégias podem ser adotados para a condução desses processos?

Como forma de reduzir incertezas e riscos, mecanismos de isomorfismo apresentam-se como opções de razoável impacto para adoção na condução do projeto. A coordenação da e-PING tem se beneficiado dos três tipos de isomorfismo: (1) mimético - ao buscar referências em projetos já em implantação de outros países, adotar a estrutura de grupos de trabalho para o projeto, prática já amplamente disseminada em projetos da administração pública federal, ou ao especificar padrões que já são considerados de mercado como componentes da arquitetura; (2) coercitivo - ao estabelecer a obrigatoriedade de uso dos padrões pelos órgãos do Poder Executivo do Governo Federal através de portaria normativa; (3) normativo - decorrente da participação nos grupos de trabalho dos técnicos especializados em TICs de vários órgãos.

A adoção desses mecanismos pode trazer vários benefícios diretos para o projeto. Um exemplo onde claramente se pode identificar esses efeitos é no que diz respeito a homologação de padrões que já são largamente usados (padrões de mercado). Ao optar por esses padrões a coordenação da e-PING elimina pontos de conflitos, visto que as especificações não trazem mudanças drásticas no ambiente tecnológico de alguns órgãos obrigados a adotar, pois vários padrões já estavam sendo utilizados. 
(3) de que forma esses mecanismos e estratégias podem influenciar na percepção pelos agentes implicados pela padronização da relevância dos padrões definidos e na conseqüente propensão a adoção?

Os mecanismos de isomorfismo miméticos podem ajudar nessa percepção, por exemplo, ao sinalizam para os potenciais adotantes que o caminho que está sendo trilhado pela e-PING é um parecido com o de outros países e que os padrões adotados são os de mercado. O isomorfismo coercitivo, por sua vez, materializado através da imposição de aderência aos padrões, já deixa explícita a necessidade da mudança, o que acarreta as suas adoções, pelo menos em tese, independente da noção de relevância.

(4) de que forma os mecanismos e estratégias adotadas podem influenciar na efetividade desses processos?

É senso comum que os ambientes políticos e institucionais são componentes de grande relevância para qualquer projeto da administração pública, em especial os relativos à implementação dos serviços de governo eletrônico. Esses projetos dependem altamente das estruturas de TICs estabelecidas ao longo do tempo num contexto de independência entre os órgãos, com trocas de experiências e informações limitadas, uso de múltiplas arquiteturas, adoção de metodologias e métodos de implementação diferentes por projeto/órgão, além de grande variação no conhecimento e adoção de novas arquiteturas e tecnologias.

O estabelecimento de padrões num contexto como esse é uma tarefa extremamente complicada. Mudanças nos processos de gestão de informação dos órgãos podem ser difíceis de serem implementadas como decorrência do uso de sistemas legados ou até mesmo não permitidas por conta de atos legais limitantes. Mesmo em casos onde não há impedimentos mais fortes, a simples questão de operacionalizar a mudança esbarra em limitações como ausência de pessoal com as habilidades e conhecimento necessários para sua execução. O custo da mudança tem de ser percebido como 
necessário. Logo, a percepção da relevância dos padrões definidos se apresenta como fator altamente condicionador da propensão a adotá-los.

Os processos de desenvolvimento e implementação da e-PING é baseado num modelo de gestão inclusivo, permitindo a todos os interessados se pronunciarem através de consultas/audiências públicas. Um ponto de efetividade dessa estratégia é que as audiências e consultas públicas servem para levar para um fórum comum as expectativas dos agentes interessados, o que pode reduzir os prováveis conflitos que podem surgir durante a adoção dos padrões.

Como principais resultados da pesquisa foram identificados várias ações onde o isomorfismo está presente, e também vários mecanismos de legitimação usados pelo Grupo de Coordenação da e-PING no sentido de institucionalizar o processo de desenvolvimento e implementação da arquitetura e, como isso, consolidar a relevância dos padrões especificados.

No entanto, os resultados também indicam que embora a adoção desses mecanismos e estratégias possa influenciar positivamente os processos de institucionalização da arquitetura, essas ações apresentam efetividade limitada em decorrência principalmente do ambiente e do contexto onde os referidos processos ocorrem.

Estabelecer Interoperabilidade não é somente integrar sistemas redes. Não se restringe unicamente a troca de dados entre sistemas e também não contempla simplesmente definição de tecnologias. É, na verdade, a soma de todos esses fatores, considerando também a existência de um legado de sistemas, de plataformas de hardware e software instaladas. Deve se basear em princípios que tratam da diversidade de componentes, com a utilização de produtos diversos de fornecedores distintos. É necessário ter por meta a consideração de todos os fatores para que os sistemas possam atuar cooperativamente, fixando as normas, as políticas e os padrões necessários para alcançar esses objetivos. Para se conseguir uma interoperabilidade efetiva, as pessoas devem estar engajadas num esforço contínuo para assegurar que sistemas, processos e culturas de uma organização sejam gerenciados e direcionados para maximizar oportunidades de troca e reuso de informações (BRASIL, 2007a). 
Para uma arquitetura de interoperabilidade ter sucesso é necessário gerenciar muitos desafios, incluindo burocracias complexas e órgãos com culturas enraizadas que não valorizam a abertura e cooperação com outros órgãos. Também em alguns casos existem leis e regras que proíbem ou limitam os órgãos em trocarem dados e informação. Isso inclui atos de proteção de dados, leis de privacidade e/ou políticas de confidencialidade de registros financeiros. Alguns órgãos nacionais têm ordenamentos específicos que tornam difícil para eles participarem em atividades cooperativas e, consequentemente, interoperar com outros.

O desenvolvimento dos Padrões de Interoperabilidade de Governo Eletrônico (e-PING) estabeleceu uma estratégia de como lidar com a diversidade de equipamentos, de protocolos, de padrões e normas para realizar essa integração. Para o Secretário da SLTI, Rogério Santanna, esse é um avanço importante porque o governo brasileiro é o primeiro da América Latina a dispor de um padrão de interoperabilidade fortemente definido como já faz a Europa, os Estados Unidos, a Austrália e outros países há mais tempo. Esse padrão está sendo utilizado não só pelo Poder Executivo que o produziu, mas também pelo Legislativo e Judiciário. (BRASIL, 2007b)

\subsection{SUGESTÕES E RECOMENDAÇÕES}

Além de não serem tarefas fáceis de serem executadas, acredita-se que a forma pela qual os processos de desenvolvimento e implementação de padrões de interoperabilidade para governo eletrônico são conduzidos pode influenciar de forma significativa a intenção de adoção dos agentes implicados pela padronização. Por conta disso, algumas ações podem ser adotadas de forma a aumentar a percepção desses agentes da relevância das especificações definidas na arquitetura.

Deve ser dada atenção às políticas, critérios e avaliações de compras para assegurar a aderência. Segundo Ghosh (2005), as políticas públicas para apoio efetivo a interoperabilidade tem que começar com uma necessidade obrigatória para não incluir compatibilidade com softwares previamente comprados como um critério de seleção para aquisição de softwares novos. Em vez disso, a interoperabilidade com softwares de múltiplos vendedores deve ser o critério de compatibilidade imprescindível a ser observado. Sugere-se que o documento referência da e-PING seja mais explícito no que se refere aos procedimentos a serem adotados e aspectos a serem observados nos processos de aquisição de TICs que estejam de alguma forma contemplada nas especificações definidas na arquitetura. 
Também é importante o governo criar incentivos para nutrir uma "cultura de reuso" nos sistemas. O reuso de sistemas diminui os problemas de interoperabilidade entre os órgãos, pois estariam usando as mesmas aplicações. E naturalmente, essas aplicações deveriam estar em conformidade com os padrões definidos. Os motivadores para reuso incluem, por exemplo, redução de custos e flexibilidade e nas arquiteturas de TIC e sistemas subjacentes. Alinhado a isto, os recursos financeiros poderiam ser reduzidos e não alocados a projetos que fossem iniciativas duplicadas de outras já existentes. Também deveria ser dado reconhecimento aos órgãos que reusassem aplicações ou serviços. Isto poderia ser na forma de divulgação dessas iniciativas no site do projeto e também através de um evento ou cerimônia de reconhecimento, onde os órgãos poderiam receber premiações simbólicas.

Outra forma para promover a aderência à arquitetura é construir uma comunidade para apoiar os padrões endossados. Esta comunidade, que agiria como um grupo de apoio, seria composta de usuários e fornecedores de tecnologias e/ou serviços que estivessem em conformidade com as especificações estabelecidas. A existência de tal comunidade também seria útil para aqueles que estivessem implementando projetos usando os padrões pela primeira vez. Este método é semelhante a como organizações internacionais de padrões asseguram adesão aos padrões definidos.

Uma estratégia possível para monitoramento da conformidade com os padrões definidos pela arquitetura seria adotar um processo com pontos de controles para aprovar e acompanhar os projetos de TICs. Os projetos em que fosse obrigatória a aderência aos padrões definidos na arquitetura seriam revisados regularmente e avaliados como eles estavam sendo implementados, incluindo a possibilidade de parar o projeto que não estivesse seguindo as especificações originais. Uma inspeção aleatória dos principais projetos de TICs também seria uma forma de se verificar a adesão aos padrões de interoperabilidade.

Em situações quando for necessária uma legislação específica para a implantação dos padrões, a nova lei deve ser ampla o suficiente para dar poderes a um órgão de certificar a aderência, mas não deve ser específica demais ou muito detalhada sobre o que os padrões sejam obrigatórios. Os padrões específicos devem ser definidos em regulamentação, pois é mais fácil atualizar. 
Definir métricas ou medidas de sucesso também é muito importante para o estabelecimento de padrões de interoperabilidade. Porém, definir essas métricas não é fácil como também a interoperabilidade não é um absoluto. Não é um processo de tudo ou nada e é difícil de medir. Para Hamilton, Rosen e Summers (2002), a verdadeira interoperabilidade é muito mais que só conectividade. É também uma função de conceitos operacionais e cenários, políticas, processos, e procedimentos. Por isto, desenvolver e aplicar medidas precisas em uma área multidimensional e complexa como interoperabilidade são tarefas difíceis (KASUNIC e ANDERSON, 2004).

Embora reconhecendo a dificuldade de se definir métricas em interoperabilidade, alguns modelos têm sido propostos. Whitt (2004) propõe um teste de interoperabilidade composto de dez testes de interfaces externas e dez testes de contextos internos. Já Kasunic e Anderson (2004) oferecem quatro conjuntos de medidas para avaliar interoperabilidade: (1) aderência técnica, (2) interoperabilidade de sistemas, (3) interoperabilidade operacional, e (4) interoperabilidade organizacional e cultural.

Mesmo que o governo não precise de métricas muito precisas, a definição e aplicação de algumas medidas básicas podem ajudar a avaliar e, com isso, facilitar o sucesso da arquitetura. Um teste relativamente básico útil foi proposto por Hamilton, Rosen e Summers (2002) em Desenvolvendo uma Matriz de Interoperabilidade (Developing Interoperability Matrix). Eles propõem que para a interoperabilidade acontecer, um sistema deve satisfazer pelo menos um dos seguintes requisitos:

- Gerar dados que são usados por outro sistema;

- Processar ou consumir dados que são gerados por outro sistema;

- Confiar em outro sistema para a entrega de dados; ou

- Ser um software que funciona na mesma plataforma como outro sistema.

Outro possível mecanismo de reforço é o estabelecimento de uma Certificação de Interoperabilidade, representando o nível de interoperabilidade de um órgão. Este é outro modo para incentivar os órgãos em adotar as especificações da arquitetura, mas depende do estabelecimento de critérios (métricas ou outras medidas) para avaliar o nível alcançado. Uma abordagem relacionada a certificações já idealizada pela coordenação da e-PING é a criação de um selo e-PING e a administração de processo que certifique a aderência de determinado serviço ou produto à arquitetura. 
Finalmente, publicando manuais de referência em como construir sistemas que são aderentes a arquitetura reforça positivamente os padrões. Construir protótipos reais e distribuir seus códigos fontes, documentação, e especificações seriam de utilidade para outros órgãos que estão começando a desenvolver há pouco tempo os seus próprios sistemas e que precisem adotar os padrões.

\subsection{CONTRIBUIÇÕES}

A análise dos processos de desenvolvimento e implementação da e-PING permitiu identificar as seguintes contribuições da pesquisa:

1. Investigação da efetividade do uso de estratégias e mecanismos de legitimação em processos de institucionalização dentro de ambiente de governo eletrônico;

2. Identificação de pontos críticos que podem implicar na efetiva adoção de uma arquitetura de interoperabilidade para governo eletrônico, surgidos em decorrência da condução dos processos de padronização. A multiplicidade de agentes envolvidos, aliada à limitação de recursos para implementação dos padrões especificados se evidenciam como fortes condicionadores para disseminação da arquitetura.

3. Entendimento dos processos de desenvolvimento e implementação de uma arquitetura de interoperabilidade para governo eletrônico sob o ponto de vista de abordagem sociotécnica, identificando as ligações de suas fases com os conceitos dos referenciais da teoria institucional e de padronização.

4. Aprofundamento do conhecimento acerca da adoção de estruturas organizacionais matriciais para projetos na administração pública, na forma de grupo de trabalhos, e suas prováveis implicações no processo de institucionalização dos produtos e/ou práticas definidas por estes grupos.

\subsection{SUGESTÃO DE PESQUISAS FUTURAS}

Algumas sugestões para pesquisas futuras podem ser apresentadas com vistas ao aprofundamento das questões tratadas aqui nesse estudo ou expansão da compreensão do tema a partir de outras possibilidades abordagens e/ou escopo: 
- Investigar se os mecanismos de legitimação estão sendo usados objetivando o aprimoramento das especificações da arquitetura através da discussão e envolvimento dos agentes impactados pelos padrões ou se estão servindo de suporte para atenuação do impacto das decisões tomadas pelo grupo de coordenação.

- Efetuar uma análise comparativa entre as estratégias adotadas pelo governo brasileiro e por outros governos, com especial atenção no projeto do governo britânico (e-GIF), tendo em vista ter sido este a base conceitual da arquitetura de interoperabilidade brasileira.

- Avaliar até que ponto as audiências e consultas públicas influenciam no processo de especificação da arquitetura, através, por exemplo, da identificação dos atores participantes e suas inter-relações no ambiente extra consultas e audiências, objetivando investigar possíveis arranjos em torno de interesses comuns.

- Analisar os processos de desenvolvimento e implementação dos padrões sob as perspectivas de outras abordagens sócio técnicas, como por exemplo, a Actor-Network Theory (ANT) ou Social Construction of Technology (SCOT).

- Avaliar a correlação entre a percepção da relevância das especificações definidas e da legitimação da condução do processo de seu estabelecimento e o nível de adoção dos referidos padrões.

- Identificar as implicações da adoção da arquitetura em áreas específicas do governo objetivando mapear benefícios decorrentes e barreiras relacionadas.

- Avaliar as implicações da adoção dos padrões nos modelos de negócios de fornecedores de serviços e produtos de TICs para governo.

- Investigar a propensão à adoção da e-PING por organizações de outros poderes além do Executivo Federal, desobrigados do uso das especificações definidas no padrão.

- Identificar quais órgãos governamentais estão efetivamente adotando a arquitetura, a partir da análise de quais padrões estão sendo observados.

- Avaliar a correlação entre a percepção do padrão como resultado de um consenso das discussões dos GTs (com a consequente dissociação entre o que foi decidido, quem 
decidiu e quem o decisor representava) e o comportamento individual dos membros durante o processo dessas discussões.

- Verificar se existe alguma correlação entre o nível de participação dos membros dos GTs e a ausência de sanções posteriores pela não adoção dos padrões.

- Analisar se existe alguma correlação entre as escolhas dos padrões especificados e a ausência de sanções explícitas na portaria normativa que institucionalizou a arquitetura.

\subsection{CONSIDERAÇÕES FINAIS}

Embora o estabelecimento do padrão e-PING possa ser visto como um processo de institucionalização incompleta, sem obter a devida relevância objetivada pela coordenação do projeto, o processo em si se conforma como catalisador para a consolidação da SLTI como órgão de autoridade no que se refere ao assunto de padronização. Sendo o lócus de discussão e estabelecimento de outros padrões em TICs além da e-PING (como o e-MAG - Modelo de Acessibilidade de Governo Eletrônico, as especificações de referência para aquisição de estações de trabalho e notebooks, por exemplo), ela torna-se referência dentro do Governo Federal e, consequentemente, aumenta a percepção não só externa mas como também interna ao governo, da legitimidade da sua competência na tomada de decisões sobre esses temas, inclusive num posterior realinhamento da trajetória da própria e-PING.

As especificar padrões de facto, possíveis de adoção sem maiores conflitos, a SLTI consolida o padrão e-PING, adquirindo uma condição de poder efetuar mudanças nas estratégias de cobrança de adoção das suas especificações num momento posterior. Essas mudanças de estratégias teriam respaldo na percepção de relevância efetiva da arquitetura adquirida pelos adotantes por conta da real experimentação dos resultados proporcionados.

Portanto, é de se esperar alguma reorientação nos processos de desenvolvimento e implementação da e-PING e também nas diretrizes e ações para promoção da sua disseminação e efetiva adoção.

As sugestões apresentadas aqui nesse trabalho não se esgotam em si, não são mutuamente exclusivas e nem tampouco as análises pretendem ser exaustivas. Espera-se, pois, que possam ser consideradas como uma forma adicional de contribuição para o entendimento das práticas 
compreendidas nesses processos. Ao mesmo tempo, é também esperado que se tenha alcançado o um avanço na referência teórica sobre os processos de padronização sob o ponto de vista dos conceitos de legitimação e isomorfismo propostos na Teoria Institucional. 


\section{REFERÊNCIAS}

ADAE. Le Cadre Commun d'Intéroperabilité version 2.1, 2003. disponível em <http://www.adae.gouv.fr/article.php3? id_article=219>, Acesso em 03 out 2006.

AKBULUT, A. An investigation of the factors that influence electronic information sharing between state and local agencies. $\mathrm{PhD}$ Dissertation Thesis. Louisiana State University, 2003.

ANDERSEN, D.; DAWES, S. Government information management. A primer and casebook. Englewood Cliffs, NJ: Prentice Hall, 1991.

AVGEROU, C. The significance of context in information systems and organisational change. Info Systems, 11, p. 43-63, 2001.

AVGEROU, C. Information systems and global diversity. Oxford: Oxford University Press, 2002.

AVGEROU, C.; CIBORRA, C.; CORDELLA, A,; KALLINIKOS, J.; SMITH, M. The role of information and communication technology in building trust in governance: toward effectiveness and results. Washington, D.C.: Inter-American Development Bank, 2005.

BAUM, C.; DI MAIO, A. Gartner's four phases of e-government model. Stanford: Gartner Group, 2000. (Research Note)

BENBASAT, I., GOLDSTEIN, D.; MEAD, M. The case research strategy in studies of information systems. MIS Quarterly, v.11, n.3, September, p.369-386, 1987.

BENT, S.; KERNAGHAN, K.; MARSON, D. Innovations and good practices in singlewindow service. Canada: Canadian Centre for Management Development, 1999.

BRASIL. Decreto de 08 de maio de 1992. Dispõe sobre a adoção, pela Administração Pública Federal, do modelo de referência para comunicação e interoperação de sistemas de tratamento da informação. Diário Oficial da União, Brasília, DF, 11 mai 1992.

. Proposta de política de governo eletrônico para o Poder Executivo Federal. Grupo de Trabalho “Novas formas eletrônicas de interação”. Brasília: Ministério do Planejamento, Orçamento e Gestão, 2000a.

Decreto de 18 de outubro de 2000. Cria, no âmbito do Conselho de Governo, o Comitê Executivo do Governo Eletrônico, e dá outras providências. Diário Oficial da União, Brasília, DF, 19 out. 2000b.

Regimento Interno do Comitê Executivo do Governo Eletrônico. Brasília: Comitê Executivo do Governo Eletrônico, 2000c. 
Dois anos de governo eletrônico - balanço preliminar. Brasília: Casa Civil da Presidência da República, Ministério do Planejamento, Orçamento e Gestão, Secretaria Executiva do Comitê Executivo do Governo Eletrônico, 2002a.

Dois anos de governo eletrônico - balanço de realizações e desafios futuros. Brasília: Casa Civil da Presidência da República, Ministério do Planejamento, Orçamento e Gestão, Comitê Executivo do Governo Eletrônico, 2002b.

Decreto de 29 de outubro de 2003. Institui Comitês Técnicos do Comitê Executivo do Governo Eletrônico e dá outras providências. Diário Oficial da União, Brasília, DF, 30 out. 2003b.

e-PING: Padrões de interoperabilidade de governo eletrônico - versão 1.0 . Brasília: Comitê Executivo de Governo Eletrônico, 2004.

Utilidade Pública. Brasil.Gov. 2003a. Disponível em <http://www.brasil.gov.br/ utilidade.htm>. Acesso em 19 dez 2005.

Avaliação do Programa de Governo Eletrônico. Brasília: Tribunal de Contas da União, 2006.

e-PING: Padrões de interoperabilidade de governo eletrônico - versão 3.0 . Brasília: Comitê Executivo de Governo Eletrônico, 2007.

Entrevista com Rogério Santanna, 2007b. Disponível em $<$ https://www.governoeletronico.gov.br/anexos/entrevista-dr-rogerio-santanna>. Acesso em 14 dez. 2007.

BUNDUCHI, R.; GRAHAM, I.; SMART, A.; WILLIAMS, R. Heterogeneity in Standard Settings: The tensions shaping the emergence of standard bodies - The case of a British standards body for health informatics. Prometheus, Vol. 23, No. 2, pp. 149-166, 2005.

BURREL, G.; MORGAN, G. Sociological paradigms and organisational analysis. London: Heinemann, 1979.

CALLON, M. Some elements of a sociology of translation: domestication of the scallops and the fishermen of St Brieuc Bay. In LAW, J. (Ed.), Power, Action and Belief. London: Routledge \& Kegan Paul, 1986, pp. 196-233.

Techno-economic networks and irreversibility. In LAW, J. (Ed.), A Sociology of Monsters: Essays on Power, Technology and Domination. London: Routledge, 1991, pp. $132-61$.

CALLON, M.; LATOUR, B. Unscrewing the big Leviathan: how actors macro-structure reality and how sociologists help them to do so. In KNORR-CETINA, K.; CICOUREL, A. (Eds), Advances in Social Theory and Methodology. London: Routledge \& Kegan Paul, 1981, pp. 277-303. 
CASTELLS, M. The Internet galaxy: reflections on the internet, business and society. New York: Oxford University Press, 2001.

CEC. Commission of the European Communities, Council Directive 91/250/EEC of 14 May 1991 on the legal protection of computer programs, 1991.

CEC. Commission of the European Communities, eEurope 2005: An information society for all. Sevilla European Council, 21/22 June, 2002.

CENTER FOR TECHNOLOGY IN GOVERNMENT. Some assembly required: building a digital government for the 21st century. Albany: Center for Technology in Government, University at Albany, State University of New York, 1999.

$\mathrm{CHOH}, \mathrm{K}$. Innovation and Standardization in Technological Trajectories: A Schumpeterian Perspective and Three Models of Standardization in the Information Technology Industry”. Proceedings of 1st IEEE Conference on Standardisation and Innovation in Information Technology, SIIT’99, Aachen, Germany, September pp.15-17, 1999.

CIBORRA, C.; NAVARRA, D. Good governance and development aid: risks and challenges of e-government in Jordan. In Korpela, M.; Montealegre, R.; Poulymenakou, A. Organizational Information Systems in the Context of Globalization. Dordrecht: Kluwer, 2003.

CIOC. Federal Chief Information Officer Council, Federal Enterprise Architecture Framework, version 1.1, 1999.

CIOC. Federal Chief Information Officer Council, E-Gov Enterprise Architecture Guidance, draft-version 2.0, 2002.

COMMISSION OF THE EUROPEAN COMMUNITIES. Linking up Europe: the importance of interoperability for e-government services. Brussels: European Communities, 2003.

COMMISSION OF EUROPEAN COMMUNITIES. European Interoperability Framework for Pan-European e-Government Services - version 1.0. Luxembourg: European Communities, 2004.

CRIADO, J.; RAMILO, M. e-Administración: ¿un Reto o una Nueva Moda para las Administraciones del Siglo XXI?. Algunos Problemas y Perspectivas de Futuro en torno a Internet y las Tecnologías de la Información y la Comunicación en las Administraciones Públicas. Revista Vasca de Administración Pública, 61 (I), pp. 11-43, 2001.

DAVID, P.; GREENSTEIN, S. The economics of compatibility standards: an introduction to recent research. The Economics of Innovations and New Technology, 1 (1-2), 3-41, 1990.

DAVID, P.; STEINMUELLER, W. Economics of compatibility standards and competition in telecommunication networks. Information Economics and Policy, 6(3-4): 217-241, 1994. 
DAWES, S.; BLONIARZ, P. Knowledge networking in the public sector. New York: Center for Technology in Government, University at Albany/SUNY, 2001. DAWES, S. Interagency information sharing: expected benefits, manageable risks. Journal of Policy Analysis and Management, Vol. 15, No. 3, p 377-394, 1996.

DELOITTE \& TOUCHE. The citizen as customer. CMA Management, Dec2000/Jan2001, 74(10): 58, 2001.

DIMAGGIO, P; POWELL. The iron cage revisited: institucional isomorfism and collective rationality in organizational fields. American Sociological Review, Vol. 48, No. 2, 1983, pp. 147-160.

e-Government Unit, e-Government Interoperability Framework, version 6.0, London, 2004.

Egyedi, T. Beyond Consortia, Beyond Standardisation? New Case Material and Policy Threads. Final Report for the European Commission. Delft, 2001.

EPAN - EUROPEAN PUBLIC ADMINISTRATION NETWORK. Key principles of an interoperability architecture. Ireland, 2004.

EU. eGovernment Research in Europe. European Commission., 2001. Disponível em: http://europa.eu.int/information_society/programmes/egov_rd/text_en.htm. Acesso em: 07 nov 2005.

FERNANDES, A. Compras governamentais no Brasil: como funcionam os principais sistemas em operação. Brasília: BNDES, 2002. 9 p. Disponível em: http://federativo.bndes.gov.br/f_estudo.htm. Acesso em: 19 dez 2005.

FERNANDES, A.; AFONSO, J. e-Governo no Brasil: experiências e perspectivas. Revista do BNDES, Rio de Janeiro, v. 8, n. 15, p. 21-64, jun. 2001.

FERNANDES, C. Estratégia, planejamento e organização do governo eletrônico no Brasil: situação atual, problemas e perspectivas. In: XI Congreso Internacional del CLAD sobre la Reforma del Estado y de la Administración Pública. Ciudad de Guatemala, 7-10 nov. 2006.

Organização do governo eletrônico no Brasil: situação atual, problemas e propostas. In: KNIGHT, P.; FERNANDES, C.: CUNHA, M. (Orgs.). e-Desenvolvimento no Brasil e no mundo: subsídios e Programa e-Brasil. São Caetano do Sul: Yendis, 2007.

FISH, S. Interpretive research: a new way of viewing organizational communication. Public Administration Quarterly, vol. 14, no. 1, p.67-74, Spring 1990.

FOMIN, V.; KEIL, T.; LYYTINEN, K. Theorizing about standardization: integrating fragments of process theory in light of telecommunication standardization wars. Sprouts: working papers on Information Environments, Systems and Organizations, 2003. 
GARUD, R.; JAIN, S.; KUMARASWAMY, A. Institutional Entrepreneurship in the Sponsoring of Common Technological Standards: The Case of Sun Microsystems and Java. Academy of Management Journal, 2000.

GIDDENS, A. A constituição da sociedade. São Paulo: Martins Fontes, 1984.

GIL, A. Métodos e técnicas de pesquisa social. São Paulo: Atlas, 1995.

GODOY, A. Pesquisa qualitativa: tipos fundamentais. Revista de Administração de Empresas, São Paulo: FGV, p.20-38, mai/jun/1995

GHOSH, R. Open Standards and Interoperability Report: An Economic Basis for Open Standard. $\quad$ Maastricht, 2005.2 Disponível em <http://flosspols.org/deliverables/D04HTML/FLOSSPOLS-D04-openstandards-v6.html>, Acesso em 14 dez 2007.

GRAHAM, I.; SPINARDI, G.; WILLIAMS, R.; WEBSTER, J. The Dynamics of EDI Standard Development. Technology Analysis \& Strategic Management, 7(1): 3-20, 1995.

GRANDE, J.; ARAUJO, M..; SERNA, M.. La necesidad de teoría(s) sobre gobierno electrónico: uma propuesta integradora. In: Concurso de ensayos y monografías del CLAD sobre reforma del estado y modernización de la administración pública. 16., 2002, Caracas. Anais eletrônicos... Caracas: Centro Latinoamericano de Administración para el Desarollo (CLAD), 2002.

GUIJARRO, L. Interoperability frameworks and enterprise architectures in e-government initiatives in Europe and the United States. Government Information Quarterly, volume 24, issue 1, pp 89-101, 2007.

HAGEN, M; KUBICEK, H. One-stop-government in Europe: results of 11 national surveys. Bremen: University of Bremen, 2000.

HAMILTON, J; ROSEN, J; SUMMERS, P. Developing Interoperability Matrix, 2002.

HAMILTON, J; ROSEN, J; SUMMERS, P. Developing Interoperability Metrics, 2002. Disponível

<http://www.eng.auburn.edu/users/hamilton/security/spawar/6_Developing_Interoperability_ Metrics.pdf>, Acesso em 18 dez 2008.

HANSETH, O.; MONTEIRO, E. Standards and standardization processes. In: Understanding information infrastructure, 1998 (manuscrito).

HANSETH, O.; MONTEIRO, E.; HATLING, M. Developing information infrastructure: The tension between standardization and flexibility. Science, Technology and Human Values. Vol. 21, No. 4, pp. 407-426, 1996. 
HARTLEY, J. F. Case studies in organizational research. In: CASSEL, C., SYMON, G. (eds.). Qualitative methods in organizational research - a pratical guide. Londres: Sage, 1994.

HILLER, J.; BÉLANGER, F. Privacy strategies for electronic government. e-government Series. Arlington, VA: Price water house Coopers Endowment for the Business of Government, 2001.

HOFFMAN, A. Institutional evolution and change: environmentalism and the U.S. chemical industry. Academy of Management Journal, Vol. 42, No.04, p. 351-371, 1999.

IDABC. Enterprise and Industry DG, European Interoperability Framework for panEuropean e-government services, version 1.0, Brussels, 2004.

IEEE Standards Information Network. IEEE 100. The authoritative dictionary of IEEE standards terms, Seventh Edition. New York, NY: IEEE, 2000.

HOLMSTRÖM, J.; STALDER, F. Drifting technologies and multi-purpose networks: the case of the Swedish cashcard. Information and Organization, Vol. 11 No. 3, pp. 187-206, 2001.

INTOSAI. Auditing E-government. Viena: Intosai, Standing Committee on IT Audit, Task Force for Auditing E-Government, 2003.

JONES, M.; KARSTEN, H. Review: Structuration Theory and Information Systems Research. The Judge Institute of Management . Cambridge University Research Papers in Management Studies, Working Paper, 11/2003.

KAKABADSE, A.; KAKABADSE, N.; KOUZMIN, A. Reinventing the.democratic governance project through information technology? A growing agenda for debate. Public Administration Review. Washington, v. 63, n. 1, p. 44-60, jan./fev. 2003.

KASUNIC, M; ANDERSON, W. Measuring Systems Interoperability: Challenges and Opportunities, $2004 . \quad$ Disponível em <http://www.sei.cmu.edu/pub/documents/04.reports/pdf/04tn003.pdf>, Acesso em 17 jan 2008.

KLEIN, H.; MYERS, M. A set of principles for conducting and evaluating Interpretive Field Studies in Information Systems. MIS Quartely, v. 23, no. 01, p. 67-94, March 1999.

KBST, Standards and Architectures for e-Government Applications, version 2.0, 2003. Disponível em <http://www.kbst.bund.de/SAGA>, Acesso em 20 out 2006.

LANDSBERGEN JR, D.; WOLKEN JR, G. Realizing the promise: government information systems and the fourth generation of information technology. Public Administration Review. Vol. 61 (2), p. 205-218, march/april, 2001. 
LAYNE, K.; LEE, J. Developing fully functional e-government: a four stage model. Government Information Quarterly, 18(2): 12-136, 2001.

LATOUR, B. Science in Action: How to Follow Scientists and Engineers through Society. Cambridge: Harvard University Press, 1987.

Aramis or the Love of Technology. Cambridge: Harvard University Press, 1996.

B. Pandora's Hope: Essays on the Reality of Science Studies. Cambridge: Harvard University Press,1999.

LAW, J. (Ed.). A Sociology of Monsters: Essays on Power, Technology and Domination. London: Routledge, 1991.

Organizing Modernity. Oxford: Blackwell, 1994.

LAW, J.; HASSARD, J. (Eds). Actor Network Theory and after. Oxford: Blackwell, 1999.

MADON, S. Computer based information systems for development planning. In BHATNAGAR, S.; ODEDRA, M. Social implications of computers in developing countries. New Delhi: Tata McGrow-Hill, 1992.

MANGEMATIN, V. e CALLON, M. Technological competition, strategies of the firms and the choice of the first users: The case of road guidance technologies. Research Policy, 24 (3), 441-458, 1995.

MEDEIROS, P. Governo eletrônico no Brasil: aspectos institucionais e reflexos na governança. Brasília: Universidade de Brasília, 2004.

MOON, M. The evolution of e-government among municipalities: rhetoric or reality? Public Administration Review 62(4): 424-433, 2002.

MONTEIRO, E.; HEPSØ, V. Infrastructure strategy formation: seize the day at Statoil. In CIBORRA, C. et al. (Eds), From Control to Drift: The Dynamics of Corporate Information Infrastructures, Oxford: Oxford University Press, 2000.

MORETON, R.; SLOANE, A.; SIMON, E. Implementing information management and technology standards: a framework. Technology Management, 2 (6), 275-288, 1995.

NATIONAL AUDIT OFFICE. Better public services through e-government. Londres: The Stationery Office, 2002.

OECD. E-government: analysis framework and methodology. Paris: OECD, 2001.

OECD. The e-government imperative. Paris: OECD, 2003. 
OKOT-UMA, R.. Electronic governance: re-inventing good governance. Londres: Commonwealth Secretariat London, 2001.

OLIVEIRA, C. Governo na era da informação: o caso do portal Bahia.gov. Lauro de Freitas: UNEB, 2003. 96p.

ORLIKOWSKI, W.; BAROUDI, J. Studying Information Technology in Organizations: research approaches and assumptions. Information Systems Research, vol. 2, no. 01, March 1991.

ORLIKOWSKI, W.; ROBEY, D. Information Technology and the structuring of organisations. Information Systems Research, v. 2, no. 2, p. 143-169, June 1991.

PERENS, B. Open Standards: Principles and Practice. http://www.perens.com/OpenStandards/Definition.html (2007).

PETTIGREW, A. Contextualist research: a natural way to link theory and practice. In: LAWLER, E. Doing research that is useful in theory and practice. San Francisco: Jossey Bass. 222-249, 1985.

POWELL, W.; DIMAGGIO, P. The new institucionalism in organisational analysis. Chicago: Chicago Press, 1991.

PRATCHETT, L. New technologies and the modernization of local government: an analysis of biases and constraints. Public Administration. Vol. 77, nº4, pp.731-750, 1999.

REALINI, A. G2G E-Government: The Big Challenge for Europe. Master's Thesis. Department of Informatics - University of Zurich: Switzerland, 2004.

REINO UNIDO. e-Government Interoperability Framework (e-GIF). Londres: Cabinet Office, 2001.

RIEDL, R. Affordance in e-government. Proceedings of Electronic Government : 2nd International Conference - EGOV 2003, Prague, Czech Republic, September 1-5, 2003.

ROCHELEAU, B. Governmental information systems problems and failures: a preliminary review. Public Administration and Management: An Interactive Journal, 2:3, 1997.

ROESCH, S. Projetos de estágio e de pesquisa em administração. São Paulo: Atlas, 1999.

ROGERS, E. Diffusion of Innovations. 4a.ed. New York: Free Press, 1995.

RUSSEL, S.; WILLIAMS, R. Social Shaping of Technology: Frameworks, Findings and Implications for Policy with Glossary of Social Shaping Concepts. In SORENSEN, K; WILLIAMS, R. (eds.). Shaping Technology, Guiding Policy. Cheltenham: Edward Elgar, pp. 37-132. 
WHITT, L. The Good, The Bad, and The Ugly of Interoperability Metrics, 2004. Disponível em <http://www.opengroup.org/public/member/proceedings/q104/ges-whit.pdf>, Acesso em 12 jan 2008.

STAKE, R. The art of case study research. USA: Sage Publications, 1995.

SCOTT, W. Richard. Institutions and organizations. 2a. ed. Thousand Oaks: Sage, 2001.

SIAU, K.; LONG, Y. Innovations through information technology. Hershey: Idea Group Inc., 2004.

SLIMAN, E. Business Case for Open Standards. Disponível em $<$ http://www.openstandards.net/viewOSnet1C.jsp?showModuleName=businessCaseForOpen Standards>. Acesso em 13 jan 2008.

SLOANE, A. The standards process: tools and methods for standards tracking and implementation. Computer Standards \& Interfaces, 22, 5-12, 2000.

SWANN, G. The economics of standardization: final report for standards and technical regulations directorate - Department of Trade and Industry. Manchester Business School, 2000.

TASSEY, G. Standardization in technology-based markets. Research Policy, 29(4-5): 587602, 2000.

UK. e-GIF - e-Government Interoperability Framework, version 6.1. Office of the eEnvoy - Cabinet Office, London: United Kingdom Geverment, 2004.

UNITED NATIONS. Global survey of e-Government. Nova York: United Nations Division for Public Economics and Public Administration, American Society for Public Administration, 2001.

. Benchmarking e-Government: a global perspective. Nova York: Division for Public Economics and Public Administration, American Society for Public Administration, 2002.

World Public Sector Report 2003: e-Government at the Crossroads. Nova York: Department of Economic and Social Affairs, Division for Public Administration and Development Management, 2003.

UNITED NATIONS DEVELOPMENT PROGRAMME. e-Government interoperability: Guide. Bangkok: United Nations Development Programme, Regional Centre, 2007a.

UNITED NATIONS DEVELOPMENT PROGRAMME. e-Government interoperability: Overview. Bangkok: United Nations Development Programme, Regional Centre, 2007b. 
VERGARA, S. C. Projetos e relatórios de pesquisa em administração. São Paulo: Atlas, 1998.

VERMAN, L. Standardization: A New Discipline. Hamden, CT: Arden Books, 1973.

VRIES, H. de. Standards for the Nation: Analysis of National Standards Organisations. Dordrecht: Kluwer Academic Publishers, 1999.

WALSHAM, G. Interpreting information systems in organisations. West Sussex: John Wiley\&Sons, 1993.

Actor-network theory and IS research: current status and future prospects. In LEE, A.,; LIEBENAU, J.; DEGROSS, J. (Eds), Information Systems and Qualitative Research. London: Chapman \& Hall, 1997.

WALSHAM, G.; SAHAY, S. GIS for district-level administration in India: problems and opportunities. MIS Quarterly, Vol. 23, No. 1, pp. 39-66, 1999.

WILLIAMS, R. Universal Solutions or Local Contingencies: Tensions and Contradictions in the Mutual Shaping of Technology and Work Organisation. Innovation Organizational Change and Technology. I. McLoughlin and D. Mason. London, International Thompson Business Press: 170-185, 1997.

WILLIAMS, R.; BUNDUCHI, R.; GERST, M.; GRAHAM, I.; POLLOCK, N.; PROCTER, R.; Voß, A. Understanding the evolution of standards: alignment and reconfiguration in standards development and implementation arenas. Proceedings of the 4S \& EASST Conference. Paris, 2004.

WILLIAMS, R.; EDGE, D. The Social Shaping of Technology. Research Policy, 25(6): 856899, 1996.

WORLD BANK. A definition of e-Government. World Bank's E-government Website. Disponível em <http://www1.worldbank.org/publicsector/egov/definition.htm>. Acesso em 18 jul. 2005.

YIN, R. Estudo de caso: planejamento e métodos. 2a ed. Porto Alegre: Bookman, 2001. 
ANEXOS

ANEXO A - ROTEIRO DA $1^{\text {a }}$ ENTREVISTA

ANEXO B - ROTEIRO DA $2^{\text {a }}$ ENTREVISTA

ANEXO C - ROTEIRO DA $3^{\text {a }}$ ENTREVISTA

ANEXO D - PORTARIA NORMATIVA Nº 5, DE 11 DE JULHO DE 2005

ANEXO E - HISTÓRICO DA e-PING

ANEXO F - INTEGRANTES DOS GRUPOS DE TRABALHO DA e-PING V 3.0

ANEXO G - DECRETO N 1.048, DE 21 DE JANEIRO DE 1994

ANEXO H - DECRETO DE 18 DE OUTUBRO DE 2000

ANEXO I - DECRETO DE 29 DE OUTUBRO DE 2003 


\section{ANEXO A - ROTEIRO DA $1^{\text {a }}$ ENTREVISTA}

- Qual o objetivo do estabelecimento de uma arquitetura de interoperabilidade de governo eletrônico?

- O documento referência da e-PING afirma que seu modelo se baseia na experiência do projeto e-GIF do governo Britânico. Em que termos essa base tem sido usada?

- O documento também apresenta um diagrama simplificado sobre a estrutura de governança do projeto. Como efetivamente ocorrem as relações entre os diversos órgãos e as áreas do MP que compõem essa estrutura?

- Por que foram escolhidos a SLTI/MP, o SERPRO e o ITI como coordenadores do projeto?

- Foram criados cinco segmentos para agrupamento dos padrões a serem adotados e também cinco grupos de trabalhos, um para cada segmento definido. Alguma razão específica para isso?

- Quais são as funções/atividades dos Grupos de Trabalhos? E quais são as do Grupo de Coordenação?

- Como essas funções/atividades são efetuadas pelos grupos? 


\section{ANEXO B - ROTEIRO DA $2^{\text {a }}$ ENTREVISTA}

- Quais foram os objetivos almejados pela coordenação da e-PING ao decidir a realização da pesquisa diagnóstico de adoção da arquitetura?

- Que pontos positivos e negativos podem ser destacados dentro dos resultados obtidos na pesquisa?

- Em relação aos pontos negativos apontados, existe um plano de ação definido para ajuste das situações?

- Como foi realizada a pesquisa: escolha dos respondentes, coleta dos dados, definição das questões, análise das respostas?

- Como é realizado o processo de realização das consultas e audiências públicas?

- Como é o processo de análise e incorporação/descarte das questões submetidas pelos participantes das audiências e consultas públicas?

- Que subsídios as consultas e audiências públicas têm trazido para o processo de especificação dos padrões da arquitetura?

- Existem muitas perguntas originadas de um mesmo participante nas consultas públicas. Como a coordenação da e-PING avalia essa situação?

- Alguns debates têm se intensificado por conta das consultas públicas em relação à questão software livre X software proprietário. Que tipo de contribuição para o desenvolvimento da e-PING essa intensificação de debate pode trazer? 


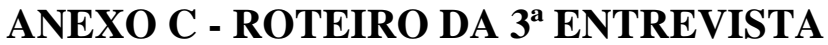

- Como se dá o processo de formação dos Grupos de Trabalho (GTs)? Como ocorre o ingresso dos membros? O Grupo de Coordenação (GC) possui um processo diferente?

- Existe uma renovação constante dos membros dos GTs e do GC desde o início do projeto. Existe alguma razão específica para essas mudanças? Quais as principais razões para essas mudanças?

- Como se dá o processo de escolha dos padrões que comporão a arquitetura desde sua indicação até sua homologação? Existe algum ponto onde existe uma gargalho do processo ou uma demanda maior de tempo?

- Na versão 2.0 da e-PING, dos 182 padrões especificados, apenas 12 estavam classificados como homologados. Qual é a expectativa de evolução do número de especificações homologadas. Esse número atual de padrões homologados está acima, no ponto idealizado ou abaixo dessa expectativa?

- Em algumas respostas das pesquisas de diagnóstico sobre a e-PING que foram feitas por essa coordenação, foram mencionadas por diversos órgãos dificuldades em adotar os padrões. De que forma a coordenação da e-PING idealiza a redução dessas restrições?

- Além das respostas às pesquisas, que outros indícios têm revelado no sentido de adoção da e-PING? (EX: especificação de conformidade com a arquitetura inclusa nos editais de concorrências publicados pelos órgãos)

- Como está sendo tratado o aspecto da compulsoriedade da adoção da arquitetura? Alguma estratégia ou mecanismo específico para fazer cumpri-la?

- Como foi o processo da substituição do padrão XML para ODF? Que razões levaram a coordenação a fazer essa mudança? Houve pressões internas e/ou externas? 
- O projeto e-PING possui inter-relacionamento com algum outro projeto de governo eletrônico? Caso positivo, como ocorre esse processo?

- Na segunda pesquisa sobre a e-PING houve uma redução de quase 5\% em relação à primeira dos respondentes que "conhece as políticas e especificações técnicas da e-PING". Existe alguma opinião formada pela coordenação sobre as causas dessa redução?

- Também houve uma redução no percentual de "organizações que utilizam a e-PING". E sobre essa redução, existe alguma opinião sobre as causas?

- Das organizações já adotantes da arquitetura, existe alguma estatística de quantas são as que são obrigadas a adotá-la? E das que são obrigadas, quais ainda não o fizeram?

- Qual é o cronograma de versionamento da arquitetura atualmente definido?

- Dentro do grupo de coordenação existem membros de diversos órgãos. Existe alguma hierarquia definida dentro do grupo em relação aos membros?

- O MP interfere, de alguma forma, nas decisões de investimentos em TICs dos órgãos? 
ANEXO D - PORTARIA NORMATIVA Nº 5, DE 11 DE JULHO DE 2005

\author{
Institucionaliza os Padrões de Interoperabilidade de \\ Governo Eletrônico - e-PING, no âmbito do Sistema \\ de Administração dos Recursos de Informação e \\ Informática - SISP, cria sua Coordenação, definindo \\ a competência de seus integrantes e a forma de \\ atualização das versões do Documento.
}

O SECRETÁRIO DE LOGÍSTICA E TECNOLOGIA DAINFORMAÇÃO, no uso das atribuições que lhe confere o art. 27 do Decreto $\mathrm{n}^{0}$ 5.433, de 25 de abril de 2005, sem prejuízo do disposto no Decreto $\mathrm{n}^{0}$ 1.048, de 21 de janeiro de 1994, Considerando a necessidade de assegurar a operação integrada entre equipamentos, programas e sistemas de informática, visando o pleno aproveitamento dos potenciais de intercâmbio de dados e informações no âmbito da Administração Pública Federal direta, autárquica e fundacional, o avanço na constituição da infra-estrutura para o desenvolvimento do Governo Eletrônico e a racionalização de custos, resolve:

Art. $1^{\circ} \mathrm{O}$ planejamento da implantação, desenvolvimento ou atualização de sistemas, equipamentos e programas em Tecnologia da Informação e Comunicação - TIC, no âmbito da Administração Pública Federal direta, autárquica e fundacional, técnicas, reger-seá, por políticas, diretrizes e especificações, visando assegurar de forma progressiva a interoperabilidade de serviços e sistemas de Governo Eletrônico.

$\S 10$ As políticas, diretrizes e especificações técnicas de interoperabilidade serão sistematizadas na forma de uma arquitetura denominada Padrões de Interoperabilidade de Governo Eletrônico - e- PING e adotadas de forma compulsória, com fulcro base nas disposições do inciso IV do art. $6^{\circ}$, e inciso I do art. $7^{\circ}$, do Decreto ${ }^{\circ} 1.048$, de 21 de janeiro de 1994, pelos órgãos e entidades integrantes do Sistema de Administração dos Recursos de Informação e Informática - SISP, a partir da sua publicação. 
$\S 2^{\circ}$ A e-PING será amplamente divulgada e sua disseminação ativamente promovida, por meio de adesão, a ser obtida junto às demais administrações públicas em todos os níveis e esferas, aos fornecedores governamentais e a empresas, entidades e outras pessoas jurídicas de direito privado que mantenham relacionamentos por meio eletrônico com a Administração Pública Federal.

$\S 30$ As políticas, diretrizes e especificações técnicas da e- PING, relativas aos sistemas de segurança da informação, observarão as normas, padrões e outras disposições estabelecidas pela Secretaria- Executiva do Conselho de Defesa Nacional, conforme disposto no inciso VIII do art. $4^{\circ}$ do Decreto ${ }^{\circ}{ }^{3.505}$, de 13 de junho de 2000.

Art. $2^{\circ}$ Fica criada a Coordenação da e-PING, com o objetivo de providenciar suas revisões e atualizações subseqüentes, bem como apoiar tecnicamente seu planejamento, sua implantação, sua gestão e sua disseminação.

Art. $3^{\circ}$ A Coordenação da e-PING será integrada por representantes dos seguintes órgãos e entidades:

I - Secretaria de Logística e Tecnologia da Informação do Ministério do Planejamento, Orçamento e Gestão - SLTI/MP, que o coordenará;

II - Controladoria-Geral da União - CGU;

III - Instituto Nacional de Tecnologia da Informação - ITI;

IV - Serviço Federal de Processamento de Dados - SERPRO;

V - Empresa de Processamento de Dados da Previdência Social - DATAPREV;

VI - Departamento de Informática do SUS - DATASUS;

VII - Banco do Brasil - BB;

VIII - Caixa Econômica Federal - CEF; e

IX - Associação Brasileira de Empresas Estaduais de Processamento de Dados - ABEP;

$\S 1^{\circ}$ Ato do Secretário de Logística e Tecnologia da Informação designará os titulares e respectivos suplentes da Coordenação da e-PING, mediante indicações encaminhadas pelos órgãos e entidades.

$\S 2^{\circ} \mathrm{A}$ participação no Comitê não implicará no recebimento de qualquer remuneração adicional. 
Art. $4^{\circ}$ Compete à Coordenação da e-PING:

I - coordenar a elaboração e atualização das políticas, das diretrizes e das especificações técnicas que compõem a e-PING, bem como as alterações e os acréscimos em razão de sua revisão e de sua atualização;

II - acompanhar a implementação e propor medidas relativas ao planejamento, à divulgação e à disseminação da e-PING;

III - manifestar-se sobre questões técnicas e operacionais relacionadas com a adoção e a conformidade a e-PING por órgãos e entidades integrantes do SISP e outros interessados;

IV - constituir grupos de trabalho, mediante designação pelos órgãos da Administração Pública Federal, para a elaboração de propostas de diretrizes e especificações técnicas a serem submetidas à Coordenação da e-PING;

V - promover a fiscalização e adotar as medidas executivas necessárias ao cumprimento do disposto no Documento de Referência da e-PING, comunicando e acionando, para providências, os órgãos de controle interno, quando necessário; e

VI - aprovar seu Regimento Interno próprio, que estabelecerá as regras de funcionamento e de procedimentos a serem observadas para desempenho das atribuições estabelecidas nesta Portaria.

$\S 1^{\circ}$ Os órgãos e entidades que integram a Coordenação da e- PING poderão prestar apoio técnico aos trabalhos nas suas áreas de atuação e conhecimento.

$\S 2^{\circ}$ Poderão ser convidados a participar das reuniões da Coordenação da ePING e dos Grupos de Trabalho nele constituídos, representantes de órgãos e entidades da Administração Pública Federal não-integrantes da Coordenação, de outras Administrações Públicasou da sociedade, observado com base nas o disposto no ições do parágrafo único do art. $3^{\circ}$, do Decreto ${ }^{\circ} 1.048$, de 1994.

$\S$ 3o No desempenho de suas atribuições, os Coordenadores dos Grupos de Trabalho referidos no inciso IV do artigo 4o desta Portaria terão assento na Coordenação da ePING. 
Art. 50 Ao Ministério do Planejamento, Orçamento e Gestão, no exercício das atribuições legais de coordenação e gestão do SISP, por intermédio da SLTI, incumbe a coordenação executiva das atividades de implantação, manutenção e disseminação da ePING, competindo-lhe:

I - aprovar as políticas, as diretrizes e as especificações técnicas que compõem a e-PING, bem como as alterações e acréscimos em razão de sua revisão e atualização, mediante consulta prévia à Coordenação da e-PING;

II - prover a infra-estrutura administrativa e os recursos orçamentários e financeiros necessários às atividades da e-PING e apoiar o funcionamento da Coordenação da e-PING e de seus grupos de trabalho;

III - supervisionar técnica e normativamente os órgãos e entidades integrantes do SISP na aplicação das políticas, diretrizes e especificações técnicas da e-PING;

IV - elaborar e divulgar orientações técnicas, inclusive na forma de manuais e materiais instrucionais;

V - manter e operacionar, em colaboração com a Coordenação da e-PING, e operacionar sítio na Internet para publicações relacionadas à e-PING, resposta a consultas e outros serviços e informações conexos ao tema;

VI - fomentar iniciativas de divulgação e de capacitação de servidores públicos para a aplicação da e-PING;

VII - celebrar e manter, empara colaboração com os órgãos e entidades integrantes da Coordenação da e-PING, acintercâmbio e cooperação técnica nacional e internacional na área de padrões de interoperabilidade; e

VIII - mediante acordos específicos, com o Órgão Central, visando a prestação de serviços de apoio técnico e operacional à implementação e atualização da e-PING, poderão colaborar com o SISP, as entidades do Poder Público e da iniciativa privada, interessadas no desenvolvimento de projetos de interesse comum, nos termos do parágrafo único do art. $3^{\circ}$, do Decreto $n^{\circ} 1.048$, de 1994.

Art. $6^{\circ}$ A proposta da e-PING denominada Documento de Referência, elaborada pela sua Coordenação, será atualizada periodicamente em versões, submetida a processo de consulta pública e publicada no Diário Oficial da União e no sítio de que trata o inciso V do art. $5^{\circ}$ desta Portaria. 
Parágrafo único. As consultas públicas referidas no caput serão conduzidas pelo Ministério do Planejamento, Orçamento e Gestão.

Art. $7^{\circ}$ Esta Portaria entra em vigor na data de sua publicação.

\section{ROGÉRIO SANTANNA}


ANEXO E - HISTÓRICO DA e-PING

\begin{tabular}{|c|c|}
\hline Ações & Data \\
\hline $\begin{array}{l}\text { Visita do Secretário da SLTI/MP ao Governo Britânico para } \\
\text { conhecer o modelo britânico de interoperabilidade (e-GIF) }\end{array}$ & Junho/2003 \\
\hline Seminário e-Gov - Padrões de Interoperabilidade & $03 / 11 / 2003$ \\
\hline Formação do Comitê Constituinte da e-PING & $07 / 11 / 2003$ \\
\hline Reunião do Comitê Constituinte da e-PING & $14 / 11 / 2003$ \\
\hline Seminário Técnico para os Grupos de Trabalho & $24 / 11 / 2003$ \\
\hline $\begin{array}{l}\text { Emissão de Ofício Circular n 10/2003/DSR-SLTI aos órgãos para indicação dos } \\
\text { componentes dos Grupos de Trabalho }\end{array}$ & $05 / 12 / 2003$ \\
\hline Rodada de aferição e convergência dos rumos de cada Grupo de Trabalho & $05 / 12 / 2003$ \\
\hline Seminário para constituição dos Grupos de Trabalho & $15 / 12 / 2003$ \\
\hline Início das reuniões temáticas dos Grupos de Trabalho & $05 / 01 / 2004$ \\
\hline Seminário e-PING (SERPRO) & $06 / 01 / 2004$ \\
\hline Reunião do Comitê Constituinte da e-PING & $20 / 01 / 2004$ \\
\hline Reunião do Comitê Constituinte da e-PING & $10 / 02 / 2004$ \\
\hline Seminário e-PING (SERPRO Regional) & $11 / 02 / 2004$ \\
\hline Nota Técnica para a versão preliminar da e-PING & $18 / 02 / 2004$ \\
\hline Fim das reuniões temáticas dos Grupos de Trabalho & $04 / 03 / 2004$ \\
\hline Reunião do Comitê Constituinte da e-PING & $23 / 03 / 2004$ \\
\hline Apresentação da e-PING para o Arquivo Nacional & $24 / 03 / 2004$ \\
\hline Apresentação da e-PING para o Comitê Técnico de Integração de Sistemas & $30 / 03 / 2004$ \\
\hline Reunião do Comitê Constituinte da e-PING & $02 / 04 / 2004$ \\
\hline
\end{tabular}




\begin{tabular}{|c|c|}
\hline Apresentação da e-PING para a ABEP & $27 / 04 / 2004$ \\
\hline Reunião do Comitê Constituinte da e-PING & $07 / 05 / 2004$ \\
\hline Palestra Implementação da e-PING & $11 / 05 / 2004$ \\
\hline Reunião dos Coordenadores dos Grupos de Trabalho & $12 / 05 / 2004$ \\
\hline Seminário Técnico e-PING (ABEP) & $18 / 05 / 2004$ \\
\hline Apresentação da e-PING no congresso CONIP 2004 & $19 / 05 / 2004$ \\
\hline Reunião do Comitê Constituinte da e-PING & 26/05/2004 \\
\hline Publicação do Aviso de Consulta Pública no DOU & $28 / 05 / 2004$ \\
\hline Abertura do processo de Consulta Pública & $01 / 06 / 2004$ \\
\hline Publicação do Aviso de Audiência Pública no DOU (RS) & $03 / 06 / 2004$ \\
\hline Realização da Audiência Pública no RS & $18 / 06 / 2004$ \\
\hline Reunião do Comitê Constituinte da e-PING & $01 / 07 / 2004$ \\
\hline Publicação do Aviso de Audiência Pública no DOU (SP) & $05 / 07 / 2004$ \\
\hline Reunião do Comitê Constituinte da e-PING & $08 / 07 / 2004$ \\
\hline Realização da Audiência Pública em SP & |12/07/2004 \\
\hline Publicação do Aviso de Audiência Pública no DOU (DF) & 22/07/2004 \\
\hline Publicação do Aviso de Audiência Pública no DOU (RJ) & 28/07/2004 \\
\hline Realização da Audiência Pública no DF & $02 / 08 / 2004$ \\
\hline Publicação do Aviso de Audiência Pública no DOU (MG) & $06 / 08 / 2004$ \\
\hline Realização da Audiência Pública no RJ & 11/08/2004 \\
\hline Realização da Audiência Pública em MG & $16 / 08 / 2004$ \\
\hline Publicação do Aviso de Audiência Pública no DOU (PE) & $19 / 08 / 2004$ \\
\hline
\end{tabular}




\begin{tabular}{|c|c|}
\hline Realização da Audiência Pública em PE & 30/08/2004 \\
\hline Encerramento da Consulta Pública & $31 / 08 / 2004$ \\
\hline $\begin{array}{l}\text { Emissão de Ofício Circular aos órgãos para indicação dos componentes dos } \\
\text { Grupos de Trabalho da e-PING }\end{array}$ & $10 / 09 / 2004$ \\
\hline Apresentação da e-PING no congresso SECOP 2004 & $08 / 10 / 2004$ \\
\hline $\begin{array}{l}\text { Início das reuniões temáticas dos Grupos de Trabalho para análise das } \\
\text { contribuições encaminhadas através da Consulta Pública e das Audiências } \\
\text { Públicas }\end{array}$ & 26/10/2004 \\
\hline $\begin{array}{l}\text { Envio do documento de referência para análise pela Consultoria Jurídica deste } \\
\text { Ministério }\end{array}$ & $04 / 11 / 2004$ \\
\hline Apresentação da e-PING no congresso Latinoware & $12 / 11 / 2004$ \\
\hline Apresentação da e-PING (DATASUS) & $16 / 11 / 2004$ \\
\hline Apresentação da e-PING (ELETROBRÁS) & $17 / 11 / 2004$ \\
\hline Apresentação da e-PING no evento de Inclusão Digital & 19/11/2004 \\
\hline Fim das reuniões temáticas dos Grupos de Trabalho & 26/11/2004 \\
\hline Reunião do Comitê Constituinte da e-PING & $01 / 12 / 2004$ \\
\hline Atualização do sítio da e-PING (http://www.eping.e.gov.br/) & $17 / 12 / 2004$ \\
\hline Conclusão da versão 1.0 do documento de referência da e-PING & 20/12/2004 \\
\hline $\begin{array}{l}\text { Lançamento da versão } 1.0 \text { do documento de referência da e-PING na TELEXPO } \\
2005\end{array}$ & $01 / 03 / 2005$ \\
\hline \begin{tabular}{|l} 
Envio da Portaria Ministerial de institucionalização da e-PING para a assinatura \\
do Ministro do Planejamento, Orçamento e Gestão
\end{tabular} & 22/03/2005 \\
\hline Apresentação da e-PING em congresso realizado na França & 29/03/2005 \\
\hline Envio do termo de parceria com a ANOREG para análise da Consultoria Jurídica & $08 / 04 / 2005$ \\
\hline
\end{tabular}




\begin{tabular}{|c|c|}
\hline Apresentação da e-PING para no evento PNAGE & $10 / 05 / 2005$ \\
\hline Apresentação da e-PING no congresso CONIP 2005 & $19 / 05 / 2005$ \\
\hline Reunião da Coordenação da e-PING & $07 / 06 / 2005$ \\
\hline Assinatura do termo de parceria com a ANOREG & $22 / 06 / 2005$ \\
\hline Publicação do estrato do termo de parceria com a ANOREG no DOU & $28 / 06 / 2005$ \\
\hline Publicação da Portaria Ministerial de institucionalização da e-PING no DOU & $15 / 07 / 2005$ \\
\hline Artigo para o congresso CONEGOV 2005 & $25 / 07 / 2005$ \\
\hline Apresentação da e-PING no congresso SECGOV 2005 & |12/09/2005 \\
\hline $\begin{array}{l}\text { Início dos trabalhos de atualização do documento de referência da e-PING para a } \\
\text { Publicação da versão } 1.5\end{array}$ & $01 / 11 / 2005$ \\
\hline Reunião da Coordenação da e-PING & $08 / 11 / 2005$ \\
\hline Apresentação e-PING para o projeto e-GOIA & $09 / 11 / 2005$ \\
\hline Apresentação da e-PING para o Governo do Paraguai & $07 / 12 / 2005$ \\
\hline Seminário Técnico e-PING (MP) & |13/12/2005 \\
\hline Reunião da Coordenação da e-PING & $14 / 12 / 2005$ \\
\hline Atualização do sítio da e-PING (http://www.eping.e.gov.br/) & $16 / 12 / 2005$ \\
\hline Publicação da versão 1.5 do documento de referência da e-PING & $16 / 12 / 2005$ \\
\hline $\begin{array}{l}\text { Emissão de Ofício aos órgãos para indicação dos componentes dos Grupos de } \\
\text { Trabalho da e-PING }\end{array}$ & $05 / 01 / 2006$ \\
\hline Reunião da Coordenação da e-PING & 26/01/2006 \\
\hline Início dos trabalhos dos GTs para a publicação da versão 2.0 da e-PING & $01 / 02 / 2006$ \\
\hline Reunião da Coordenação da e-PING & $07 / 03 / 2006$ \\
\hline Apresentação da e-PING no congresso TELEXPO 2006 & $08 / 03 / 2006$ \\
\hline
\end{tabular}




\begin{tabular}{|c|c|}
\hline Apresentação da e-PING na Conferência TI-GOV & $14 / 03 / 2006$ \\
\hline Videoconferência com o Governo Argentino & 07/04/2006 \\
\hline Reunião da Coordenação da e-PING & $11 / 04 / 2006$ \\
\hline Seminário Técnico e-PING (BB) & $11 / 05 / 2006$ \\
\hline Seminário Técnico e-PING (CAIXA) & $12 / 05 / 2006$ \\
\hline Reunião da Coordenação da e-PING & $12 / 05 / 2006$ \\
\hline Início da pesquisa de utilização da e-PING & $12 / 05 / 2006$ \\
\hline Artigo para a Conferência Internacional/Oficina de Autores do Projeto e-Brasil & $22 / 05 / 2006$ \\
\hline Início da Pesquisa e-PING & $15 / 05 / 2006$ \\
\hline Seminário Técnico e-PING (BB) & $25 / 05 / 2006$ \\
\hline Fim da Pesquisa e-PING & 06/06/2006 \\
\hline Reunião da Coordenação da e-PING & 09/06/2006 \\
\hline $\begin{array}{l}\text { Apresentação da e-PING no Encontro Multilateral IBAS - Índia, Brasil, África do } \\
\text { Sul (CONIP/SP) e divulgação no estande da e-PING }\end{array}$ & 28/06/2006 \\
\hline Reunião da Coordenação da e-PING & $10 / 07 / 2006$ \\
\hline Resultado da Pesquisa e-PING & $11 / 07 / 2006$ \\
\hline $\begin{array}{l}\text { Apresentação da e-PING no I Fórum do PROMOEX: Formação da Rede de } \\
\text { Informação e Portal do Controle Externo }\end{array}$ & $14 / 07 / 2006$ \\
\hline Reunião da Coordenação da e-PING & $24 / 07 / 2006$ \\
\hline $\begin{array}{l}\text { Apresentação da e-PING na Reunião do Comitê Técnico de Implementação de } \\
\text { Software Livre }\end{array}$ & $25 / 07 / 2006$ \\
\hline Reunião da Coordenação da e-PING & $11 / 08 / 2006$ \\
\hline Publicação do Aviso da Consulta Pública no DOU & $16 / 08 / 2006$ \\
\hline
\end{tabular}




\begin{tabular}{|c|c|}
\hline Publicação do Aviso da Consulta Pública do CPD no DOU & $17 / 08 / 2006$ \\
\hline Abertura do processo de Consulta Pública & $18 / 08 / 2006$ \\
\hline Abertura do processo de Consulta Pública do CPD & $21 / 08 / 2006$ \\
\hline $\begin{array}{l}\text { Palestra no CONGED - Congresso de Tecnologia para Gestão de Dados e } \\
\text { Metadados do Cone Sul }\end{array}$ & $24 / 08 / 2006$ \\
\hline Publicação do Aviso da Audiência Pública no DOU (DF) & $22 / 08 / 2006$ \\
\hline Realização da Audiência Pública no DF & $04 / 09 / 2006$ \\
\hline Publicação do Aviso de Audiência Pública via videoconferência & $13 / 09 / 2006$ \\
\hline $\begin{array}{l}\text { Apresentação e-GOV/ e-PING no } 1^{\circ} \text { Encontro Técnico dos Integrantes do } \\
\text { Sistema de Gestão de Documentos de Arquivo - SIGA }\end{array}$ & $13 / 09 / 2006$ \\
\hline $\begin{array}{l}\text { Apresentação da e-PING no } 1^{\circ} \text { Seminário de Padrões e Softwares Livres na } \\
\text { Câmara Legislativa do DF }\end{array}$ & $15 / 09 / 2006$ \\
\hline Apresentação da e-PING no CONIP Judiciário & $19 / 09 / 2006$ \\
\hline $\begin{array}{l}\text { Apresentação da e-PING na Câmara Técnica de Informação e Informática no } \\
\text { Ministério da Saúde }\end{array}$ & 22/09/2006 \\
\hline Realização da Audiência Pública via videoconferência & 27/09/2006 \\
\hline Reunião da Coordenação da e-PING & $04 / 10 / 2006$ \\
\hline Apresentação da e-PING na CELEPAR & $09 / 10 / 2006$ \\
\hline Encerramento da Consulta Pública da e-PING & $17 / 10 / 2006$ \\
\hline Encerramento da Consulta Pública do CPD & 20/10/2006 \\
\hline Reunião da Coordenação da e-PING & $01 / 11 / 2006$ \\
\hline Publicação do Aviso de Consulta Pública da LAG no DOU & $08 / 11 / 2006$ \\
\hline Abertura do processo de Consulta Pública da LAG & 10/11/2006 \\
\hline Publicação da versão 2.0 do documento de referência da e-PING & 17/11/2006 \\
\hline
\end{tabular}




\begin{tabular}{|c|c|}
\hline Reunião da Coordenação da e-PING & $14 / 12 / 2006$ \\
\hline Reunião da Coordenação da e-PING & 25/01/2007 \\
\hline Publicação da versão 2.0.1 do documento de referência da e-PING (em Espanhol) & 30/01/2007 \\
\hline Reunião da Coordenação da e-PING & 28/02/2007 \\
\hline Reunião da Coordenação da e-PING & 28/03/2007 \\
\hline |Publicação da versão 2.0.1 do documento de referência da e-PING (em Inglês) & 05/04/2007 \\
\hline Reunião da Coordenação da e-PING & 25/04/2007 \\
\hline Reunião da Coordenação da e-PING & $30 / 05 / 2007$ \\
\hline Início da pesquisa e-PING 2007 & |11/06/2007 \\
\hline Reunião da Coordenação da e-PING & 27/06/2007 \\
\hline Fim da pesquisa e-PING 2007 & 29/06/2007 \\
\hline |Resultado da pesquisa e-PING 2007 & $13 / 07 / 2007$ \\
\hline Reunião da Coordenação da e-PING & $01 / 08 / 2007$ \\
\hline Publicação da versão 1.0 do Catálago de Padrão de Dados - CPD & $16 / 08 / 2007$ \\
\hline Reunião da Coordenação da e-PING & 29/08/2007 \\
\hline Reunião da Coordenação da e-PING & 26/09/2007 \\
\hline Publicação do Aviso de Consulta Pública no DOU & $10 / 10 / 2007$ \\
\hline Publicação do Aviso de Audiência Pública no DOU (DF) & $10 / 10 / 2007$ \\
\hline Abertura do processo de Consulta Pública & $15 / 10 / 2007$ \\
\hline Realização da Audiência Pública no DF & |24/10/2007 \\
\hline Reunião da Coordenação da e-PING & 26/10/2007 \\
\hline Publicação do Aviso de Audiência Pública no DOU (RJ) & 29/10/2007 \\
\hline
\end{tabular}




\begin{tabular}{||l||l||}
\hline Realização da Audiência Pública no RJ & $13 / 11 / 2007$ \\
\hline \hline Encerramento da Consulta Pública & $16 / 11 / 2007$ \\
\hline \hline Reunião da Coordenação da e-PING & $23 / 11 / 2007$ \\
\hline \hline Publicação da versão 3.0 do documento de referência da e-PING & $14 / 12 / 2007$ \\
\hline
\end{tabular}


ANEXO F - INTEGRANTES DOS GRUPOS DE TRABALHO DA A-PING V 3.0

F.1. Grupo de Coordenação (agrupado por instituição de origem do participante)

- Associação Brasileira de Empresas Estaduais de Processamento de Dados (ABEP)

Dayse Vianna

Paulo Cezar Coelho

Banco do Brasil (BB)

Ulisses de Sousa Penna

Caixa Econômica Federal (CAIXA)

Ângela B. Baylo

- Empresa de Tecnologia e Informações da Previdência Social (DATAPREV)

Humberto Degrazia Campedelli

José Antônio Borba Soares

Rodrigo Novais Coutinho

- Ministério da Justiça (MJ)

Jorilson da Silva Rodrigues

- Ministério da Saúde (MS)

Eliane Pereira dos Santos

Ernani Bento Bandarra

Márcia Helena Gonçalves Rollemberg

- Ministério das Relações Exteriores (MRE)

Celso Ricardo Hottum Meira

- Ministério do Planejamento, Orçamento e Gestão - Secretaria de Logística e

Tecnologia da Informação (MP/SLTI)

Leandro Corte (Coordenador Geral)

Ednylton Maria Franzosi

Eduardo Favero

José Ney de Oliveira Lima

Leonardo Boselli da Motta

Leonardo Lanna Guillén

Nazaré Lopes Bretas

Rogério Santanna dos Santos

Sylmara Campos Pinho Garcia 
- Presidência da República (PR)

Marcelo André de Barros Oliveira

- Presidência da República - Instituto Nacional de Tecnologia da Informação (ITI)

Mauricio Augusto Coelho

Renato da Silveira Martini

Viviane Regina Lemos Bertol

- Serviço Federal de Processamento de Dados (SERPRO)

Antônio Sérgio Borba Cangiano

Elói Juniti Yamaoka

Geancarlo Noronha Vinhal

Paulo Cezar Czarnewski

Wagner Junqueira Araújo

\section{F.2. Grupo de Trabalho Interconexão}

Leonardo Lanna Guillén (MP/SLTI) - (Coordenador)

Adriano Soriano (CAIXA)

Areno Pires Filho (MC)

Carlos Bellone Neto (RFB)

Daniel Moreira Guilhon (CGU)

Filipe Guimarães (MRE)

Frederico Duarte Guerra de Macedo (ME)

José Rodrigues Gonçalves Júnior (ITI)

Júlio César Japiassu Lyra (MJ)

Leonardo Boselli da Motta (MP/SLTI)

Luciene Pinheiro Capra (ANS)

Odilon de Freitas Militão Neto (CAIXA)

Paulo Guilherme Lanzillotti Jannuzzi (DATAPREV)

Ruben César Macedo (CELEPAR-PR)

Sérgio de Oliveira Barcellos (MCT)

Sílvia Aparecida da Cunha (MP/CGTI)

Ulisses de Sousa Penna (BB)

\section{Subgrupo: Web Services}

Ednylton Maria Franzosi (MP/SLTI) - (Coordenador) 
Bruno Pacheco (SERPRO)

Carlos Falcão Maranhão (MS/ANS)

Cláudio Muniz Machado (MS)

Elaine Fabiano Tocantins (MJ)

Louise Neves (SERPRO)

Mauricio Dayrell (MMA)

Paulo Azevedo (BB)

\section{Colaboradores}

Claudia do Socorro Ferreira Mesquita (MP/SLTI)

Patrycia Barros de Lima Klaydianos (MP/SLTI)

\section{F.3. Grupo de Trabalho Segurança}

Jorilson da Silva Rodirgues (MJ) - (Coordenador)

Alessandra Silva Moura(ANS)

Dante de Matos Gomes(PRODEB)

Edgar Luciano Morais Martins (MP/SLTI)

Érica Dantas (STJ)

Filipe Carneiro Guimarães (MRE)

Gleyner Martins Novais (SERPRO)

Humberto Degrazia Campedelli (DATAPREV)

Igor Guimarães (MC)

José D’Aleluia Nascimento (MinC)

José Maria Leocádio (SERPRO)

Júlio César de Magalhães (FNDE)

Luiz Augusto Barbosa Mozzer (CGU)

Maisa Netto Ludemer (MC)

Marcelo Henrique Rios dos Reis (MT)

Marco Antônio Reis Henriques (RFB)

Marcos José Cândido Euzébio (BACEN)

Ricardo Luiz Chiacchio (MCidades)

Roberto dos Santos Rodrigues (MCT)

Rodrigo Costa dos Santos (ELETROBRÁS)

Sérgio Carreira dos Santos (IPHAN) 
F.4. Grupo de Trabalho Meios de Acesso

Mauricio Augusto Coelho (ITI) - (Coordenador)

Renato da Silveira Martini (ITI) - (Coordenador)

Carlos Bellone Neto (RFB)

Cleisson Rodrigues (MTur)

Eduardo Viola (MCT)

Eliane Aristóteles Moreira (DATAPREV)

Eliane Pereira dos Santos (MS)

Ellio Alves de O. Soares (CEF)

Geancarlo Noronha Vinha (SERPRO)

Hilton P. Mendes Sobrinho (MS)

Jean Carlo Rodrigues (ITI)

Paloma Nascimento (MT)

Paulo Édison de Souza (MEC)

Rosane dos Santos Lourenço (MT)

Rubem César Macedo (CELEPAR-PR)

Thimoteo Borges (CGU)

Viviane Regina Lemos Bertol (ITI)

\section{F.5. Grupo de Trabalho Organização e Intercâmbio de Informações}

Eloi Juniti Yamaoka (SERPRO) - (Coordenador)

Aline Ramalho Bezerra (MJ)

Ana Lúcia de Medeiros (CORREIOS)

Ângela B. Baylo (CAIXA)

Aurélia Dolores Gonçalves Bruner (ELETROBRAS)

Beatriz Barreto Brasileiro Lanza (CELEPAR)

Brenda Couto de Brito Rocco (AN-CC)

Cláudia Carvalho Masset Lacombe Rocha (AN-CC)

Dalva Clementina Luca (MJ)

Dayse Vianna (PRODERJ)

Dilma de Fátima Avellar Cabral da Costa (AN-CC)

Eliane Pereira dos Santos (MS)

Elizabeth da Silva Maçulo (AN-CC)

Fernanda Hoffmann Lobato (MP/SLTI) 


\section{F.5. Grupo de Trabalho Organização e Intercâmbio de Informações (continuação)}

Geny Conte Pessoa (SERPRO)

Hilda Pimentel (ANCINE)

João Alberto Lima (Senado Federal)

Ligia Leindorf Bartz Kraemer (UFPR)

Luciana Ferreira Pinto da Silva (INEP)

Luciano Seite Nishikawa (CAIXA)

Marcia Helena Gonçalves Rollemberg (MS)

Márcia Izabel Fugizawa Souza (EMBRAPA)

Márcia Luzia Albertini (MS)

Márcio Imamura (IBGE)

Marcos Augusto Francisco Borges (CPqD)

Margareth da Silva (AN-CC)

Maria de Fátima Porcaro (IPT)

Maria do Socorro Rodrigo de Medeiros (INEP)

Maria Valéria Lins Tenório (ATI-PE)

Neuza Arantes Silva (MAPA)

Paulo César Pereira Soares (FUNARTE)

Paulo Cezar Czarnewski (SERPRO)

Ricardo Torres Lenzi (INEP)

Rosiane Fonseca (ANCINE)

Samuel Batista dos Santos (IPT)

Sérgio Silva dos Santos (MAPA)

Siomara Zgiet (MS)

Taciano Tres (BB)

Vicente de Paula Teixeira (CGU)

Virgilio Dantas Lins Filho (ME)

Vivianne Muniz Veras Barrozo (SERPRO)

Wilson Yociteru Yamaji (AGU)

\section{F.6. Grupo de Trabalho Áreas de Integração para Governo Eletrônico}

Nazaré Lopes Bretas (MP/SLTI) - (Coordenadora)

Adelino Fernando Correia (DATASUS/MS)

Adriano de Medeiros (INCRA) 
F.6. Grupo de Trabalho Áreas de Integração para Governo Eletrônico (continuação)

Ana Lúcia Viçoso da Cruz Almeida (DATAPREV)

Antônio Albuquerque (PR)

Padrões de Interoperabilidade de Governo Eletrônico - versão de 14/12/2007 68

Documento de Referência da e-PING - Versão 3.0

Carlos Bellone Neto (RFB)

Ceres Albuquerque (ANS)

Cláudio Manoel Cordeiro (SERPRO)

Frederico Duarte Guerra de Macedo (ESPORTES)

Maurício M. Martinez (MEC)

Mônica Lucatelli (DATAPREV)

Paulo Henrique Santana (MMA)

Pedro Paulo Cirineo (BB)

Ricardo de Lima (INCRA)

Rogério Werneck (DIRTI/PR)

Sylmara Campos Pinho Garcia (MP/SLTI)

Wagner Gardusi Guarizo (PR)

\section{Colaboradores}

Igor de Freitas (MDS)

Felix de Sousa (MDS)

\section{Subgrupo: Padrões para Intercâmbio de Informações Espaciais}

Roberto Penido Duque Estrada (DSG/CIGEX) - COORDENADOR

Alex Araújo (CAIXA)

Aramis Mota (GSI/PR)

Christian André H. Govastki (MME/SEE)

Dêner Lima F. Martins (ABIN/PR)

Ellio Alves de O. Soares (CAIXA)

Eneias Roberto Shüller (CAIXA)

Fernando Gibotti (CAIXA)

Gerson Barrey (MEC)

Gilberto Ribeiro Queiroz

Gustavo Araújo (MME) 
F.6. Grupo de Trabalho Áreas de Integração para Governo Eletrônico (continuação)

Subgrupo: Padrões para Intercâmbio de Informações Espaciais (continuação)

Hisao Fujimoto (MME)

Jorge D. M. Cerqueira (PR/GSI)

Linda Soraya Issmael (DSG/CIGEX)

Lúbia Vinhas (INPE)

Lúcia Helena Luz (CAIXA)

Moema José de Carvalho Augusto (IBGE)

Mosar Rabelo Júnior (MMA)

Silmara Ramos (PR/GSI)

Silvio Carlos Heitor Jorge (CAIXA)

Tálsia Garcia Meira (DIRTI/CC/PR)

Valdevino S. Campos Neto (ANA)

Zandhor F. S. Cavalli Pradi (MS)

\section{Colaboradores}

Carlos Brasileiro (MDS)

Edmar Morett (MMA)

Enos Josué Rose (MCIDADES)

Rafael M. Sperb (Univali)

Wilfredo Pacheco (ANA)

Werner Leyh (MS)

\section{Ilustrações}

Hezrai de Souza Cruz (MP/SLTI) 


\section{ANEXO G - DECRETO N 1.048, DE 21 DE JANEIRO DE 1994}

\section{Dispõe sobre o Sistema de Administração dos \\ Recursos de Informação e Informática, a Administração Pública Federal, e dá outras providências.}

O PRESIDENTE DA REPÚBLICA, no uso das atribuições que lhe confere o art. 84, incisos IV e VI, da Constituição, e tendo em vista o disposto nos arts. 30 e 31 do Decreto-Lei $n^{\circ}$ 200, de 25 de fevereiro de 1967, no art. 11 da Lei $n^{\circ}$ 8.490, de 19 de novembro de 1992, e no art. $4^{\circ}$ do Decreto ${ }^{\circ} 741$, de 4 de fevereiro de 1993,

\section{DECRETA:}

Art. $1^{0}$ - Ficam organizados, sob a forma de Sistema, com a denominação de Sistema de Administração dos Recursos de Informação e Informática - SISP, o planejamento, a coordenação, a organização, a operação, o controle e a supervisão dos recursos de informação e informática dos órgãos e entidades da Administração Pública Federal direta, autárquica e fundacional, em articulação com os demais sistemas que atuam direta ou indiretamente na gestão da informação pública federal.

Parágrafo único. É facultada às Forças Armadas e aos órgãos de política externa e de segurança a inclusão, no SISP, dos recursos de informação e informática, a critério de seus respectivos dirigentes.

Art. $2^{\circ}$ - O Sistema de Administração dos Recursos de Informação e Informática tem por finalidade:

I - assegurar ao Governo Federal suporte de informação adequado, dinâmico, confiável e eficaz; 
II - facilitar aos interessados a obtenção das informações disponíveis, resguardados os aspectos de sigilo e restrições administrativas ou previstas em dispositivos legais;

III - promover a integração entre programas de governo, projetos e atividades, visando a definição de políticas, diretrizes e normas relativas à gestão dos recursos do Sistema;

IV - estimular o uso racional dos recursos de informação e informática, no âmbito da Administração Pública Federal, visando a melhoria da qualidade e da produtividade do ciclo da informação;

V - estimular o desenvolvimento, a padronização, a integração, a normalização dos serviços de produção e disseminação de informações, de forma desconcentrada e descentralizada;

VI - propor adaptações institucionais necessárias ao aperfeiçoamento dos mecanismos de gestão dos recursos de informação e informática;

VII - estimular e promover a formação, o desenvolvimento e o treinamento dos servidores que atuam na área de informação e informática.

$\S 1^{0}$ - São recursos de informação os conjuntos ordenados de procedimentos automatizados de coleta, tratamento e recuperação da informação, e seus respectivos acervos.

$\S 2^{\circ}$ - São recursos de informática o conjunto formado pelos equipamentos, materiais e programas de computador que constituem a infra-estrutura tecnológica de suporte automatizado ao ciclo da informação, que envolve as atividades de produção, coleta, tratamento, armazenamento e disseminação.

Art. $3^{\circ}$ - Integram o Sistema de Administração dos Recursos de Informação e Informática - SISP:

I - como Órgão Central: a Secretaria da Administração Federal da Presidência da República, representada pela Subsecretaria de Planejamento, Coordenação e Desenvolvimento Gerencial e Organizacional; 
II - a Comissão de Coordenação, formada pelos representantes dos Órgãos Setoriais, presidida por representante do Órgão Central;

III - os Órgãos Setoriais, representados junto à unidade gestora do Sistema pelos titulares das unidades de modernização e informática dos Ministérios Civis e equivalentes nos Ministérios Militares e Secretarias da Presidência da República;

IV - os Órgãos Seccionais, representados pelos dirigentes dos órgãos que atuam na área de administração dos recursos de informação e informática, nas autarquias e fundações.

Parágrafo único. Poderão colaborar com o SISP, mediante acordos específicos com o Órgão Central, as entidades do Poder Público e da iniciativa privada, interessadas no desenvolvimento de projetos de interesse comum.

Art. $4^{\circ}$ - Compete ao Órgão Central do SISP:

I - orientar e administrar o processo de planejamento estratégico, coordenação geral e normalização relativa aos recursos de informação e informática da Administração Pública Federal;

II - definir, elaborar, divulgar e implementar, com apoio da Comissão de Coordenação, as políticas, diretrizes e normas relativas à gestão dos recursos do Sistema e ao processo normativo de compras do Governo na área de informática;

III - promover a elaboração de planos de formação, desenvolvimento e treinamento do pessoal envolvido na área de abrangência do Sistema;

IV - incentivar ações prospectivas, visando acompanhar as inovações técnicas da área de informática, de forma a atender às necessidades de modernização dos serviços da Administração Pública Federal;

V - promover a disseminação das informações disponíveis, de interesse comum, entre os órgãos e entidades da Administração Pública Federal.

Art. $5^{\circ}$ - Compete à Comissão de Coordenação: 
I - participar da elaboração e implementação das políticas, diretrizes e normas relativas à gestão dos recursos do Sistema e ao processo normativo de compras do Governo na área de informática;

II - assessorar o Órgão Central no cumprimento de suas atribuições;

III - promover o intercâmbio de conhecimentos entre seus participantes e homogeneizar o entendimento das políticas, diretrizes e normas;

IV - acompanhar e avaliar os resultados da regulamentação emanada do Órgão Central e propor ajustamentos.

Art. $6^{\circ}$ - Compete aos Órgãos Setoriais, como integrantes do SISP:

I - coordenar, planejar, articular e controlar os recursos de informação e informática, no âmbito dos Ministérios ou das Secretarias da Presidência da República;

II - coordenar, planejar e supervisionar os sistemas de informação, no âmbito dos Ministérios, das Secretarias da Presidência da República, das autarquias e fundações;

III - fornecer subsídios ao Órgão Central, por intermédio da Comissão de Coordenação, para a definição e elaboração de políticas, diretrizes e normas relativas ao Sistema;

IV - cumprir e fazer cumprir as políticas, diretrizes e normas emanadas do Órgão Central;

V - participar, como membro da Comissão de Coordenação, dos encontros de trabalho programados para tratar de assuntos relacionados com o SISP.

Art. $7^{\circ}$ - Compete aos Órgãos Seccionais, como integrantes do SISP:

I - cumprir e fazer cumprir as políticas, diretrizes e normas emanadas do Órgão Setorial;

II - subsidiar o Órgão Setorial na elaboração de políticas, diretrizes, normas e projetos setoriais; 
III - participar dos encontros de trabalho programados para tratar de assuntos relacionados com o SISP.

Art. $8^{\circ}$ - A Secretaria da Administração Federal da Presidência da República baixará normas e instruções necessárias à implantação e ao funcionamento do SISP.

Art. $9^{\circ}$ - Este Decreto entra em vigor na data de sua publicação.

Brasília, 21 de janeiro de 1994; $173^{\circ}$ da Independência e $106^{\circ}$ da República.

\section{ITAMAR FRANCO}

Romildo Canhim 


\section{ANEXO H - DECRETO DE 18 DE OUTUBRO DE 2000}

\section{Cria, no âmbito do Conselho de Governo, o Comitê Executivo do Governo Eletrônico, e dá outras providências.}

O PRESIDENTE DA REPÚBLICA, no uso da atribuição que lhe confere o art. 84, inciso VI, da Constituição,

\section{DECRETA:}

Art. 1o Fica criado, no âmbito do Conselho de Governo, o Comitê Executivo do Governo Eletrônico, com o objetivo de formular políticas, estabelecer diretrizes, coordenar e articular as ações de implantação do Governo Eletrônico, voltado para a prestação de serviços e informações ao cidadão.

Art. 2o Integram o Comitê Executivo:

I - o Chefe da Casa Civil da Presidência da República, que o presidirá;

II - os Secretários-Executivos dos Ministérios;

III - o Secretário-Geral do Ministério das Relações Exteriores;

IV - o Subchefe do Gabinete de Segurança Institucional da Presidência da República;

V - o Secretário de Organização Institucional do Ministério da Defesa;

VI - o Subsecretário-Geral da Secretaria-Geral da Presidência da República;

VII - o Secretário de Avaliação, Promoção e Normas da Secretaria de Comunicação de Governo da Presidência da República;

VIII - o Procurador-Geral da União.

\section{Art. 3o Compete ao Comitê:}

I - coordenar e articular a implantação de programas e projetos para a racionalização da aquisição e da utilização da infra-estrutura, dos serviços e das aplicações de tecnologia da informação e comunicações no âmbito da Administração Pública Federal; 
II - estabelecer as diretrizes para a formulação, pelos Ministérios, de plano anual de tecnologia da informação e comunicações;

III - estabelecer diretrizes e estratégias para o planejamento da oferta de serviços e de informações por meio eletrônico, pelos órgãos e pelas entidades da Administração Pública Federal;

IV - definir padrões de qualidade para as formas eletrônicas de interação;

V - coordenar a implantação de mecanismos de racionalização de gastos e de apropriação de custos na aplicação de recursos em tecnologia da informação e comunicações, no âmbito da Administração Pública Federal;

VI - estabelecer níveis de serviço para a prestação de serviços e informações por meio eletrônico; e

VII - estabelecer diretrizes e orientações e manifestar-se, para fins de proposição e revisão dos projetos de lei do Plano Plurianual, de Diretrizes Orçamentárias e do Orçamento Anual, sobre as propostas orçamentárias dos órgãos e das entidades da Administração Pública Federal, relacionadas com a aplicação de recursos em investimento e custeio na área de tecnologia da informação e comunicações.

Art. 4o O Ministério do Planejamento, Orçamento e Gestão exercerá as atribuições de Secretaria-Executiva e proverá o apoio técnico-administrativo necessário ao funcionamento do Comitê, sem prejuízo do disposto no Decreto no 1.048, de 21 de janeiro de 1994.

Art. 5o O Comitê poderá constituir grupos de trabalho específicos.

$\S 1$ o Poderão ser convidados para participar dos grupos de trabalho representantes de órgãos e entidades públicas e privadas.

§ 2o O Comitê definirá, no ato de criação do grupo, seus objetivos específicos, sua composição e prazo para conclusão do trabalho.

Art. 6 o O Grupo de Trabalho Interministerial instituído pelo Decreto de 3 de abril de 2000 integrará o Comitê na qualidade de Grupo de Assessoramento Técnico.

Art. 7o O Comitê apresentará relatórios periódicos de suas atividades ao Presidente da República. 
Art. 8o A participação no Comitê e nos grupos de trabalho não enseja remuneração de qualquer espécie, sendo considerada serviço público relevante.

Art. 9o O Comitê, no prazo de trinta dias de sua instalação, aprovará seu regimento interno dispondo sobre o seu funcionamento.

Art. 10. Este Decreto entra em vigor na data de sua publicação.

Brasília, 18 de outubro de 2000; 179o da Independência e 112o da República.

FERNANDO HENRIQUE CARDOSO

Martus Tavares

Pedro Parente 


\section{ANEXO I - DECRETO DE 29 DE OUTUBRO DE 2003}

Institui Comitês Técnicos do Comitê Executivo do Governo Eletrônico e dá outras providências.

O PRESIDENTE DA REPÚBLICA, no uso da atribuição que lhe confere o art. 84, incisos IV e VI, alínea "a", da Constituição,

\section{DECRETA:}

Art. 1o Ficam instituídos Comitês Técnicos, no âmbito do Comitê Executivo do Governo Eletrônico criado pelo Decreto sem número de 18 de outubro de 2000, com a finalidade de coordenar e articular o planejamento e a implementação de projetos e ações nas respectivas áreas de competência, com as seguintes denominações:

I - Implementação do Software Livre;

II - Inclusão Digital;

III - Integração de Sistemas;

IV - Sistemas Legados e Licenças de Software;

V - Gestão de Sítios e Serviços On-line;

VI - Infra-Estrutura de Rede;

VII - Governo para Governo - G2G, e

VIII - Gestão de Conhecimentos e Informação Estratégica.

Art. 2o_Os Comitês Técnicos serão compostos por representantes de órgãos e entidades da administração pública federal, indicados pelos integrantes do Comitê Executivo do Governo Eletrônico.

$\S$ 1。 Ato dos Ministros de Estado Chefe da Casa Civil da Presidência da República e do Planejamento, Orçamento e Gestão estabelecerá a composição das Comitês e designará seus membros e coordenadores. 
$\S$ 2o_Em seus impedimentos, os membros das Câmaras serão substituídos por seus suplentes.

$\S$ 3o_Os órgãos e entidades cujos representantes integrem os respectivos Comitês Técnicos prestarão o necessário apoio técnico e administrativo ao seu funcionamento, inclusive por meio da designação de servidores dos seus quadros para a atuação em atividades e projetos.

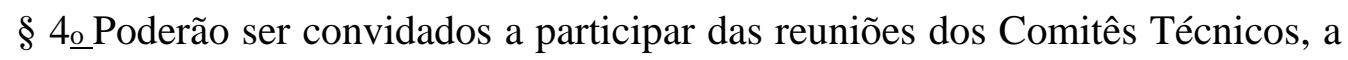
juízo do seu coordenador, representantes de outros órgãos e entidades públicas, de empresas privadas ou de organizações da sociedade civil.

§ 5o o Secretário-Executivo do Comitê Executivo do Governo Eletrônico supervisionará os trabalhos dos Comitês Técnicos, inclusive por meio da convocação dos seus coordenadores para participação em reuniões periódicas de acompanhamento.

Art. 3ㅌEste Decreto entra em vigor na data de sua publicação.

Brasília, 29 de outubro de 2003; 182oda Independência e 115oda República.

\author{
LUIZ INÁCIO LULA DA SILVA \\ Guido Mantega
}

Publicada no D.O. do dia 30 de outubro de 2003. Seção 1, páginas 4 